\title{
Remediation of Deep Vadose Zone Radionuclide and Metal Contamination: Status and Issues
}

\author{
PE Dresel \\ MJ Truex \\ $\mathrm{K}$ Cantrell
}

December 2008

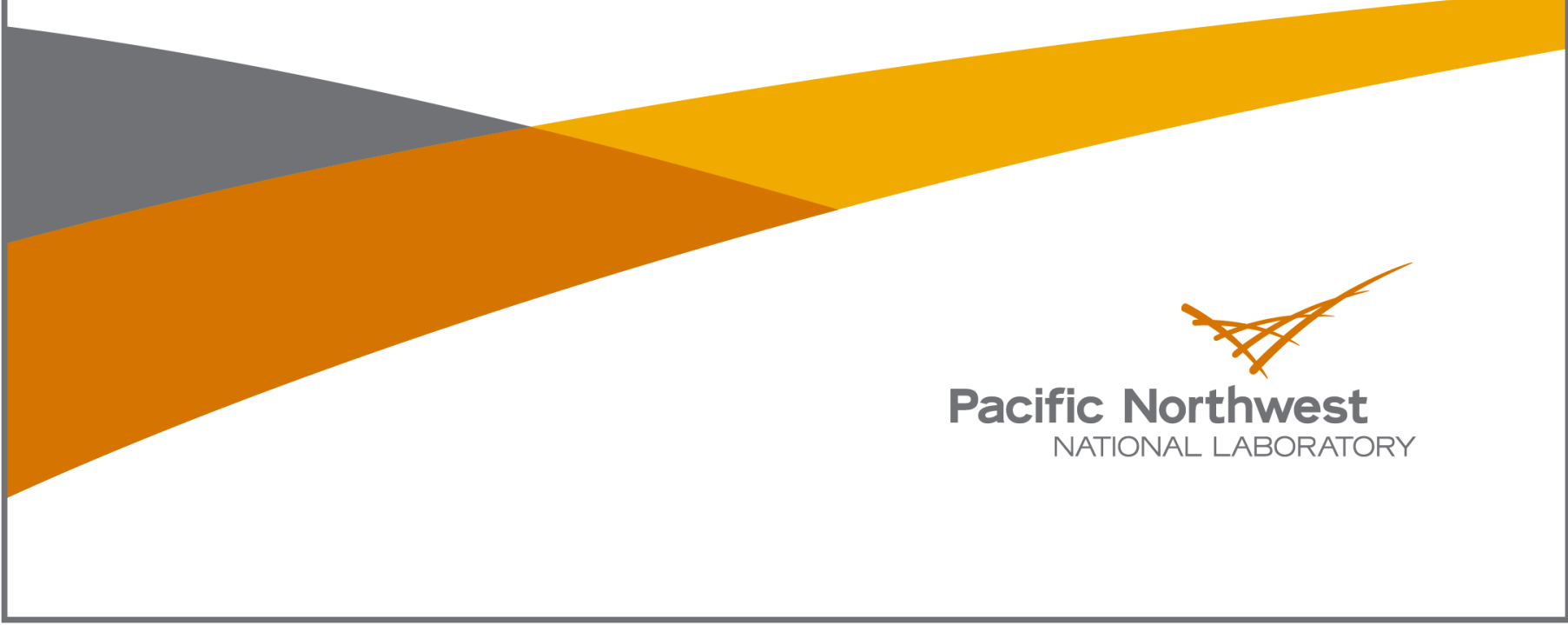




\title{
DISCLAIMER
}

This report was prepared as an account of work sponsored by an agency of the United States Government. Neither the United States Government nor any agency thereof, nor Battelle Memorial Institute, nor any of their employees, makes any warranty, express or implied, or assumes any legal liability or responsibility for the accuracy, completeness, or usefulness of any information, apparatus, product, or process disclosed, or represents that its use would not infringe privately owned rights. Reference herein to any specific commercial product, process, or service by trade name, trademark, manufacturer, or otherwise does not necessarily constitute or imply its endorsement, recommendation, or favoring by the United States Government or any agency thereof, or Battelle Memorial Institute. The views and opinions of authors expressed herein do not necessarily state or reflect those of the United States Government or any agency thereof.

\author{
PACIFIC NORTHWEST NATIONAL LABORATORY \\ operated by \\ BATTELLE \\ for the \\ UNITED STATES DEPARTMENT OF ENERGY \\ under Contract DE-AC05-76RL01830
}

Printed in the United States of America

Available to DOE and DOE contractors from the

Office of Scientific and Technical Information,

P.O. Box 62, Oak Ridge, TN 37831-0062;

ph: (865) 576-8401

fax: (865) 576-5728

email: reports@adonis.osti.gov

Available to the public from the National Technical Information Service,

U.S. Department of Commerce, 5285 Port Royal Rd., Springfield, VA 22161

ph: (800) 553-6847

fax: $(703) 605-6900$

email: orders@ntis.fedworld.gov

online ordering: http://www.ntis.gov/ordering.htm 


\section{Remediation of Deep Vadose Zone Radionuclide and Metal Contamination: Status and Issues}

PE Dresel

MJ Truex

K Cantrell

December 2008

Prepared for the

U.S. Department of Energy

under Contract DE-AC05-76RL01830

Pacific Northwest National Laboratory

Richland, Washington 99352 



\section{Executive Summary}

The U.S. Department of Energy (DOE) Environmental Management initiative Enhanced Remediation Methods: Scientific \& Technical Basis for In Situ Treatment Systems for Metals \& Radionuclides is tasked to provide both scientific information and cost effective in situ remediation technologies needed to treat metals and radionuclide contamination. To support this task, researchers at Pacific Northwest National Laboratory conducted a literature review to report on the state of the maturity of deep vadose zone remediation technologies for metal contaminants including some radionuclides. The purpose of this report is to provide

- A summary of potential remediation strategies and their state of maturity as a basis for further development

- Information to policy makers to determine productive areas for short- and longer-term investment to meet initiative goals.

This report is focused on contaminants of high interest at U.S. Department of Energy sites, technetium-99 and uranium, but other contaminants are potentially of interest, including chromium, mercury, plutonium, and strontium-90. Co-contaminants are considered in evaluating remediation technologies, because they can have an impact on the effectiveness of the remediation and may also need to be addressed to protect human health and the environment.

Deep vadose zone contamination is primarily a concern as an ongoing source of groundwater contamination and exposure to human or ecological receptors through the groundwater pathway. For in situ remediation in the vadose zone, contaminant removal or long-term sequestration will be required to protect groundwater for many of the contaminants of potential concern at DOE sites. Thus, longevity of the remedial action under the expected future conditions at a site is an important consideration.

This document describes potential remediation approaches for the vadose zone and identifies applied science and engineering needs for remediation of metals and radionuclides in the deep vadose zone. The document focuses on mechanisms that may be used to sequester or remove metals from the subsurface. It evaluates requirements to move the mechanisms forward on a development path to produce a viable remediation technology. Each remediation mechanism is assessed for its state of maturity, potential applicability to DOE deep vadose issues, and issues that need to be resolved to produce a successful remedial technology.

The remediation methods discussed may be broadly grouped into mobilization and recovery methods and fixation and sequestration methods. A variety of physical, chemical, and biological processes may apply to both groups. Bioremediation is considered separately from chemical processes in this document. Table S-1 briefly describes the processes considered and summarizes the evaluation with regard to state of development and path forward toward viable remediation technology. The table provides a suggested ranking of the technologies regarding priority for research and development (R\&D) investment. The main recommendations are as follows:

1. A balanced approach to developing concepts at different stages of maturity is needed to address deep vadose remediation challenges. Transfer of remediation technologies from groundwater, shallow vadose zone, or waste treatment applications generally will require additional laboratory and proofof-principle field testing. Methods with a clear development path through this process are likely to 
have more immediate payoff, whereas novel methods without a track record in other areas have a greater risk but may overcome major challenges in the existing methods.

2. In evaluating proposed development or proof-of-principle testing of remedial technologies, the target scale should be considered. Some technologies may not be applicable to widely dispersed contamination but may be valuable for addressing small high-risk areas of contamination.

3. It is likely that significant new breakthroughs in treatment of the deep vadose zone will entail a combination of different chemical and physical processes to overcome shortcomings in individual methodologies. Possible hybrid remediation methods that show promise include the following:

a. reduction of uranium or technetium followed by geochemical manipulation to sequester the reduced species under precipitated mineral coating such as carbonate minerals or iron oxides

b. gaseous reduction to fix contaminants in place followed by liquid treatment for permanent sequestration while avoiding mobilization of the contaminant at the liquid front

c. coupling of aerobic biological activity to develop biomass with subsequent development of anaerobic conditions for bioreduction

d. coupled abiotic/biotic processes such as bioremediation of co-contaminants (e.g., nitrate) allowing for more effective reduction of metals and radionuclides.

4. Delivery of chemical reactants or nutrients to targeted areas of the deep vadose zone is a major issue for the success of all remedial processes. At this time, gas phase or foam-based delivery appear to be the most advantageous for deep vadose remediation. Three-phase gas, liquid, and solid, foam-based delivery may also be effective for dispersing nanoparticles in the subsurface. Electrokinetic methods should be evaluated to enhance delivery of chemicals, especially in areas where low permeability or high heterogeneity limits the effective treatment of contaminated zones.

5. Phosphate phases show great promise for stabilization of contaminants of interest and may provide significant hydraulic control. Emplacement and development of low-temperature phosphates in the vadose zone should be studied further. The relationship of phosphate formation to its role in biological processes needs to be better understood to develop new remedial options. Delivery mechanisms including triethyl phosphate gas and phosphate surfactants should be evaluated. A greater understanding of the role of phosphate in mercury and technetium geochemistry is needed.

6. Research on the emplacement of carbonate and possibly silicate phases would be valuable for chemical and physical sequestration. Methods to control $\mathrm{pH}$ for manipulation of the carbonate system, such as carbon dioxide or ammonia gas need further development. Technetium-carbonate geochemical relationships are not as well developed as for uranium and need more investigation.

7. Thus far only a few reductants have been considered for in situ vadose zone remediation. Other reductants should be considered, either to provide preferential reaction with the target constituents or to produce reduced phases with better stability as more oxic conditions return. Alternate gaseous reductants and zero-valent iron are potential targets. However, the successful deployment of zerovalent iron first requires further understanding of reported enhancement of oxidative reactions by iron surfaces and effective methods for particulate delivery

8. Chemical, electrochemical, or biochemical manipulations to alter subsurface permeability likely will allow more targeted sequestration and greater longevity that surface capping. These processes should be evaluated versus grouting or polymer methods for in situ hydraulic control. 
9. Desiccation is undergoing testing at Hanford and progress should be monitored with respect to information useful for future desiccation applications or as input for evaluation and development of other gas-phase technologies. 
Table S.1. Technology Summary

\begin{tabular}{|c|c|c|c|}
\hline Technology & Description & State of Development & Development Path \\
\hline \multicolumn{4}{|c|}{ Contaminant Mobilization and Recovery } \\
\hline \multirow[t]{2}{*}{$\begin{array}{l}\text { Soil flushing with water } \\
\text { or complexants }\end{array}$} & $\begin{array}{l}\text { Mobilization of contaminants with } \\
\text { water or aqueous solutions so they can } \\
\text { be removed and treated or disposed. }\end{array}$ & $\begin{array}{l}\text { Mature technology. In situ field } \\
\text { deployment for shallow vadose zone has } \\
\text { taken place. }\end{array}$ & $\begin{array}{l}\text { This area is not considered a high priority } \\
\text { for } R \& D \text {. }\end{array}$ \\
\hline & $\begin{array}{l}\text { Ability to recover mobilized } \\
\text { contaminants typically depends on } \\
\text { driving them to groundwater then using } \\
\text { groundwater treatment, thus impacting } \\
\text { groundwater remediation decisions. }\end{array}$ & $\begin{array}{l}\text { Applicability to deep vadose zone has not } \\
\text { been demonstrated. Uniformity of } \\
\text { treatment needs to be addressed. }\end{array}$ & $\begin{array}{l}\text { Assess local hydrogeology and contaminan } \\
\text { mobility when considering site-specific } \\
\text { deployment. }\end{array}$ \\
\hline \multirow[t]{3}{*}{$\begin{array}{l}\text { Biosurfactant and } \\
\text { exopolysaccharide } \\
\text { flushing }\end{array}$} & $\begin{array}{l}\text { Biosurfactants tend to have lower } \\
\text { foaming and biodegrade faster than } \\
\text { synthetic surfactants. }\end{array}$ & $\begin{array}{l}\text { Conceptual; limited study. Treatment } \\
\text { uniformity and contaminant recovery } \\
\text { issues exist. }\end{array}$ & $\begin{array}{l}\text { This area is not considered a high priority } \\
\text { for } R \& D \text {. }\end{array}$ \\
\hline & $\begin{array}{l}\text { Exopolysaccharides are large molecules } \\
\text { that also bind to metals. }\end{array}$ & & $\begin{array}{l}\text { Not as likely to be productive as } \\
\text { biogeochemical fixation technologies. }\end{array}$ \\
\hline & & & $\begin{array}{l}\text { Implications of mobilization by biological } \\
\text { processes may need to be understood for } \\
\text { other remediation strategies. }\end{array}$ \\
\hline \multirow[t]{3}{*}{ Surfactant flushing } & $\begin{array}{l}\text { Surfactant solutions or foams may be } \\
\text { used to mobilize metals or other } \\
\text { contaminants. }\end{array}$ & $\begin{array}{l}\text { Conceptual and/or laboratory-scale } \\
\text { evaluations. Most research thus far has } \\
\text { targeted saturated conditions. }\end{array}$ & $\begin{array}{l}\text { This area is not considered a high priority } \\
\text { for } R \& D \text {. }\end{array}$ \\
\hline & & & $\begin{array}{l}\text { Not as likely to be productive as fixation } \\
\text { technologies. }\end{array}$ \\
\hline & & & $\begin{array}{l}\text { Implications of mobilization by chemical } \\
\text { processes may need to be understood for } \\
\text { other remediation strategies. }\end{array}$ \\
\hline
\end{tabular}


Table S.1. (contd)

\begin{tabular}{|c|c|c|c|}
\hline Technology & Description & State of Development & Development Path \\
\hline $\begin{array}{l}\text { Electrokinetic } \\
\text { mobilization and } \\
\text { recovery }\end{array}$ & $\begin{array}{l}\text { Application of an electric field in the } \\
\text { soil induces contaminant mobilization } \\
\text { through electromigration, } \\
\text { electroosmosis, or electrophoresis. } \\
\text { Particularly applicable to low- } \\
\text { permeability sediments. }\end{array}$ & $\begin{array}{l}\text { Method has been implemented in selected } \\
\text { shallow vadose zone contaminant areas. } \\
\text { Ability to deploy at depth and/or over } \\
\text { large areas may be an issue. }\end{array}$ & $\begin{array}{l}\text { This area is not considered a high priority } \\
\text { for } R \& D \text {. } \\
\text { Identify suitable chemical enhancements for } \\
\text { particular applications if considering } \\
\text { deployment on a site-specific basis. }\end{array}$ \\
\hline $\begin{array}{l}\text { Hybrid electrokinetic } \\
\text { delivery of treatment } \\
\text { chemicals }\end{array}$ & $\begin{array}{l}\text { Mobilization of fluids to target areas by } \\
\text { application of electric fields. }\end{array}$ & $\begin{array}{l}\text { Laboratory testing performed for } \\
\text { reduction of chromate. Control of } \\
\text { subsurface chemical conditions is critical. }\end{array}$ & $\begin{array}{l}\text { This area is a high priority for } R \& D \text { applied } \\
\text { to remedial design. } \\
\text { Recommend further R\&D for chemical } \\
\text { fixation in low-permeability sediments and } \\
\text { enhancement of other remediation systems. }\end{array}$ \\
\hline $\begin{array}{l}\text { Hybrid electrokinetic- } \\
\text { permeable reductive } \\
\text { barrier }\end{array}$ & $\begin{array}{l}\text { Electrical fields can enhance the } \\
\text { reductive effectiveness of permeable } \\
\text { barriers. }\end{array}$ & $\begin{array}{l}\text { Laboratory testing performed for } \\
\text { reduction of chromate. Placement of } \\
\text { electrodes and barriers in deep vadose } \\
\text { zone may be problematic. May be useful } \\
\text { in areas of low-permeability, high } \\
\text { saturation sediments. }\end{array}$ & $\begin{array}{l}\text { This area is not considered a high priority } \\
\text { for deep vadose zone } R \& D \text {. } \\
\text { Assess local geochemical and hydrological } \\
\text { conditions when considering deployment on } \\
\text { a site-specific basis. }\end{array}$ \\
\hline Enhanced Volatilization & $\begin{array}{l}\text { Volatilization by heating is limited to } \\
\text { zero-valent mercury }(\mathrm{Hg}) \text {, organic } \\
\text { mercury species, and potentially iodine- } \\
129 \text {. } \mathrm{Hg}(\mathrm{II}) \text { would have to be reduced } \\
\text { to } \mathrm{Hg}(0) \text { for volatilization. }\end{array}$ & $\begin{array}{l}\text { Conceptually simple but only laboratory- } \\
\text { scale evaluations were found. }\end{array}$ & $\begin{array}{l}\text { This area is not considered a high priority } \\
\text { for } R \& D \text {. } \\
\text { Assess local geochemical and hydrological } \\
\text { conditions when considering deployment on } \\
\text { a site-specific basis. }\end{array}$ \\
\hline
\end{tabular}


Table S.1. (contd)

\begin{tabular}{|c|c|c|c|}
\hline Technology & Description & State of Development & Development Path \\
\hline \multicolumn{4}{|c|}{ Enhanced Sorption } \\
\hline $\begin{array}{l}\text { Chemical manipulation } \\
\text { of solution or solid } \\
\text { surfaces to retard } \\
\text { transport. }\end{array}$ & \multirow[t]{2}{*}{$\begin{array}{l}\text { Addition of materials to increase } \\
\text { sorptive surfaces (altered mineralogy or } \\
\text { particle size) or to alter aqueous } \\
\text { speciation can retard chemical } \\
\text { movement. }\end{array}$} & $\begin{array}{l}\text { Mature concept. Less fundamental } \\
\text { information on desorption processes than } \\
\text { for sorption. }\end{array}$ & $\begin{array}{l}\text { This area is not considered a high priority } \\
\text { for R\&D applied to remedial design. } \\
\text { Fundamental research on desorption } \\
\text { processes would be valuable. }\end{array}$ \\
\hline \multicolumn{3}{|r|}{ Mineral Precipitation } & \\
\hline $\begin{array}{l}\text { Phosphate phase } \\
\text { precipitation }\end{array}$ & $\begin{array}{l}\text { Phosphates are a viable form for } \\
\text { uranium sequestration and can promote } \\
\text { sequestration by iron and aluminum } \\
\text { oxides. Hydroxyapatite can sequester } \\
\text { strontium-90 (Sr-90). Phosphate } \\
\text { phases also show potential for mercury } \\
\text { sequestration but little is known about } \\
\text { technetium-phosphate interactions. }\end{array}$ & $\begin{array}{l}\text { Field-scale testing for sequestration of } \\
\text { uranium in phosphate phases is being } \\
\text { performed at the Hanford Site. } \\
\text { A treatability test has been performed at } \\
\text { the Hanford Site for sequestration of Sr- } \\
90 \text { in hydroxyapatite. }\end{array}$ & $\begin{array}{l}\text { This area is a high priority for } R \& D \text { applied } \\
\text { to remedial design. } \\
\text { Further } R \& D \text { of remediation based on } \\
\text { phosphate phases is likely to be productive. } \\
\text { Investigate difficulties in formation of } \\
\text { autunite. }\end{array}$ \\
\hline & & & $\begin{array}{l}\text { Understanding the uranium system will } \\
\text { provide a framework for addressing other } \\
\text { contaminants. }\end{array}$ \\
\hline
\end{tabular}


Table S.1. (contd)

\begin{tabular}{|c|c|c|c|}
\hline Technology & Description & State of Development & Development Path \\
\hline $\begin{array}{l}\text { Carbonate phase } \\
\text { precipitation }\end{array}$ & $\begin{array}{l}\text { Substitution into rhombohedral or } \\
\text { orthorhombic carbonate minearals can } \\
\text { sequester the contaminants. Solid } \\
\text { solutions tend to be more stable than } \\
\text { pure end members. } \\
\text { Carbonate minerals are often near } \\
\text { saturation in the vadose zone and } \\
\text { groundwater. }\end{array}$ & $\begin{array}{l}\text { Substitution of strontium, uranium and } \\
\text { chromium into carbonates has been } \\
\text { shown but not developed into remediation } \\
\text { technology. }\end{array}$ & $\begin{array}{l}\text { This area is a high priority for } R \& D \text { applied } \\
\text { to remedial design. } \\
\text { Carbonate systems should be evaluated for } \\
\text { chemical fixation in the vadose zone. } \\
\text { Conduct laboratory testing prior to field } \\
\text { deployment to evaluate contaminant } \\
\text { substitution into calcium or iron carbonates. } \\
\text { Characterize technetium interaction with } \\
\text { carbonate minerals prior to any proof-of- } \\
\text { principle testing. }\end{array}$ \\
\hline $\begin{array}{l}\text { Other precipitation } \\
\text { mechanisms }\end{array}$ & $\begin{array}{l}\text { Potential phases include the following: } \\
\text { - } \quad \text { silicate minerals (e.g. clays, } \\
\text { boltwoodite) } \\
\text { - barium chromate } \\
\text { dipotassium 1,3- } \\
\text { benzendiamidoethanethiol for } \\
\text { mercury sequestration. } \\
\text { Iron oxyhydroxides may sequester } \\
\text { contaminants but are likely to be most } \\
\text { effective when redox reactions are } \\
\text { involved (see below). }\end{array}$ & $\begin{array}{l}\text { A number of mineral precipitation } \\
\text { mechanisms have been suggested for in } \\
\text { situ remediation but have not been tested. } \\
\text { In situ production of uranium silicate } \\
\text { phases has been documented at the } \\
\text { Hanford Site, however, the uranium was } \\
\text { readily leached with carbonate solutions. }\end{array}$ & $\begin{array}{l}\text { This area is considered a secondary priority } \\
\text { for } R \& D \text { applied to remedial design. } \\
\text { Investigate novel silicate forms for } \\
\text { sequestration of contaminants. } \\
\text { Monitor developments for other potential } \\
\text { mechanisms. }\end{array}$ \\
\hline
\end{tabular}


Table S.1. (contd)

\begin{tabular}{|c|c|c|c|}
\hline Technology & Description & State of Development & Development Path \\
\hline \multicolumn{4}{|c|}{ Oxidation-Reduction Processes } \\
\hline Zero-valent iron & $\begin{array}{l}\text { Zero-valent iron forms a permeable } \\
\text { reactive barrier for reduction of } \\
\text { contaminant species in the subsurface. } \\
\text { Emplacement may be through trenching } \\
\text { techniques or injection of microscale or } \\
\text { nanoscale particles. }\end{array}$ & $\begin{array}{l}\text { Zero-valent iron has been demonstrated to } \\
\text { effectively sequester a wide variety of } \\
\text { metals and radionulcides in saturated } \\
\text { systems. Its effectiveness in the vadose } \\
\text { zone is unknown. }\end{array}$ & $\begin{array}{l}\text { This area is considered a secondary priority } \\
\text { for R\&D applied to remedial design. } \\
\text { Evaluate potential impacts of iron surfaces } \\
\text { in promoting oxidative reactions in the } \\
\text { vadose zone. Development of effective } \\
\text { emplacement methods for nanoscale iron } \\
\text { particles in the vadose zone is needed prior } \\
\text { to deployment. }\end{array}$ \\
\hline Sodium dithionate & $\begin{array}{l}\text { Sodium dithionate has been shown to } \\
\text { be an effective reductant for } \mathrm{Cr}(\mathrm{VI}) \text { in } \\
\text { saturated systems. It reduces Fe(III) to } \\
\mathrm{Fe}(\mathrm{II}) \text {, which subsequently reduces } \\
\mathrm{Cr}(\mathrm{VI}) \text {. }\end{array}$ & $\begin{array}{l}\text { Application to the vadose zone has not } \\
\text { been demonstrated. }\end{array}$ & $\begin{array}{l}\text { This area is not considered a high priority } \\
\text { for } R \& D \text {. } \\
\text { Assess local geochemical and hydrological } \\
\text { conditions when considering deployment on } \\
\text { a site-specific basis. }\end{array}$ \\
\hline & & & $\begin{array}{l}\text { Comparison to other reductants may depend } \\
\text { on economics. }\end{array}$ \\
\hline Sulfide salts and minerals & $\begin{array}{l}\text { Calcium polysulfide is an effective } \\
\text { reductant for Cr(VI) but mobilization } \\
\text { by the dithionate solution is likely to } \\
\text { occur so some impacts on groundwater } \\
\text { can be expected. Polysulfide can also } \\
\text { reduce uranium and technetium but } \\
\text { those elements are more easily } \\
\text { reoxidized in the vadose zone than } \\
\text { chromium. }\end{array}$ & $\begin{array}{l}\text { Field deployment for } \mathrm{Cr}(\mathrm{VI}) \text { remediation } \\
\text { has taken place at a number of } \\
\text { commercial sites. }\end{array}$ & $\begin{array}{l}\text { This area is not considered a high priority } \\
\text { for } R \& D \text {. } \\
\text { Assess local geochemical and hydrological } \\
\text { conditions when considering deployment on } \\
\text { a site-specific basis. }\end{array}$ \\
\hline
\end{tabular}


Table S.1. (contd)

\begin{tabular}{|c|c|c|c|}
\hline Technology & Description & State of Development & Development Path \\
\hline Ferrous iron & $\begin{array}{l}\text { The addition of liquid ferrous iron, } \\
\text { sometimes mixed with other reductants, } \\
\text { can reduce } \mathrm{Cr}(\mathrm{VI}), \mathrm{Tc}(\mathrm{VII}) \text {, or } \\
\text { potentially other contaminants. The } \\
\text { reduction mechanism may be through a } \\
\text { homogeneous reaction in solution or be } \\
\text { a surface-mediated heterogeneous } \\
\text { reaction. }\end{array}$ & $\begin{array}{l}\text { A treatment solution of } 0.20 \mathrm{M} \text { ferrous } \\
\text { sulfate was found to be effective for } \\
\text { treatment of source zones and plumes in } \\
\text { the saturated zone. } \\
\text { Pilot-scale demonstration completed at } \\
\text { two Cr(VI) contaminated sites in the } \\
\text { saturated zone. Application to the vadose } \\
\text { zone has not been demonstrated. }\end{array}$ & $\begin{array}{l}\text { Ferrous iron reductant is not considered a } \\
\text { high priority for } R \& D \text {. } \\
\text { Success will depend on the ability to deliver } \\
\text { Fe(II) to the contaminant zone prior to } \\
\text { oxidation by soil oxygen and without } \\
\text { mobilizing the contaminants at the liquid } \\
\text { front. }\end{array}$ \\
\hline Gaseous reduction & $\begin{array}{l}\text { Gas-phase reductants such as } \mathrm{H}_{2} \mathrm{~S} \text { are } \\
\text { easily transported through the vadose } \\
\text { zone and can reduce contaminants in } \\
\text { the vadose zone. }\end{array}$ & $\begin{array}{l}\text { Successful field-scale demonstration of } \\
\mathrm{Cr}(\mathrm{VI}) \text { remediation in the vadose zone has } \\
\text { been completed at a government } \\
\text { installation. }\end{array}$ & $\begin{array}{l}\text { This area is a high priority for } R \& D \text { applied } \\
\text { to remedial design. } \\
\text { Evaluate novel gaseous reductants and } \\
\text { address questions of toxicity. Investigate } \\
\text { issues of reoxidation. }\end{array}$ \\
\hline \multicolumn{4}{|c|}{ Biological Sequestration Processes } \\
\hline Direct reduction & $\begin{array}{l}\text { Direct biological reduction of } \\
\text { contaminants may occur if the } \\
\text { contaminant is reduced as part of the } \\
\text { metabolic process, fortuitously reduced } \\
\text { by bacterial enzymes, or reduced as a } \\
\text { microbial response to the toxicity of the } \\
\text { contaminant. }\end{array}$ & $\begin{array}{l}\text { Field-scale application has occurred for } \\
\text { some of the target contaminants and } \\
\text { laboratory information exists for all of the } \\
\text { contaminants in the saturated zone. }\end{array}$ & $\begin{array}{l}\text { This area is a high priority for } R \& D \text { applied } \\
\text { to remedial design. } \\
\text { Develop combined aerobic and anaerobic } \\
\text { processes for the vadose zone and verify the } \\
\text { effectiveness of amendment delivery. } \\
\text { Quantify the stability of induced precipitates } \\
\text { similar to chemically induced precipitates. }\end{array}$ \\
\hline Indirect reduction & $\begin{array}{l}\text { Microbially reduced species, such as } \\
\text { iron and sulfur compounds, can } \\
\text { subsequently reduce contaminants. } \\
\text { This capability may be particularly } \\
\text { important for technetium and uranium. }\end{array}$ & $\begin{array}{l}\text { Field-scale application has occurred for } \\
\text { some of the target contaminants and } \\
\text { laboratory information exists for all of the } \\
\text { contaminants in the saturated zone. }\end{array}$ & $\begin{array}{l}\text { This area is a high priority for } R \& D \text { applied } \\
\text { to remedial design. } \\
\text { Develop combined aerobic and anaerobic } \\
\text { processes for the vadose zone and verify the } \\
\text { effectiveness of amendment delivery. }\end{array}$ \\
\hline & & & $\begin{array}{l}\text { Quantify the stability of induced precipitates } \\
\text { similar to chemically induced precipitates. }\end{array}$ \\
\hline
\end{tabular}


Table S.1. (contd)

\begin{tabular}{|c|c|c|c|}
\hline Technology & Description & State of Development & Development Path \\
\hline Coprecipitation & $\begin{array}{l}\text { Biologically catalyzed mineral } \\
\text { precipitation can sequester } \\
\text { contaminants. }\end{array}$ & $\begin{array}{l}\text { Interactions of biological processes with } \\
\text { mineral precipitation mechanisms }\end{array}$ & $\begin{array}{l}\text { This area is a high priority for } R \& D \text { applied } \\
\text { to remedial design. } \\
\text { Bacterially mediated phosphate processes } \\
\text { likely will be a productive area for } \\
\text { investigation. Investigate coupled abiotic } \\
\text { and biotic processes. }\end{array}$ \\
\hline & & & $\begin{array}{l}\text { Quantify the stability of induced precipitates } \\
\text { similar to chemically induced precipitates. }\end{array}$ \\
\hline
\end{tabular}


Table S.1. (contd)

\begin{tabular}{ccc}
\hline Technology & Description & State of Development \\
\hline
\end{tabular}

Caps and covers

Thermal treatment

In situ vitrification and sub-melting thermal fixation provide physical and chemical sequestration. , reducing contaminant transport to the water table. Covers may be combined with other fixation technologies.
Thermal treatment has been demonstrated for relatively small volumes of contaminated sediment.

Caps and covers control infiltration and

Cap and cover technologies are well established but may need engineering for site-specific applications.

contaminated sediment.
Removing water from the vadose zone reduces the pore fluid available to support downward transport and can form a capillary barrier to impede migration. Induced precipitation of mineral phases may further immobilize contaminants.
This area is not considered a high priority for deep vadose zone $R \& D$.

Consider deployment on a site-specific basis. Assess local conditions for design.

(Design and maintenance of very large covers can be challenging.)

Develop long-term performance prediction and monitoring.

This area is not considered a high priority for deep vadose zone $R \& D$.

Development of more efficient thermal technologies may produce cost savings for particular applications. Further

development of lower-temperature thermal treatment would speed up treatment and reduce energy costs.

A soil desiccation treatability test is being planned for the Hanford Site, following laboratory and modeling efforts.
This area is a high priority for $R \& D$ applied to remedial design.

Soil desiccation is an important area for development and is being demonstrated through site remediation treatability testing. $R \& D$ areas that will provide value to future site testing and deployment include developing an understanding of rewetting phenomena and model development to support long-term performance prediction.

Consider site-specific conditions for field deployment. 
Table S.1. (contd)

\begin{tabular}{|c|c|c|c|}
\hline Technology & Description & State of Development & Development Path \\
\hline Permeability control & $\begin{array}{l}\text { Physical or geochemical technologies } \\
\text { applied to limit interconnected porosity } \\
\text { through precipitation of mineral phases, } \\
\text { grouting, or polymer additions. }\end{array}$ & $\begin{array}{l}\text { Grouting technology is fairly well } \\
\text { established but few applications are } \\
\text { documented for deep vadose remediation } \\
\text { permeability control. Deep soil mixing is } \\
\text { an alternate technology to grout injection } \\
\text { that has been deployed at some } \\
\text { commercial sites. } \\
\text { Geochemical manipulations for } \\
\text { controlling permeability are not well } \\
\text { developed. Electrokinetic methods have } \\
\text { been used for geotechnical applications. }\end{array}$ & $\begin{array}{l}\text { This area is a high priority for } R \& D \text { applied } \\
\text { to remedial design. } \\
\text { Evaluating the practicality of geochemical } \\
\text { permeability control is a secondary priority. } \\
\text { This could include developing a greater } \\
\text { understanding of mechanisms for } \\
\text { manipulating conditions to precipitate } \\
\text { mineral phases including electrokinetic or } \\
\text { biological interactions. }\end{array}$ \\
\hline
\end{tabular}

Gas-phase delivery $\quad$ Gaseous delivery to the deep vadose zone has advantages because of the ease of transport through the sediments with minimal effect from gravitational and capillary forces.

Foam delivery

\section{Chemical Delivery}

Injection of $\mathrm{H}_{2} \mathrm{~S}$ for reduction of $\mathrm{Cr}(\mathrm{VI})$ has been demonstrated in the field.

Treatability studies for gas-phase reagents are planned for the Hanford Site.

Gas-phase delivery of nutrients to promote biodegradation is another application that is being considered.

Foam delivery under saturated conditions has been described, but only initial work has been done on understanding the viability of foam delivery for deep vadose remediation.
This area is a high priority for $R \& D$ applied to remedial design.

Address the controversy at some sites over the safety of $\mathrm{H}_{2} \mathrm{~S}$ injection so that the technology can be deployed.

Investigate alternate gases for chemical remediation or bioremediation.

This area is a high priority for $R \& D$ applied to remedial design.

flushing, liquid chemical delivery, or delivery of nanoparticles to minimize the gravitational effects impacting reagent distribution.
Determine the practical extent of injection through laboratory and field testing and the impacts of heterogeneities.

Understand the impacts to water saturation from the ultimate breakdown of foam. 
Table S.1. (contd)

\begin{tabular}{|c|c|c|c|}
\hline Technology & Description & State of Development & Development Path \\
\hline \multirow[t]{4}{*}{ Nanoparticles } & \multirow{4}{*}{$\begin{array}{l}\text { Nanoparticle injection may be the most } \\
\text { practical way to deliver solid reactants } \\
\text { to the deep vadose zone. The nano-size } \\
\text { particles may have advantages in terms } \\
\text { of reactivity. }\end{array}$} & $\begin{array}{l}\text { Air injection of nanoparticles has been } \\
\text { tested and foam delivery is being } \\
\text { considered. }\end{array}$ & $\begin{array}{l}\text { This area is considered a secondary priority } \\
\text { for } R \& D \text { applied to remedial design. }\end{array}$ \\
\hline & & & Investigate air versus foam delivery. \\
\hline & & $\begin{array}{l}\text { The effectiveness using of nanoparticles } \\
\text { for treating deep or large areas of } \\
\text { contamination has not been demonstrated. }\end{array}$ & $\begin{array}{l}\text { Evaluate the impacts of particle size and } \\
\text { surface modification. }\end{array}$ \\
\hline & & $\begin{array}{l}\text { Nanoscale zero-valent iron may increase } \\
\text { chemical oxidation through the interaction } \\
\text { of the iron particles with dissolved } \\
\text { oxygen to form powerful oxidants. }\end{array}$ & $\begin{array}{l}\text { Evaluate the chemical reactions of zero- } \\
\text { valent iron or other nanomaterials in oxic } \\
\text { vadose zone conditions. }\end{array}$ \\
\hline
\end{tabular}





\section{Acknowledgments}

This work was supported by the U.S. Department of Energy (DOE), Environmental Management Office of Engineering and Technology. This work was performed at Pacific Northwest National

Laboratory, which is operated by Battelle Memorial Institute for the DOE under Contract

DE-AC05-76RL01830. 



\title{
Acronyms, Minerals, Terminology
}

\author{
amorphous hydrated ferric oxide $\mathrm{Fe}_{2} \mathrm{O}_{3} \cdot \mathrm{H}_{2} \mathrm{O}$ (amorphous) \\ aragonite \\ $\mathrm{CaCO}_{3}$ (orthorhombic) \\ autunite \\ $\mathrm{Ca}\left(\mathrm{UO}_{2}\right)_{2}\left(\mathrm{PO}_{4}\right)_{2} \cdot 10-12 \mathrm{H}_{2} \mathrm{O}$ (tetragonal) \\ BDET \\ dipotassium salt of 1,3-benzendiamidoethanethiol \\ bgs \\ below ground surface \\ boltwoodite \\ $(\mathrm{K}, \mathrm{Na})\left(\mathrm{UO}_{2}\right)\left(\mathrm{HSiO}_{4}\right) \cdot 0.5(\mathrm{H} 2 \mathrm{O})$ (monoclinic) \\ calcite \\ $\mathrm{CaCO}_{3}$ (rhombohedral) \\ chernikovite \\ $\left(\mathrm{H}_{3} \mathrm{O}\right)_{2}\left(\mathrm{UO}_{2} \mathrm{PO}_{4}\right)_{2} \cdot 6 \mathrm{H}_{2} \mathrm{O}$ (tetragonal) \\ chromate \\ $\mathrm{CrO}_{4}^{2-}$ \\ chromite \\ $\mathrm{FeCr}_{2} \mathrm{O}_{4}$ (isometric) \\ cinnabar \\ $\mathrm{HgS}$ (hexagonal) \\ crandallite \\ $\mathrm{CaAl}_{3}\left[(\mathrm{OH})_{5}\left(\mathrm{PO}_{4}\right)_{2}\right] \cdot \mathrm{H}_{2} \mathrm{O}$ (trigonal) \\ Cr(III) \\ $\mathrm{Cr}(\mathrm{VI})$ \\ trivalent chromium (the most common valence state in natural \\ sediments) \\ hexavalent chromium (the valence state of chromate and dichromate) \\ $\mathrm{DC}$ \\ direct current \\ DOE \\ U.S. Department of Energy \\ EDTA \\ ethylenediaminetetraacetic acid \\ ferric oxyhydroxide \\ ferric oxide and hydroxides including amorphous hydrated ferric oxide, \\ ferrihydrite, and goethite \\ ferrihydrite \\ $\mathrm{Fe}_{2} \mathrm{O}_{3} \cdot 0.5 \mathrm{H}_{2} \mathrm{O}$ or $\mathrm{Fe}_{5} \mathrm{O}_{3}(\mathrm{OH})_{9}$ (trigonal) \\ ferrous hydroxide \\ $\mathrm{Fe}(\mathrm{OH})_{2}$ \\ gibbsite \\ $\alpha-\mathrm{Al}_{2} \mathrm{O}_{3}$ (monoclinic) \\ goethite \\ $\alpha-\mathrm{FeOOH}$ (orthorhombic) \\ hydroxylapatite \\ $\mathrm{Ca}_{5}\left[\left(\mathrm{PO}_{4}\right)_{3} \mathrm{OH}\right]$ (hexagonal) \\ hashemite \\ $\mathrm{Ba}\left(\mathrm{CrO}_{4}, \mathrm{SO}_{4}\right)$ (orthorhombic) \\ hematite \\ $\mathrm{Fe}_{2} \mathrm{O}_{3}$ (trigonal)
}




\begin{tabular}{|c|c|}
\hline iodide & $\mathrm{I}^{-}$ \\
\hline ISRM & in situ redox manipulation \\
\hline ISV & in situ vitrification \\
\hline mackinawite & $(\mathrm{Fe}, \mathrm{Ni}) \mathrm{S}_{0.9}$ (tetragonal) \\
\hline magnetite & $\mathrm{Fe}_{3} \mathrm{O}_{4}$ (isometric) \\
\hline metacinnabar & $\mathrm{HgS}$ (isometric) \\
\hline metatorbernite & $\mathrm{Cu}\left(\mathrm{UO}_{2} \mathrm{PO}_{4}\right)_{2} \cdot \mathrm{H}_{2} \mathrm{O}$ \\
\hline pertechnetate & $\mathrm{TcO}_{4}^{-}$ \\
\hline pyrite & $\mathrm{FeS}_{2}$ (isometric) \\
\hline $\mathrm{R} \& \mathrm{D}$ & research and development \\
\hline selenate & $\mathrm{SeO}_{4}^{2-}$ \\
\hline siderite & $\mathrm{FeCO}_{3}$ (rhombohedral) \\
\hline silica & $\mathrm{SiO}_{2}$ (hexagonal) \\
\hline sodium dithionite & $\mathrm{Na}_{2} \mathrm{~S}_{2} \mathrm{O}_{4}$ \\
\hline Sr-90 & strontium-90 \\
\hline strontianite & $\mathrm{SrCO}_{3}$ (orthorhombic) \\
\hline TCLP & toxicity characteristic leaching procedure \\
\hline uranium metaphosphate & $\mathrm{U}\left(\mathrm{PO}_{3}\right)_{4}$ \\
\hline uranophane & $\mathrm{Ca}\left(\mathrm{UO}_{2}\right)_{2}\left(\mathrm{HSiO}_{4}\right)_{2} \cdot 5(\mathrm{H} 2 \mathrm{O})$ (monoclinic) \\
\hline vaterite & $\mathrm{CaCO}_{3}$ (hexagonal) \\
\hline witherite & $\mathrm{BaCO}_{3}$ (orthorhombic) \\
\hline
\end{tabular}




\section{Contents}

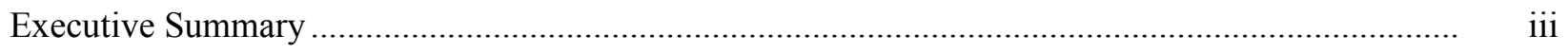

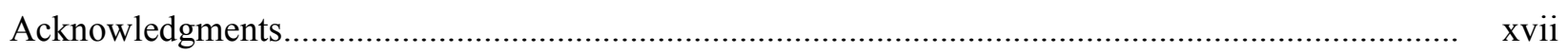

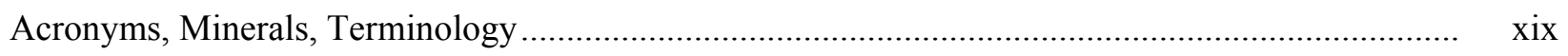

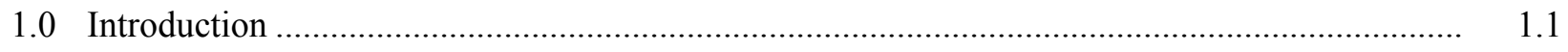

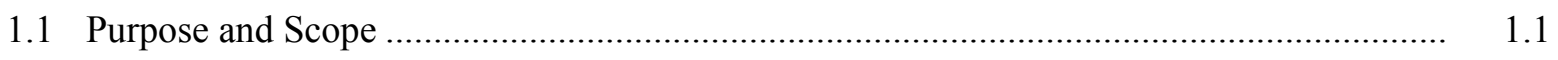

1.2 Approach to Remediation Technology Review and Assessment..................................... 1.2

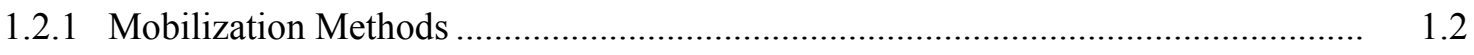

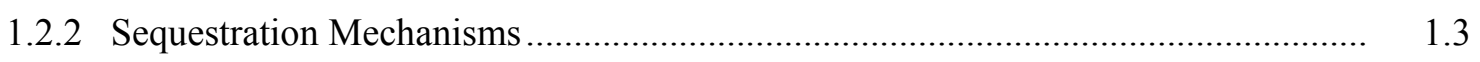

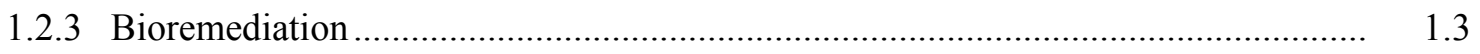

1.2.4 Considerations for Technology Implementation ................................................ 1.4

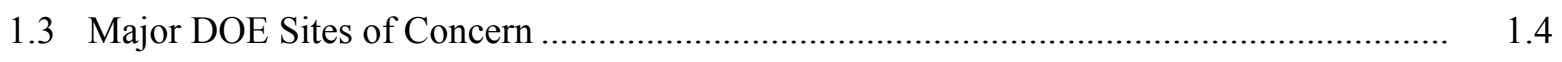

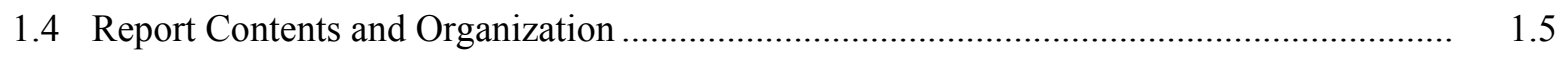

2.0 Contaminant Mobilization and Recovery ….................................................................. 2.1

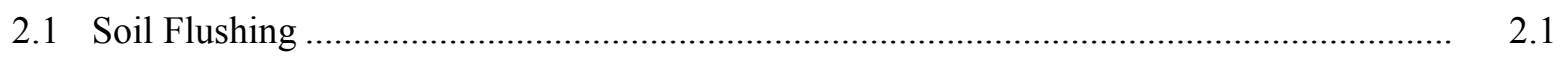

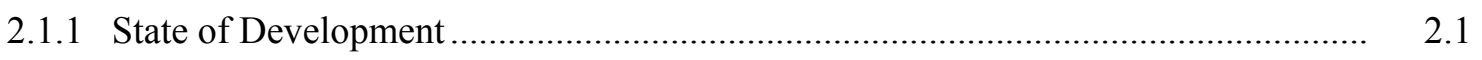

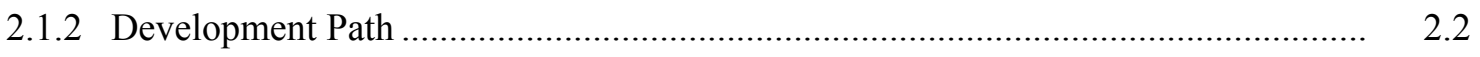

2.2 Electrokinetic Remediation .................................................................................. 2.2

2.2.1 Enhancement Techniques for Electrokinetic Remediation ................................... 2.3

2.2.2 Electrokinetic Remediation of Contaminants of Interest ...................................... 2.4

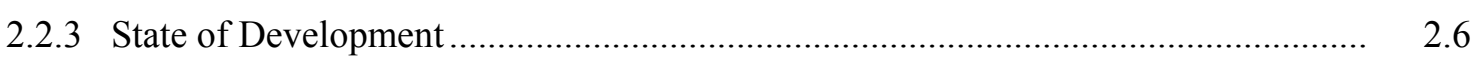

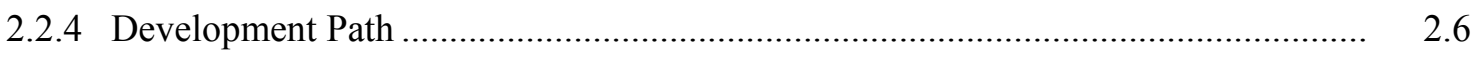

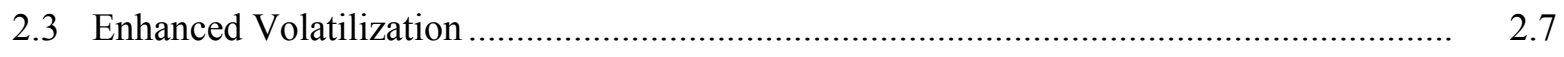

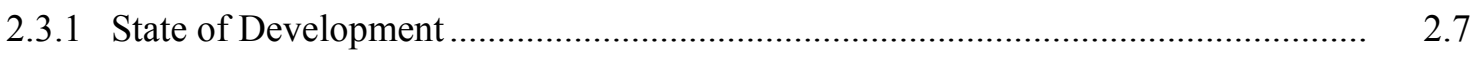

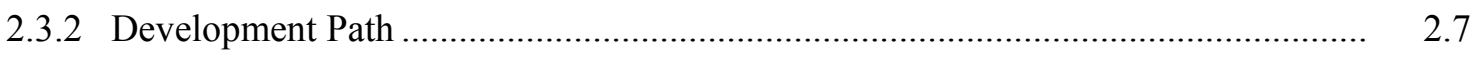

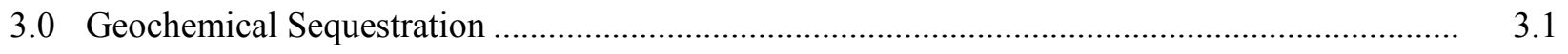

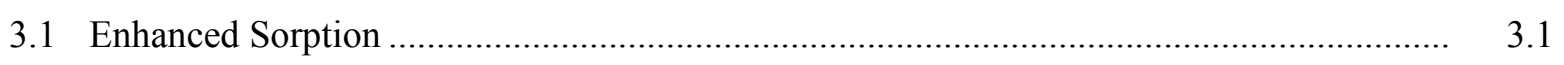

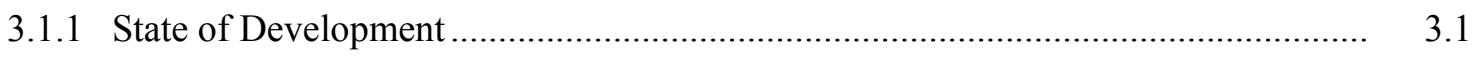

3.1.2 Development Path .................................................................................. 3.4

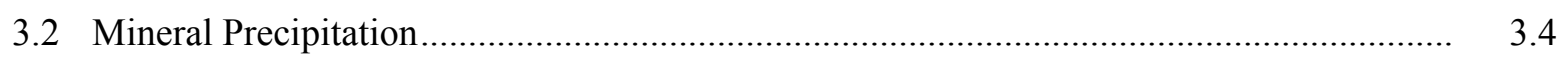

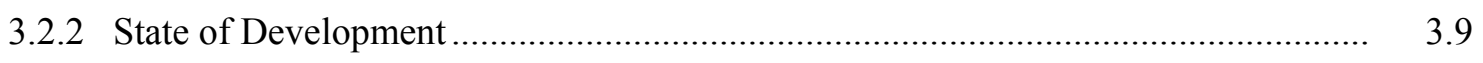

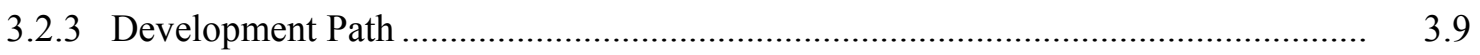

3.3 Oxidation-Reduction Processes............................................................................ 3.10

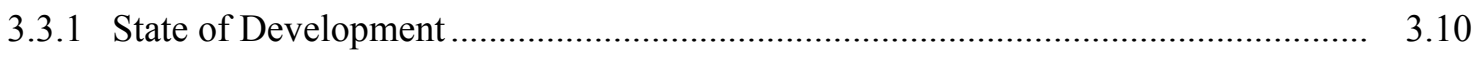

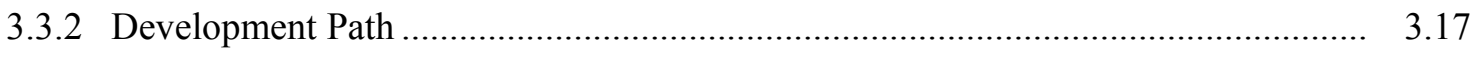

4.0 Biological Sequestration Processes .............................................................................

4.1 Factors that Impact Bioremediation in the Vadose Zone .................................................. 


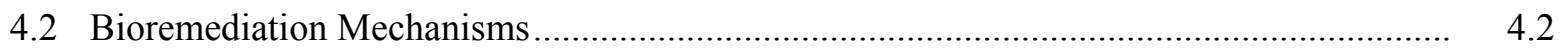

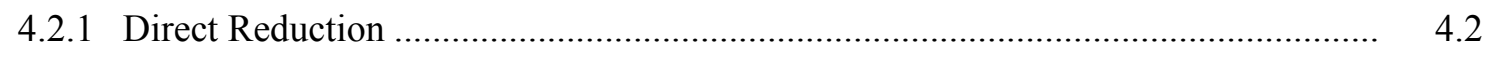

4.2.2 Microbially Induced Coprecipitation ............................................................... 4.5

4.2.3 Biologically Enhanced Sorption........................................................................ 4.5

4.2.4 Mercury Bioremediation .......................................................................... 4.6

4.2.5 Potential Impacts of Biological Reaction Byproducts........................................... 4.6

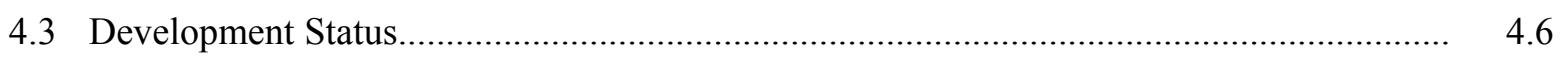

4.4 Development Path .............................................................................................. 4.7

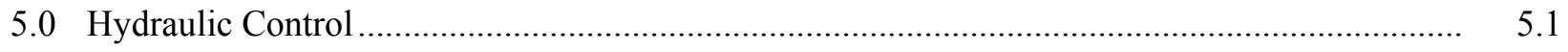

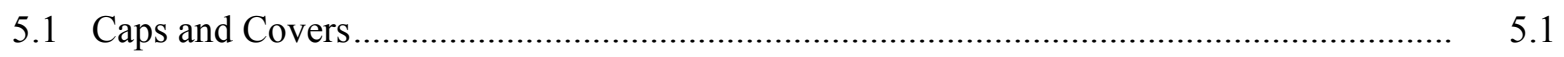

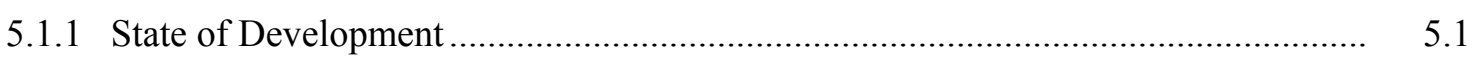

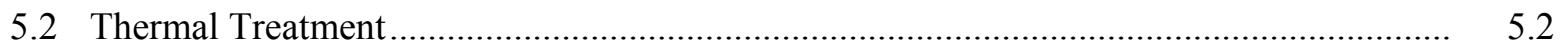

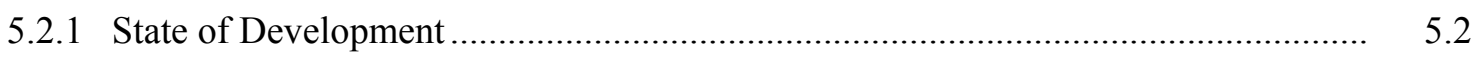

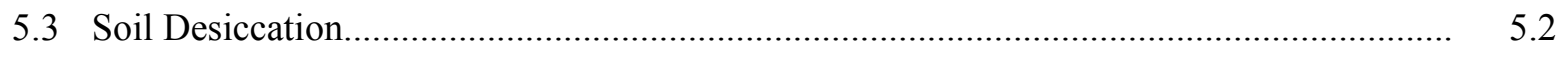

5.3 .1 State of Development ................................................................................ 5.3

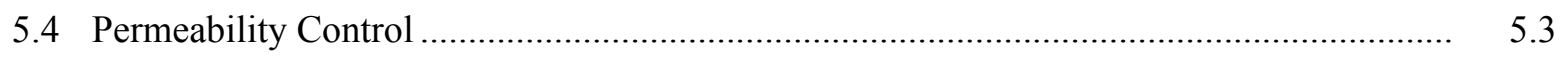

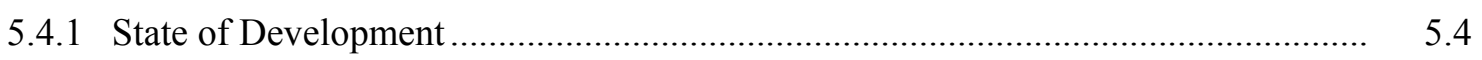

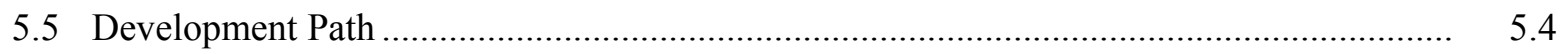

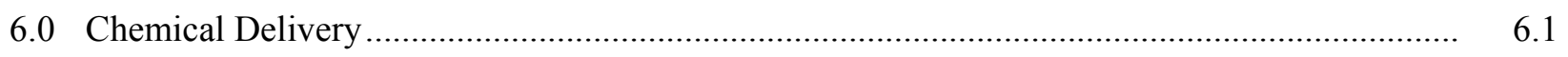

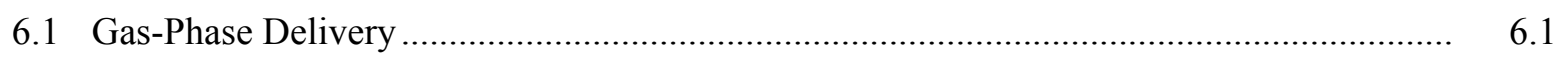

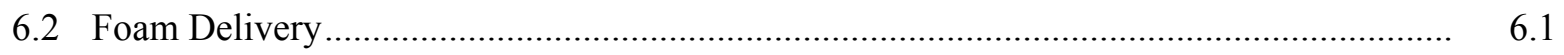

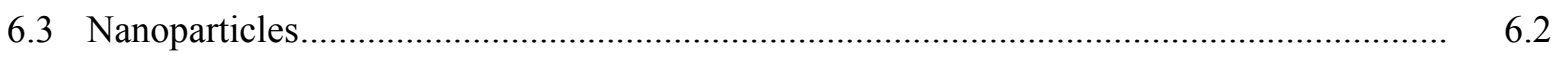

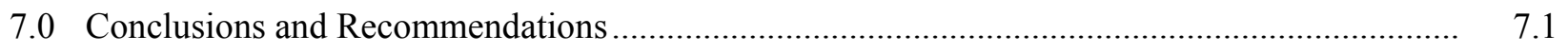

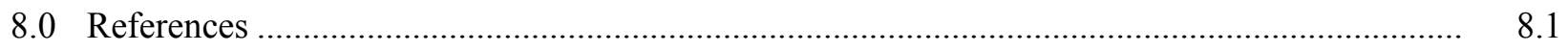

Appendix A Technology Information Sources ….................................................................. A.1

\section{Tables}

S.1 Technology Summary .................................................................................................. vi

A.1 General Response Actions, Technology Types, and Remediation Technologies Potentially Applicable to Vadose Zone Remediation . 


\subsection{Introduction}

The U.S. Department of Energy (DOE) has recognized a need for a strong and responsive applied research and engineering program to achieve safe and compliant disposition of its legacy waste and facilities. This need is addressed through the DOE Environmental Management's Office of Engineering \& Technology in accordance with the U.S. Department of Energy Office of Environmental Management (DOE-EM) Engineering and Technology Roadmap. ${ }^{l}$ The roadmap's Enhanced Remediation Methods initiative is tasked to provide both scientific information and cost effective in situ remediation technologies needed to treat metals and radionuclide contamination (Adams et al. 2008). This document was prepared by Pacific Northwest National Laboratory ${ }^{2}$ to support the roadmap by providing a scientific and technical basis for in situ treatment of deep vadose zone metals and radionuclides.

\subsection{Purpose and Scope}

The purpose of this document is two-fold: first to summarize potential remediation strategies and their state of maturity as a basis for further development, and second to inform policy makers to help determine productive areas for short-and longer-term investment to meet initiative goals. This document provides a literature review and reports on the state of maturity of deep vadose zone remediation technologies for metal contaminants including some radionuclides. It considers research and development needs for evaluation and ultimate deployment of technologies. The report focuses on contaminants of high interest at DOE sites, technetium-99 and uranium, but other contaminants are potentially of interest including chromium, mercury, plutonium, and strontium-90. In addition, cocontaminants should be considered in developing remedial actions, because they can have an impact on the effectiveness of the remediation and may also need to be addressed to protect human health and the environment. The technology evaluations are not intended to present a complete review of the literature on each remediation method but include significant papers describing the techniques.

For the purposes of this document, the deep vadose zone is considered to be the unsaturated soil, sediment, or rock above the water table and below the depth of practical and cost-effective removal through open excavation. The deep vadose zone is not considered to pose environmental or health risks through direct exposure or uptake by biota, but it may pose a risk to groundwater and subsequent ecological or human receptors. In some instances it may be necessary to consider remediation of perched, saturated water as part of deep vadose zone remediation. The actual depth cut-off between the shallow and deep vadose zone will vary between locations, because the practical depth of excavation must be decided on a site-specific basis. For example, the shallow vadose zone at the Hanford Site is considered to be the zone shallower than 15 feet, based on potential risks from radiation exposure through the surface pathway. Practical excavation depths may also depend on the extent of contamination. It may be costeffective to excavate to deeper levels for remediation of contamination with limited areal extent, while more extensive contamination would require removal of excessive amounts of the surrounding uncontaminated sediments.

${ }^{1}$ Published March 2008. Available from www.em.doe.gov.

2 Pacific Northwest National Laboratory is operated by Battelle Memorial Institute for the U.S. Department of Energy under Contract DE-AC05-76RL01830. 
Deep vadose zone contamination is primarily a concern as an ongoing source of groundwater contamination and exposure to human or ecological receptors through the groundwater pathway. For in situ remediation in the vadose zone, contaminant removal or long-term sequestration will be required to protect groundwater for many of the contaminants of potential concern at DOE sites. Thus, longevity of the remedial action under the expected future conditions at a site is an important consideration.

\subsection{Approach to Remediation Technology Review and Assessment}

This document describes potential remediation approaches for the vadose zone and identifies applied science and engineering needs for remediation of metals and radionuclides in the deep vadose zone. Whereas previous technology assessments such as those by Mulligan et al. 2001, Kaback et al. 2006, and Wittreich 2007 focused on technologies that are relatively mature and ready for field demonstration or deployment, this document takes a broader view by focusing on mechanisms that may be used to sequester or remove metals from the subsurface. The description of science and engineering needs focuses on requirements to move the mechanisms forward on a development path for producing a viable remediation technology. Each remediation mechanism is assessed for its state of maturity, potential applicability to DOE deep vadose issues, and issues that need to be resolved to produce a successful remedial technology.

In addition to the technology assessments mentioned above, several other review documents provide background for this report. Porter et al. published a review of thermodynamic and geochemical principles that may be applicable to remediation of metals including mercury (Porter et al. 2004) and the volumes "Vadose Zone Science and Technology Solutions" provide an extensive discussion of vadose zone remediation (Looney and Falta 2000). Mechanism such as sorption, oxidation-reduction, and mineral precipitation are also important in natural attenuation of contaminants and are discussed in the U.S. Environmental Protection Agency's guidance on monitored natural attenuation (Ford et al. 2007a, b). Additional technology information sources for site remediation decision-making were also reviewed and are listed in Appendix A.

The remediation methods discussed throughout this report may be broadly grouped into mobilization and recovery methods and fixation and sequestration methods. A variety of physical, chemical, and biological processes may apply to both groups. Bioremediation is considered separately from chemical processes in this document. A number of remediation methods that have been evaluated for wastewater and near-surface soil or water remediation will not be addressed here because there is no clear path to deep vadose zone application. Examples include phytoremediation, photochemical reactions, and solid phase sorbent materials or functionalized solids. Technology implementation considerations are also discussed.

\subsubsection{Mobilization Methods}

Complete removal of vadose zone contaminants would be attractive as a permanent remedial solution. This review does not include potential deep excavation options for deep vadose contamination. The following techniques are considered.

Soil flushing has been proposed as an in situ remediation technique. This method involves the use of aqueous solutions to mobilize the contaminants of interest and then extract the contaminated solution for 
treatment or disposal. Soil flushing may be enhanced by addition of chemicals (e.g., Kantar and Honeyman 2006) or surfactants (e.g., Chowdiah et al. 1998). (Soil flushing is discussed in Section 2.1.)

Electrokinetic mobilization of metals in soils has been investigated as a remediation technology. Solutes are mobilized in an applied electrical field through and electromigration, electroosmotic, and electrophoretic effects. The primary attraction of electrokinetic mobilization is in the remediation of lowpermeability sediments where other methods are ineffective. (Electrokinetic mobilization is discussed in Section 2.2.)

Vapor extraction has been used as a removal mechanism for volatile organic contaminants, but it is unlikely to be effective for even slightly volatile inorganic contaminants such as mercury. It may be possible to vent high-toxicity methylmercury from some locations to minimize transport and exposure, but this is unlikely to be an effective method for cleanup of the source area because of the presence of inorganic mercury. Elevated temperature could enhance volatilization of mercury. Removal of volatilized constituents may be required if elevated temperature is used in other remedial methods (e.g., and in situ vitrification, Section 5.2; soil desiccation, Section 5.1). Volatilization of mercury is discussed briefly in Section 2.3.

\subsubsection{Sequestration Mechanisms}

Sequestration involves fixing the vadose zone contaminants in place to significantly diminish their transport to groundwater. Sequestration can involve chemical and/or physical methods for isolation of the contaminant in a form that will not be leached by porewater. Mechanisms may include adsorption (Section 3.1), mineral precipitation (Section 3.2), abiotic oxidation-reduction processes (Section 3.3), biological sequestration (Section 4.0), or hydraulic control (Section 5.0). The mechanisms of sequestration may be interrelated and a given technological solution may involve multiple mechanisms.

Chemical sequestration mechanisms involve geochemical manipulations to sorb or precipitate the contaminant so that it is immobilized or less readily mobilized by soil moisture. This may involve manipulation of the oxidation state, $\mathrm{pH}$, or chemical concentrations to alter the geochemical equilibria.

Physical sequestration may be performed by limiting the movement of soil moisture or the contact of the moisture with the contaminants. This may occur on a large scale; e.g., by capping, soil desiccation, or permeability manipulation. Alternatively, the sequestration can occur on a small scale; e.g., by precipitation of mineral coatings over sorbed or solid-phase contaminants to armor the material against dissolution.

\subsubsection{Bioremediation}

Bioremediation is addressed as a separate section (Section 4.0) in this document, although the biologic processes may produce similar effects as abiotic processes. Bacterial reduction of contaminants is analogous to abiotic reduction, and biologic processes may result in enhanced mineral precipitation to sequester contaminants. 


\subsubsection{Considerations for Technology Implementation}

A number of factors that cross-cut the remediation mechanisms need to be considered in evaluating the practicality of deep vadose zone remediation. Proposed reactions must be thermodynamically favorable. Ideally, the contaminant will be sequestered in a thermodynamically stable state, but that is not always possible. If the chemical form is not stable, the kinetics of transformation from that form must be slow enough to provide sufficient longevity and to control the long-term contaminant flux from the treated zone. Reactions used for remediation need to be sufficiently rapid for practical treatment of the contaminated sediments.

Physical control of fluid flow is critical to successful deep vadose zone remediation but may be extremely challenging. Liquid infiltration is affected by subsurface heterogeneities and may not reach the contaminated areas for reaction. It is particularly difficult to remediate contaminants in fine-grained sediments. Interbedded coarse and fine-grained unsaturated zone sediments form capillary breaks impacting flow from fine to coarse units. Dipping beds will alter flow paths. In addition, infiltration of reactant liquids may mobilize dissolved or soluble contaminants along the reaction front, increasing contaminant transport rather than successfully sequestering the material. Gas-phase reactants are an attractive alternative for more uniform distribution of the reactant and limiting mobilization of the contaminant (Denham and Looney 2007).

Potential for remobilization of contaminants left in place after remediation must be considered for the remediation to be successful. For example, as discussed below, technetium and uranium are subject to reoxidation in the vadose zone after reductive treatment where chromium tends to remain in the reduced form. Minerals formed in the subsurface may not remain stable or may have sufficient solubility to be an issue. If capping is considered for recharge control, then the effective depth of the cap needs to be considered because heterogeneities and capillary effects will spread soil moisture into the area beneath the cap. The potential for remobilization is considered in the discussion of the different potential remediation mechanisms.

\subsection{Major DOE Sites of Concern}

A number of DOE sites have significant issues with vadose zone contamination. The major sites in the arid western United States of America tend to have deep vadose zones with low recharge. These sites include the Hanford Site in Washington, Idaho Site in Idaho, Los Alamos National Laboratory in New Mexico, and Lawrence Livermore National Laboratory in California. The sites in the eastern United States tend to have shallower vadose zone and higher recharge. These sites include the Oak Ridge Site in Tennessee and Savannah River Site in South Carolina. A review of contaminant associations found across the DOE complex was published by Riley and Zachara (1992).

The major contaminants vary between sites. At Hanford, the most significant vadose zone inorganic contaminants are technetium-99, uranium, and chromium. Tritium, mercury, nitrate, iodine-129, and other radionuclides are also found at elevated levels. At the Idaho Site, the major vadose zone contaminants are strontium-90, technetium-99, carbon-14, and possibly cesium-137, tritium, uranium, chromium, mercury, and arsenic (U.S. Department of Energy 1998; Burgess et al. 2000; Holdren et al. 2006; Keck et al. 2006). Los Alamos National Laboratory has vadose zone and perched water 
contamination including chromium, plutonium, strontium-90, tritium, and uranium (Los Alamos National Laboratory 2007). Tritium and depleted uranium are the major radionuclides and/or metal contaminants at Lawrence Livermore National Laboratory, including the geographically separate Site 300 (Burke 2007). Oak Ridge metal and radionuclide contaminants of interest include uranium, technetium-99, mercury, tritium, and curium (Hughes 2007). At the Savannah River Site, vadose zone metal and radionuclide contaminants of interest include uranium, plutonium, curium, americium, strontium-90, cesium-137, cobalt-60, aluminum, arsenic, chromium, lead, lithium, and mercury (Dai et al. 2002; Demirkanli et al. 2007; Seaman et al. 2007; Serkiz et al. 2007).

\subsection{Report Contents and Organization}

Methods of contaminant mobilization and recovery, geochemical sequestration, biological sequestration, hydraulic control, and chemical delivery and associated technologies are described in Sections 2.0 through 6.0, respectively. The current states of their development and their developmental paths forward are also presented in each section. Conclusions and recommendations follow in Section 7.0. Appendix A contains technology information sources for site remediation that were reviewed as part of the literature review. 



\subsection{Contaminant Mobilization and Recovery}

The current state of development and the development path forward for three methods of contaminant mobilization and recovery - soil flushing, electrokinetic remediation, and enhanced volatilization - are described in the following sections.

\subsection{Soil Flushing}

Soil flushing may be used for in situ mobilization and removal of vadose zone or saturated zone contaminants. In soil flushing, aqueous solutions are used to mobilize contaminants in situ (as distinct from ex-situ soil washing). The contaminants are then recovered for disposal. The solution may contain complexants to mobilize the contaminants, competing ions to enhance desorption, or manipulate Eh or $\mathrm{pH}$ to dissolve mineral phases (Wasay et al. 2001; Kantar and Honeyman 2006; Svab et al. 2008).

\subsubsection{State of Development}

A significant amount of research has been performed to develop methods for mobilization of soil contaminants. However, most field-scale tests have been performed in ex-situ systems or the shallow vadose zone. A soil flushing system installed at an industrial chromium site used infiltration basins to increase recharge through the contaminated zone and a groundwater extraction system for treatment (Sturges et al. 1991). It was relatively easy to target the contaminated sediments because of the shallow depth to groundwater, approximately 0 to $3 \mathrm{~m}$ below ground surface (bgs).

Leaching of uranium from contaminated Fernald Site soils was shown to be effective in a model exsitu heap-leaching process (Mason et al. 1997). Kantar and Honeyman (2006) reported data supporting the use of citrate to mobilize uranium in saturated flow columns. Logue et al. (2004) suggest that mobilization of uranium by citrate may result from dissolution of iron and aluminum by citrate rather than solely from complexation of U(VI) by citrate.

Biosurfactants and exopolysaccharides have been proposed for mobilization of metals in soil, but there has been limited development (Miller 1995). Biosurfactants are biodegradable and, because of their small size, they may have advantages over exopolysaccharides. Plant-source surfactants were evaluated for soil washing and soil flushing by Zhang et al. (1998) and showed advantages in terms of lower foaming and faster biodegradation at concentrations above critical micelle concentrations than synthetic surfactants.

Hydraulic control of the flushing liquid is a significant issue, both for delivery to the contaminated zone and for recovery of the mobilized contaminants. Thus, soil flushing is more practical for saturated conditions where hydraulic gradients can be controlled (Svab et al. 2008).

Surfactant foams suggested by Chowdiah et al. (1998) may overcome some issues of distributing the flushing fluid through the contaminated vadose zone, but problems in recovery of the contaminants are likely to remain. The use of biosurfactant foam for mobilization of heavy metals has been investigated in laboratory experiments (Wang and Mulligan 2004; Mulligan and Wang 2006). The use of foam may be advantageous because the foam transport is less subject to gravitational effects and thus can increase the uniformity of distribution and the surfactant can enhance mobilization of small particulates. 


\subsubsection{Development Path}

Successful soil flushing technologies are dependent on the ability to identify contaminated zones, deliver the flushing solutions to those zones, and recover the leached solution. Thus, difficulties in successful deployment will likely increase with the depth of the vadose zone contamination. Foam appears to be a promising mechanism for surfactant delivery to the vadose zone as discussed in Section 6.2 and thus could aid soil flushing of the deep vadose zone. Recovery of flushing liquids appears to only be practical through recharge to groundwater followed by groundwater extraction or other in situ remediation. This presents the difficulty in ensuring the capture of the flushing solution and the potential for long tailing of material driven deeper in the vadose zone. Soil flushing may be considered where groundwater remediation is already taking place or where effective groundwater capture can be effectively implemented. Soil flushing is a mature technology although site-specific conditions would have to be evaluated prior to its deployment.

\subsection{Electrokinetic Remediation}

Electrokinetic remediation of metal contaminants involves mobilization of the metals through an applied low-level direct current (DC). Soil moisture, groundwater, or introduced solutions provide the conductive media between the electrodes. Electrokinetic remediation is particularly useful for remediation of low-permeability sediments such as clays. Much of the laboratory-scale research on electrokinetic remediation has used kaolin or other clay materials as model low-permeability sediments.

A number of reviews of the principles of electrokinetic remediation have been published (Acar and Alshawabkeh 1993; Acar et al. 1995; U.S. Environmental Protection Agency 1997b; Alshawabkeh et al. 1999; Paillat et al. 2000; Page and Page 2002; Virkutyte et al. 2002; Lageman et al. 2005). Kelsh and Parsons (1997) reviewed DOE sites potentially amenable to electrokinetic remediation. The U.S. Environmental Protection Agency (1993) included a review of electrokinetic remediation in an evaluation of remediation options for radionuclides.

Electrokinetic remediation induces a complex series of physico-chemical effects in the subsurface. When direct current is applied to the soil, positive ions move to the negatively charged cathode and negative ions to the positively charged anode through electromigration. Water flow toward the cathode is induced through electroosmosis. Non-ionic species are mobilized with the electroosmotic water flow. Colloids are transported through electrophoresis and thus may mobilize bound contaminants. Electrophoresis may also mobilize micelles formed between contaminants and surfactants (Acar and Alshawabkeh 1993). Contaminants are removed through pumping, electroplating, precipitation, or ion exchange resins.

Electron transfer reactions at the anode electrolyze water, producing oxygen gas and hydrogen ions and lowering the $\mathrm{pH}$. The acid front moves toward the cathode and is effective at enhancing desorption of metals. Hydrogen gas and hydroxide ions are produced at the cathode, thereby increasing $\mathrm{pH}$. Hydroxides and carbonates tend to form near the cathode, limiting mobilization of cationic metals and possibly decreasing permeability. Thus, many electrokinetic remediation schemes introduce acid at the cathode or apply other methods to limit the formation of solid phases.

The effectiveness of electrokinetic remediation is a complicated function of soil properties including soil moisture, ionic strength, contaminant chemistry, the applied current, and system design. Surfactants 
or reagents such as chelating agents may be used to enhance the contaminant migration. Addition of water at the anode can improve the efficiency of contaminant removal (Virkutyte et al. 2002). Examples of enhanced electrokinetic remediation are discussed in Section 2.2.1. Most metals form cations in solution and are sorbed to sediments at moderate to high $\mathrm{pH}$ values. Thus propagation of the acid front from the anode increases the mobilization. However, chromate and pertechnetate form oxyanions in solution and uranium mobility is typically dominated by anionic carbonate complexes. An excessive decrease in $\mathrm{pH}$ can cause a switch in polarity of the zeta potential at the sediment surfaces from negative to positive reversing the electroosmotic flow and inhibiting the remediation (Acar and Alshawabkeh 1993; Yeung et al. 1997; Virkutyte et al. 2002).

In addition to mobilizing contaminants, electrokinetic processes can be used to mobilize bacteria, colloids, and chemicals in the subsurface. In these cases, electrokinetic remediation may be considered an enabling technology for other biogeochemical remediation processes. Although they are not necessarily technologies for contaminant recovery, methods for electrokinetically enhanced remediation are discussed in this section.

\subsubsection{Enhancement Techniques for Electrokinetic Remediation}

Numerous enhancement techniques have been investigated to overcome technical issues with electrokinetic remediation. These include the following:

- Water Addition: The addition of water at the anode is needed in unsaturated soils to replace water removed at the cathode (Page and Page 2002).

- $\mathrm{pH}$ Control: The addition of acid or buffers at the cathode is needed to prevent formation of solid phases and sorption/precipitation of cationic contaminants. Acetic acid is effective for $\mathrm{pH}$ control and for depolarizing the cathode reaction (Acar and Alshawabkeh 1993; Puppala et al. 1997; Page and Page 2002). Mishchuk et al. (2007) determined that nitric acid was the most effective for $\mathrm{pH}$ control in experiments of radionuclide mobilization in kaolin. Base enhancement has been investigated for remediation of anionic species (Wilson 1996).

- Surfactant Addition: Surfactants may enhance mobilization through desorption and micelle formation. Kaya and Yukselen (2005) investigated the effects of different surfactants on the surface charge of mineral phases. They recommend site-specific studies prior to deployment of surfactantenhanced electrokinetic remediation.

- Complexants: Ethylenediaminetetraacetic acid (EDTA) or other complexants have been investigated to enhance mobilization of metals (Wong et al. 1997; Yeung et al. 1997).

- Polarity Reversal: Periodic reversal of polarity can be used to minimize buildup of chemicals in the soil and physical effects such as cracking (Page and Page 2002).

- Semipermeable Membranes: The use of semipermeable membranes has been investigated to control the chemistry in the immediate vicinity of the electrodes (Puppala et al. 1997; Li et al. 1998; Wieczorek et al. 2005). Flushing hydroxyl ions from solution at the cathode avoids formation of alkaline conditions in the surrounding soil (Yeung et al. 1997). 


\subsubsection{Electrokinetic Remediation of Contaminants of Interest}

Contaminants of interest include chromium, mercury, and radionuclides. Hybrid electrokinetic technologies are also discussed here.

\subsubsection{Chromium}

Chromium is the most researched of the metal contaminants of major interest to DOE for electrokinetic remediation. A number of researchers have focused on removal of $\mathrm{Cr}$ (III) or $\mathrm{Cr}(\mathrm{III}) / \mathrm{Cr}(\mathrm{VI})$ (Acar et al. 1995; Cang et al. 2007). Given that Cr(III) is less toxic and less mobile than Cr(VI), other remediation methods have concentrated on reduction and fixation of $\mathrm{Cr}(\mathrm{VI})$. Application of electrokinetic processes to remediation of chromium is evaluated in several reviews (U.S. Environmental Protection Agency 2000b; Virkutyte et al. 2002). A number of other reports on electrokinetic remediation of chromium contamination have been published (Reddy et al. 1997; Sanjay et al. 2003; Gent et al. 2004; Sawada et al. 2004; Shrestha et al. 2007; Sivapullaiah and Prakashb 2007; Al-Hamdan and Reddy 2008).

A field demonstration to remove $\mathrm{Cr}(\mathrm{VI})$ from the vadose zone was partially successful, but postremediation soil remained above the remediation target (U.S. Environmental Protection Agency 1999). In that study, the anodes were combined into lysimeters held under tension so the electrolyte did not change the soil water saturation and soil drying could be controlled. The electrodes were placed 3 feet apart on a square grid. Another field demonstration in the vadose zone removed $60 \%$ of the chromium contamination at an electroplating site (Wieczorek et al. 2005).

Haran et al. (1996) demonstrated a system for chromium electrokinetic remediation at varying water saturations. They used an iron anode, which reacted with produced hydrogen ion, preventing the formation of an acidic front in the sediments. The $\mathrm{Cr}(\mathrm{VI})$ was transported to the vicinity of the anode where it was reduced by ferrous iron produced from the electrode corrosion.

\subsubsection{Mercury}

To be effective, electrokinetic remediation of mercury requires chemical manipulations, because of the low solubility of mercury compounds such as $\mathrm{Hg}^{0}$ and $\mathrm{HgS}$. Addition of $\mathrm{I}_{2} / \mathrm{I}^{-}$at the cathode oxidizes

the mercury and complexes it as $\mathrm{HgI}_{4}{ }^{2-}$ allowing for its mobilization and recovery (Cox et al. 1996). The recovery in laboratory experiments was better at low organic carbon contents. Reddy et al. (2003a, c) performed laboratory experiments on kaolin, glacial till, spiked with $\mathrm{Hg}(\mathrm{II})$, using EDTA or potassium iodide additions, because the mercury was already in an oxidized form. They found that recovery from the till was lower, even using higher iodide concentrations and higher voltage gradients. Later work with a mercury-spiked soil from a site contaminated with heavy metals confirmed the effectiveness of mobilizing mercury under experimental conditions (Reddy and Ala 2005). Suer and coworkers performed laboratory-scale experiments on mercury-contaminated soil and found that iodide was more effective at mobilizing mercury than chloride and that the addition of iodine was not needed for the forms of mercury in the contaminated soil studied (Suer and Allard 2003; Suer and Lifvergren 2003). 


\subsubsection{Radionuclides}

Relatively little research has been performed on electrokinetic remediation of uranium and no publications on electrokinetic remediation of technetium were found. Uranium nitrate spiked into kaolin precipitated uranium hydroxides near the cathode in electrokinetic experiments, but the addition of acetic acid enhanced the uranium removal (Ugaz et al. 1994; Acar et al. 1995). Kim et al. (2003) found acetic acid was more effective than citric acid for electrokinetic remediation of uranium from kaolin in laboratory experiments, because the electromigration towards the anode of the negatively charged uranium-citrate complex is counter to the electroosmotic flow toward the cathode. The efficiency of removal of uranium from black-shale soil was low, probably because of the large proportion of uranium bound in the solid phase.

Booher et al. (1997) report laboratory experiments on electrokinetic remediation of contaminated soils from the Hanford Site 300 Area South Process Pond under unsaturated conditions. Either citrate or carbonate solution was used to enhance uranium mobilization. They found that uranium was mobilized in the experiments, but that competing metal ions may reduce uranium mobilization. Further optimization would be needed for effective deployment. Schwartz et al. (1997) performed electrokinetic experiments on cesium mobility in Hanford sediments under saturated conditions. They used radiotracer techniques to investigate the in situ development of the contaminant distribution under the voltage gradient. They determined that the sorption of cesium was reversible in this system.

\subsubsection{Hybrid Electrokinetic Technologies}

Electrokinetic processes can enhance other remediation technologies by delivering chemicals, altering the soil chemistry, or promoting reaction through heating.

Electrokinetic remediation enhanced the distribution of ferrous iron through artificially contaminated kaolin under saturated conditions, which then reduced $\mathrm{Cr}(\mathrm{VI})$ to $\mathrm{Cr}(\mathrm{III})$ (Pamukcu et al. 2004).

Electrokinetic enhancement of biodegradation has been proposed by several researchers (Harms and Wick 2006). Joule heating of soils in situ has been deployed, combined with nutrient delivery for remediation of semivolatile and heavy petroleum compounds (Lageman et al. 2005). Benzoic acid enhanced bioremediation of trichloroethene in laboratory experiments at an optimal temperature of $30{ }^{\circ} \mathrm{C}$ (U.S. Environmental Protection Agency 2000a). Electrokinetic delivery of the organic phosphate, triethyl phosphate, along with nitrate to low-permeability kaolin soil was shown to enhance biodegradation of diesel fuel at the laboratory scale (Lee et al. 2006). The nitrate served as an electron acceptor and the triethyl phosphate provided additional nutrition for the bacterial activity. Bench-scale tests of nutrient delivery for bioremediation of chromium were reported by Reddy et al. (2003b). Electrokinetic processes can enhance transport of bacteria through porous media if the pore size is large enough (DeFlaun and Condee 1997).

A hybrid electrokinetic zero-valent iron barrier remediation system enhanced $\mathrm{Cr}(\mathrm{VI})$ reduction compared to a system without iron (Weng et al. 2007). The system decreased the total chromium removal, but its use would not be an issue where the fixation of $\mathrm{Cr}$ (III) would not be counter to cleanup goals. 


\subsubsection{State of Development}

Electrokinetic remediation research has focused on low-permeability sediments, especially clays. Remediation of low-permeability sediments by any method is an extremely challenging proposition, because of the difficulties in inducing significant fluid flow for removal or for delivery of reactants for fixation. Electroosmosis is most efficient in fine-grained sediments with high water saturation (Paillat et al. 2000). Elecroosmosis has not proven to be an effective mechanism for remediation of ionic contaminants (Lageman et al. 2005). Soils made up of clays like kaolinite with a low cation exchange capacity are easier to treat than those with a high cation exchange and buffering capacity (Page and Page 2002).

Laboratory research has been performed on a variety of clay materials, most often kaolin, contaminated or spiked with several different metals (Page and Page 2002). Notably, a number of published manuscripts do not explicitly describe the saturation state of the sediments, although it appears that laboratory-scale experiments are most often performed under saturated conditions.

Relatively few field-scale demonstrations have been reported in the literature and there is little information on successful full-scale implementations. Small- and large-scale field tests of the "Lasagna ${ }^{\mathrm{TM}}$ " electrokinetic process were performed at the DOE Paducha Site (Ho et al. 1997; Ho et al. 1999a; Ho et al. 1999b). The tests remediated $>90 \%$ of the trichloroethene contamination in the test cells up to a 6-m-x-9-m surface area and $14 \mathrm{~m}$ deep. Other field-scale studies of electrokinetic remediation have also been described in the literature (e.g., U.S. Environmental Protection Agency 1997b, 1999; Page and Page 2002; Lageman et al. 2005; Wieczorek et al. 2005).

\subsubsection{Development Path}

The success of electrokinetic remediation for deep vadose zone contamination depends on a number of factors. The geochemical processes induced by the applied voltage are complex and depend on the mineralogy of the matrix, the chemistry of the contaminant, and the system design. Control of $\mathrm{pH}$ and soil moisture is critical and enhancements for mobilization will likely be needed in most deployments.

The extent of effective treatment for electrokinetic remediation is not large, requiring an array of electrodes. This increases remediation complexity and cost. It is likely that electrokinetic remediation will not be practical for large, deep contaminated areas or where the extent of contamination is poorly defined.

Electrokinetic remediation, however, is one of the few technologies that targets low-permeability sediments. Hybrid technologies should be considered to enhance the effectiveness of other treatment options for heterogeneous or low-permeability sediments. Difficulties encountered in using electrokinetic methods to mobilize contaminants may be assets for fixation.

It is likely that electrokinetic remediation will be most effective as an enabling technology when used in combination with other methods. Electrokinetic methods have been used for soil desiccation and to promote mineral precipitation for consolidation of sediments (Mohamedelhassan and Shang 2008). Thus, electrokinetic remediation may have value in spite of considerable challenges for its successful deployment. The greatest gains for DOE sites likely would be through hybrid technologies where electrokinetic methods are used to enhance the effectiveness of chemical or biological remediation processes. 
The development of electrokinetic methods is geochemically and technologically complex, particularly for deep vadose zone applications. Significant advances will likely require testing at the laboratory scale and by field demonstration prior to full-scale deployment. It appears that there is currently only limited capability for modeling electrokinetic remediation processes to aid remediation design.

\subsection{Enhanced Volatilization}

Zero-valent mercury metal, $\operatorname{Hg}(0)$, is liquid at ambient temperatures and has a relatively high vapor pressure. Methylmercury is an organic form that can be produced in the subsurface through biologic activity and also is volatile. Methylmercury has a high toxicity and is of particular concern in the environment. Iodine-129 is also volatile, but no information was found on the application of volatilization to remediation of I-129 contamination.

Some investigation has been performed to evaluate soil heating to enhance volatilization and removal of mercury contamination from soils. In situ thermal desorption through heating soil to approximately $250{ }^{\circ} \mathrm{C}$ and vacuum extraction removed over $99 \%$ of zero-valent mercury spiked into sand (Kunkel et al. 2006).

\subsubsection{State of Development}

Volatilization is a conceptually simple technology with no major science or engineering barriers to deployment where appropriate. No in situ pilot-scale demonstrations or other tests related to volatilization for mercury remediation were found in our literature review, with the exception of the study cited above. No investigations were found related to application for $\mathrm{Hg}$ (II); however, reduction of $\mathrm{Hg}$ (II) to metallic $\mathrm{Hg}(0)$ will make it amenable to volatilization (U.S. Environmental Protection Agency 2007). An ex-situ laboratory and pilot-scale thermal desorption study with contaminated soils was successful at removing most of the mercury contamination at temperatures of 650 to $800{ }^{\circ} \mathrm{C}$ (Chang and Yen 2006).

\subsubsection{Development Path}

In situ volatilization may be suitable for subsurface mercury remediation. The method has advantages in relying on conductive heat transfer so soil heterogeneity effects will be minimized. Mercury is not very mobile in arid sites such as Hanford, and it has not been identified as a target for remediation, although high levels are found in the shallow vadose zone beneath some of the wastedisposal facilities. However, mercury is of concern at the Oak Ridge Site. Because the soil must be heated to levels above the boiling point of water for effective mercury volatilization, it is critical to ramp the temperature to avoid rapid steam production.

In situ volatilization is limited to high vapor pressure contaminants - for the metals this is primarily mercury. Thus, it will not be effective for mixed metals. In situ volatilization may also be effective for contamination containing organic compounds and possibly iodine-129. It should be noted that technetium-99 may be volatile under acidic conditions and high temperatures, but this has not been investigated. Thus, development of this technology should be targeted primarily to the evaluation of sitespecific application to mercury contamination. 



\subsection{Geochemical Sequestration}

The current state and developmental paths forward for enhanced sorption (relative to uranium, technetium, chromium, and mercury); mineral precipitation of phosphates and carbonates and other mechanisms of precipitation; and oxidation-reduction processes are discussed in the following sections.

\subsection{Enhanced Sorption}

Sorption is one of the primary processes controlling the transport of dissolved contaminants in the vadose zone and groundwater. Sorption occurs as atoms, molecules, and ions exert forces on each other at this solid-water interface. Sorption reactions are discussed primarily in terms of intermolecular interactions between solute and solid phases (Stumm and Morgan 1996). In the case of metals and radionuclides, these interactions include surface complexation reactions (surface hydrolysis and the formation of coordinative bonds at the surface with metals and with ligands) and electrostatic interactions at the surfaces, extending over longer distances than chemical forces. Reviews of sorption mechanisms of metals to minerals and soil were published by Brown and Parks (2001) and Bradl (2004). Contaminant sorption processes are discussed extensively in the U.S. Environmental Protection Agency's guidance on monitored natural attenuation (Ford et al. 2007a, b).

The chemical properties of the solution in contact with the solid phase will have a substantial effect on its sorption characteristics. For example, $\mathrm{pH}$ will have a major influence on the degree of surface hydrolysis, which in turn affects the nature and extent of surface charge. Ionic strength will affect the electrostatic nature of the surface and therefore the electrostatic interactions that can occur. In addition to these effects, the sorption process itself will change the nature of the surfaces of the solid phase and will influence further sorption.

The chemical properties of the solution in contact with the solid phase will also affect sorption as a result of interactions between dissolved species. For example, many metal ions form complexes with major anions in solution. The formation of these complex species can have a major influence on the charge and geometry of the original ion and as a result, significantly alter the sorptive properties of the ion of interest. A special case of complex formation is hydrolysis. Hydrolysis is the formation of complexes with hydroxide ions and is a strong function of $\mathrm{pH}$. Ionic strength can be an important factor that affects the activity of all dissolved ions and as a result the extent of complex formation.

Eh can also have a large influence on sorption by altering the oxidation state of the contaminant and the sorbent. Sorption of contaminant species to mineral surfaces may be an important step in the mechanism of chemical reactions including oxidation-reduction reactions (e.g., Brown et al. 1999; Zachara et al. 2007). Manipulation of oxidation state for sequestration of contaminants is discussed in Section 3.3.

\subsubsection{State of Development}

The use of chemical additives to near-surface soils to reduce metal mobility and bioavailability is a fairly well-established technology (e.g., Vangronsveld and Cunningham 1998; Iskandar 2001). A wide variety of adsorbents have been considered as sequestering agents in permeable reactive barriers 
(Morrison and Spangler 1992); however, full-scale application of the use of chemical additives to increase adsorption for remediation of metals in the deep vadose zone has not been documented. The primary reason for this is the greater difficulty in emplacing suitable adsorbents into the deep vadose zone without mobilizing the contaminant. In addition, because adsorption reactions are reversible, the potential that the adsorbed contaminants could be remobilized in the future is a significant concern.

The most significant application of sorption in remediation is likely to be in the context of natural attenuation (Krupka and Martin 2001; Yong and Mulligan 2004; Ford et al. 2007a, b). Ex-situ (pump-and-treat) adsorption methods are not considered here. Natural attenuation for metals and radionuclides relies on the natural ability of many soil and sediment components (minerals and organic matter) to sorb many metals and radionuclides. Factors that control the degree to which natural attenuation is effective for a particular metal or radionuclide depend not only on the chemical properties of the metal or radionuclide itself, but on many other geochemical factors as discussed in Section 1.2.1.

Sorption is also likely to a play a secondary role in remediation techniques that rely on other mechanisms such as precipitation and reduction as the primary method for sequestration. For example, in zero-valent iron barriers large amounts of iron oxides are formed and can act as adsorbents.

\subsubsection{Uranium Sorption}

Given the omnipresence of carbonate in natural systems and the formation of strong aqueous U(VI) carbonate complexes, sorption will be the important control for U(VI) under oxidizing conditions at dilute concentrations of dissolved uranium in most of the subsurface at the Hanford Site. An extensive review of published uranium adsorption studies is given by Environmental Protection Agency (1999). Uranium(VI) sorbs onto a variety of minerals and related phases, including clays (e.g., Ames et al. 1982; Chisholm-Brause et al. 2001), oxides and silicates (e.g., Hsi and Langmuir 1985; Waite et al. 1994), and natural organic material (e.g., Borovec et al. 1979; Shanbhag and Choppin 1981; Read et al. 1993). The compilation by Cantrell et al. (2003a) of adsorption data for U(VI) on Hanford sediment under natural Hanford groundwater conditions indicates that $\mathrm{U}(\mathrm{VI})$ sorption is moderate, with $\mathrm{K}_{\mathrm{d}}$ values ranging from approximately 0.2 to $4 \mathrm{~mL} / \mathrm{g}$.

Important environmental parameters affecting uranium sorption include redox conditions, $\mathrm{pH}$, and concentrations of complexing ligands, such as dissolved carbonate, ionic strength, and mineralogy. As with the adsorption of most dissolved metals, aqueous $\mathrm{pH}$ has a significant effect on U(VI) sorption due to the consequence of $\mathrm{pH}$ on $\mathrm{U}(\mathrm{VI})$ aqueous speciation and the number of exchange sites on variable charged surfaces of solids such as iron-oxide, aluminum-oxides, and natural organic matter. The maximum U(VI) sorption onto natural sediments occurs in the $\mathrm{pH}$ range of approximately 6 to 8 (U.S. Environmental Protection Agency 1999), with lower sorption occurring at a lower $\mathrm{pH}$ because of protonation of the sorption sites and a shift to more positively charged uranyl species in solution (e.g., see Payne and Waite 1991). Lower sorption also occurs at higher $\mathrm{pH}$ values because of the deprotonation of surface sites and the formation of higher charged anionic aqueous species $\left[\mathrm{UO}_{2}\left(\mathrm{CO}_{3}\right)_{3}{ }^{4-}\right]$ and poorly sorbing neutral ones $\left[\mathrm{Ca}_{2} \mathrm{UO}_{2}\left(\mathrm{CO}_{3}\right)_{3}{ }^{0}\right.$ (aq); (Dong et al. 2005; Fox et al. 2006)]. In the absence of dissolved carbonate, uranium sorption to iron oxide and clay minerals has been shown to be extensive and remain at a maximum at $\mathrm{pH}$ values near and above neutral $\mathrm{pH}$ (Hsi and Langmuir 1985; Kent et al. 1988). Uranium migration under natural Hanford conditions will therefore be greater at high and low $\mathrm{pH}$ values. 


\subsubsection{Technetium Sorption}

Numerous studies of the sorption of technetium on sediments, sediments, pure minerals, oxide phases, and crushed rock materials have been conducted. An extensive review of these studies is presented by U.S. Environmental Protection Agency (2004). These studies consist primarily of measurements of $\mathrm{K}_{d}$ values for $\mathrm{Tc}(\mathrm{VII})$. The adsorption of $\mathrm{Tc}(\mathrm{VII})$ oxyanion $\mathrm{TcO}_{4}{ }^{-}$is expected to range from very low to zero; i.e., $\mathrm{K}_{\mathrm{d}}$ values are approximately $0 \mathrm{~mL} / \mathrm{g}$, at near neutral and basic $\mathrm{pH}$ conditions in sediments low in organic matter, and tend to increase when $\mathrm{pH}$ values decrease to less than 5 . The $\mathrm{K}_{\mathrm{d}}$ values measured for $\mathrm{Tc}(\mathrm{VII})$ on Hanford sediment indicate that $\mathrm{Tc}(\mathrm{VII})$ sorption is low under nearly all conditions relevant to the Hanford vadose zone and upper unconfined aquifer, with $\mathrm{K}_{\mathrm{d}}$ values ranging from zero to a high of approximately $1 \mathrm{~mL} / \mathrm{g}$ (Cantrell et al. 2003a). Mattigod et al. (2003) evaluated a wide range of minerals and other substances with regard to their ability to sorb technetium. The sorption was low with a few exceptions such as some sulfides that may reduce the Tc(VII) and some man-made materials. Thus, sorption for Tc(VII) to natural minerals is not likely to be important in deep vadose remediation.

Technetium(IV) is considered to be essentially immobile, because it readily precipitates as sparingly soluble hydrous oxides and forms strong surface complexes on iron and aluminum oxides and clays. Reduction of Tc(VII) to Tc(IV) with subsequent sorption is discussed in Section 3.3.

\subsubsection{Chromium Adsorption}

Most information on $\mathrm{Cr}(\mathrm{VI})$ sorption in the general literature comes from studies with pure mineral phases (Griffin et al. 1977; Davis and Leckie 1980; Leckie et al. 1980). These studies suggest that $\mathrm{Cr}(\mathrm{VI})$ adsorbs strongly to gibbsite $\left(\alpha-\mathrm{Al}_{2} \mathrm{O}_{3}\right)$ and amorphous hydrated ferric oxide $\left[\mathrm{Fe}_{2} \mathrm{O}_{3} \cdot \mathrm{H}_{2} \mathrm{O}(\mathrm{am})\right]$ at low to medium $\mathrm{pH}$ values (i.e., $\mathrm{pH} 2$ to 7$)$ and adsorbs weakly to silica $\left(\mathrm{SiO}_{2}\right)$ at all but very low $\mathrm{pH}$. These results can be explained by considering the isoelectric points of these minerals. When the $\mathrm{pH}$ of the system is greater than the isoelectric point, the mineral surfaces have a net negative charge. When the $\mathrm{pH}$ is below the isoelectric point, the mineral surfaces have a net positive charge. Hence, anion adsorption, such as that for chromate, iodide, nitrate, selenate, and pertechnetate, generally increases as the $\mathrm{pH}$ becomes progressively lower than the isoelectric point.

The presence of competing and, less commonly, complexing ions may significantly alter chromate adsorption. Although sulfate is adsorbed less strongly on amorphous hydrated ferric oxide than $\mathrm{CrO}_{4}{ }^{2-}$, sulfate may compete for adsorption sites when present in higher concentrations (Leckie et al. 1980). Phosphate exhibits a greater competitive effect on $\mathrm{CrO}_{4}{ }^{2-}$ adsorption (MacNaughton 1977), reducing sorption by around $50 \%$ when present at equal normality.

Adsorption of $\mathrm{Cr}$ (III) to sediments has received only a nominal amount of research attention, possibly because sorption of $\mathrm{Cr}$ (III) by sediment is commonly attributed to precipitation processes for $\mathrm{Cr}$ (III)containing solids as discussed above. The limited number of published studies infer that $\mathrm{Cr}(\mathrm{III})$, like other +3 cationic metals, is strongly and specifically absorbed by sediment iron and manganese oxides

(Korte et al. 1976). X-ray photoelectron spectroscopy indicates that for sorption of Cr(VI) onto goethite $(\alpha-\mathrm{FeOOH})$, initially a small amount is reduced to $\mathrm{Cr}(\mathrm{III})$, but the majority remains as $\mathrm{Cr}(\mathrm{VI})$ (Abdel-Samad and Watson 1997). 


\subsubsection{Mercury Adsorption}

Rai et al. (1984) review the absorption behavior of mercury. Mercury(II) adsorption is dependent of $\mathrm{pH}$ and should occur to a significant extent at near neutral to basic $\mathrm{pH}$ values. Generally, in systems containing little or no organic material, adsorption of mercury is dependent on the formation of $\mathrm{Hg}(\mathrm{OH})_{2}{ }^{0}$ (aq), which readily absorbs onto oxide solids. As discussed above, the $\mathrm{Hg}(\mathrm{II})$ aqueous $\mathrm{HgCl}_{2}{ }^{0}(\mathrm{aq})$, which predominates in chloride-containing aqueous systems at neutral to acidic $\mathrm{pH}$ conditions, is only weakly adsorbed by the most common metal oxides (Rai et al. 1984). Del Debbio (1991) determined $\mathrm{K}_{\mathrm{d}}$ values for several contaminants of interest, including mercury, in a carbonate/bicarbonate system with an average $\mathrm{pH}$ of 8 . This study was part of an evaluation of the potential for the transport of contaminants of interest from a near-surface disposal facility for tank waste at the Idaho National Engineering Laboratory in southeastern Idaho on the Snake River Plain. The Snake River Plain is a semiarid structural basin underlain by an unsaturated vadose zone that has an oxic environment; these conditions are similar to those for the vadose zone at the Hanford Site. Del Debbio (1991) reported $\mathrm{K}_{\mathrm{d}}$ values of 236 to $1910 \mathrm{~mL} / \mathrm{g}$ for alluvium sediment, 81 to 998 for interbed sediment, and 9.5 to 171 for crushed basalt. The alluvium sample was taken at a depth of about $12 \mathrm{~m}$ below the land surface, and the interbed sediment was taken from the top part of the first interbed in the basalt formations at a depth of $35 \mathrm{~m}$ below the land surface.

\subsubsection{Development Path}

Sorption is an important factor in determining the need for active remediation and for evaluating natural attenuation. In addition, the effects of sorption and desorption reactions on other remediation technologies should be considered. Most basic and applied research studies concerning sorption of contaminants to sediments and soils typically focus on uptake. Considerably less information is available on desorption or the reversibility of these processes and the geochemical conditions that could enhance or reduce the rates of these processes. These issues are particularly important to long-term monitoring and future land use considerations at sites where monitored natural attenuation may be applied as a remediation option or component of an overall remediation scheme.

\subsection{Mineral Precipitation}

Mineral precipitation to control contaminant mobility is a conceptually attractive option either because of the stability of the precipitated phases or where kinetics for dissolution and release are slow. This section focuses on reactions that are not the direct result of redox reactions discussed in Section 3.3. Precipitation reactions may include precipitation of pure end members containing the contaminant or coprecipitation into solid solutions. Precipitation of amorphous or poorly crystalline phases are included. Reversible sorption is excluded from this section, but sorption followed by incorporation into the mineral structure can be a significant sequestration mechanism that is discussed here.

The main mineral species of interest include phosphates, e.g, hydoroxyapatite/autunite/chernikovite $\left[\mathrm{Ca}_{5}\left(\left(\mathrm{PO}_{4}\right)_{3} \mathrm{OH}\right) / \mathrm{Ca}\left(\mathrm{UO}_{2}\right)_{2}\left(\mathrm{PO}_{4}\right)_{2} \cdot 10-12 \mathrm{H}_{2} \mathrm{O} /\left(\mathrm{H}_{3} \mathrm{O}\right)_{2}\left(\mathrm{UO}_{2} \mathrm{PO}_{4}\right)_{2} \cdot 6 \mathrm{H}_{2} \mathrm{O}\right]$; carbonates, e.g., calcite/aragonite/siderite $\left(\mathrm{CaCO}_{3} / \mathrm{FeCO}_{3}\right)$; and ferric oxyhydroxides, e.g., ferrihydrite/goethite $\left[\mathrm{Fe}_{2} \mathrm{O}_{3} \cdot 0.5 \mathrm{H}_{2} \mathrm{O} / \alpha-\mathrm{FeOOH}\right]$. Other potential species include Hashemite $\left[\mathrm{Ba}\left(\mathrm{CrO}_{4}, \mathrm{SO}_{4}\right)\right]$. 
Mineral precipitation may physically sequester contaminants through the formation of overgrowths that slow or prevent mobilization of contaminants that are sorbed or precipitated as soluble phases. The overgrowths can also prevent reoxidation of contaminants sequestered through redox processes.

\subsubsection{Phosphates}

Information found about the interactions of uranium, technetium, strontium-90, and mercury with phospates minerals is summarized here.

\section{Uranium}

Uranium is readily incorporated into the phosphate minerals such as autunite and chernikovite (Fuller et al. 2002; Raicevic et al. 2006), and considerable research has been performed on the sequestration of uranium in phosphate phases. A study of uranium-contaminated shale from Oak Ridge showed that the uranium was associated with phosphate, even in predominantly ferric oxyhydroxide or mixed manganese/iron oxide particles (Stubbs et al. 2006). At the Coles Hill uranium deposit in Virginia, the uranium is dominantly found as meta-autunite in the saturated sapriolites but by incorporation into barium-strontium-calcium aluminum-phosphate crandallite group minerals and by sorption of uranium with phosphorous onto iron oxides mineral-grain coatings; the absence of meta-autunite in the unsaturated zone is apparently related to a lower $\mathrm{pH}$ above the water table (Jerden and Sinha 2006).

Study of sediments from the Hanford Site 300 Area indicate that contaminant uranium is associated with calcite at shallow depth, with metatorbernite $\left[\mathrm{Cu}\left(\mathrm{UO}_{2} \mathrm{PO}_{4}\right)_{2} \cdot \mathrm{H}_{2} \mathrm{O}\right]$ at intermediate depth, and sorbed to phyllosilicates in the deep vadose zone (Catalano et al. 2006).

Iron nodules downgradient from the Koongarra uranium deposit in Australia scavenge uranium from the groundwater; the uranium is precipitated in uranium-copper phosphates torbernite or metatorbernite (Sato et al. 1997). Uranium metaphosphate [U( $\left.\left.\mathrm{PO}_{3}\right)_{4}\right]$, a U(IV) phase that forms at moderately high temperature (c.a. $400^{\circ} \mathrm{C}$ ), was described in Fernald Site soils and is very resistant to dissolution or weathering (Buck et al. 1996). This may be relevant to remediation methods that produce elevated temperatures in situ.

Reaction of uranium contamination with hydroxylapatite can provide long-term sequestration by formation of low-solubility uranium phosphates, autunite and chenikovite (Fuller et al. 2002), or through sorption to the apatite surface (Wellman et al. 2007; Wellman et al. 2008). Krestou et al. (2004) suggest that uranium is removed as a calcium-uranium phosphate at $\mathrm{pH}$ greater than 9. At the Oak Ridge Site, phosphate is involved in uranium fixation through the sorption of uranium phosphate complexes to mineral surfaces, including iron and aluminum oxides, and through uranium phosphate mineral precipitation (Stubbs et al. 2006; Phillips et al. 2007). A laboratory experiment using a hydroxylapatite permeable reactive barrier showed strong uptake of uranium (Simon et al. 2004). Phosphate fertilization decreased uranium solubility, ammonium-acetate extractability, and uptake by vegetation in mine tailings (Rufyikiri et al. 2006). Liquid polyphosphate solutions have been shown to sequester uranium in Hanford Site sediments and field-scale demonstrations are in progress (Vermeul et al. 2007; Wellman et al. 2007). The use of polyphosphate allows for its injection through a greater volume of sediment and minimizes plugging of the formation in the immediate vicinity of the injection well. 


\section{Technetium-99}

Little information was found on the interactions of technetium-99 with phosphate phases. Its incorporation into magnesium-potassium phosphate ceramic has been investigated, but the stabilization process involved an initial reduction of Tc(VII) to Tc(IV) (Singh et al. 2006). Technetium-99 leaching from the ceramic was low and attributed to the combination of reduction and encapsulation by the ceramic matrix. Similarly, sorption of technetium-99 by nanoporous Sn(II/IV) phosphate occurred through redox-coupled reaction (Wellman et al. 2006). It has been reported that $\mathrm{Tc}(\mathrm{VII})$ does not form insoluble metal phosphates (Elkolaly 1993; Macaskie et al. 1996).

\section{Mercury}

Mercury(II) phosphate $\left[\mathrm{Hg}_{3}\left(\mathrm{PO}_{4}\right)_{2}\right]$ has been synthesized and characterized (Aurivillius and Nilsson 1975). Wagh et al. (2000) state that the solubility of $\mathrm{Hg}_{3}\left(\mathrm{PO}_{4}\right)_{2}$ is $1.4 \times 10^{-8} \mathrm{~mol} / \mathrm{L}$, which is equivalent to a mercury concentration of $8.4 \mathrm{ug} / \mathrm{L}$, near the drinking water standard of $2 \mathrm{ug} / \mathrm{L}$. They demonstrated the ability to stabilize mercury in a chemically bonded phosphate ceramic waste form but found they needed to reduce a portion of the mercury to cinnabar $(\mathrm{HgS})$. Mercury forms a solid solution in natural barium phosphate (Craw 2005). The phosphate solid solution immobilized the mercury, except at very low $\mathrm{pH}$. The use of Mg-K phosphate for ex-situ stabilization of mercury-contaminated soils has been tested (Borzunov et al. 2004; Randall and Chattopadhyay 2004). Phosphate increases the sorption of $\mathrm{Hg}$ (II) in $\mathrm{KClO}_{4}$ solution but not in $\mathrm{KCl}$ because of the formation of mercury-chloride complexes (Melamed and Boas 1998, 2000). No information regarding evaluations of phosphates for in situ mercury remediation and sequestration has been found.

\section{Strontium-90}

Hydroxylapatite formation for sequestration of strontium-90 has also been investigated, although strontium-90 is not of primary concern in this report. A mixture of calcium citrate and sodium phosphate is mixed into the soil or groundwater. Hydroxylapatite then precipitates as the citrate biodegrades releasing $\mathrm{Ca}^{+2}$ ions (Moore et al. 2004). A treatability test has been performed at the Hanford Site (Williams et al. 2008).

\subsubsection{Carbonates}

Substitution of contaminant metals into carbonate phases has the potential to limit their mobility in the deep vadose zone. Vadose zone porewater may be close to saturation with calcite, depending on the $\mathrm{P}_{\mathrm{CO} 2}, \mathrm{pH}$, and calcium concentration. Aragonite or vaterite will be precipitated at sufficient supersaturation with calcite. Other potential carbonate phases include rhombohedral siderite or the orthorhombic carbonates strontianite $\left(\mathrm{SrCO}_{3}\right)$ and witherite $\left(\mathrm{BaCO}_{3}\right)$.

An increase in $\mathrm{P}_{\mathrm{CO} 2}$ produces carbonic acid, $\mathrm{H}_{2} \mathrm{CO}_{3}$, resulting in dissolution of carbonates. If the porewater is sufficiently close to saturation and the kinetics are favorable, a decrease in $\mathrm{P}_{\mathrm{CO} 2}$ will result in precipitation of the carbonate mineral phase. Calcite precipitation occurs readily at low temperatures; with higher concentrations of calcium or carbonate/bicarbonate, precipitation of aragonite will take place. Precipitation of siderite may also be induced by decreasing $\mathrm{P}_{\mathrm{CO} 2}$ when the Eh is low and $\mathrm{Fe}^{2+}$ is present (Dresel 1989). Mineral surfaces with negative charge commonly result in sorption dominated by calcium. 
Pore fluids with high concentrations of other ions, e.g., sodium in Hanford tank waste releases, can exchange for calcium resulting in calcite precipitation. Other potential methods for inducing carbonate precipitation include the addition of calcium or other metals to the vadose zone sediments, or increasing bicarbonate concentration.

\section{Uranium}

Coprecipitation of uranium with aragonite from unpreserved groundwater samples has been described (Abdelouas et al. 1998). Sturchio et al. (1998) provide evidence for U(IV) substitution into calcite at the calcium lattice sites. Thus, reduction from U(VI) may promote formation of a stable solid solution. $\mathrm{U}(\mathrm{VI})$ in groundwater is mobile in the form of negatively charged carbonate complexes that will not be readily sorbed to calcite surfaces (Abdelouas et al. 1998). Reeder et al. (2000; 2001; 2004) discuss the incorporation of uranium into calcite and aragonite and provide evidence that U(VI) incorporation into calcite forms a disordered structure that is likely to be less stable. The mechanism of crystal growth affects the structural location of incorporated uranium. They conclude that calcite may not be a favorable form for long-term sequestration of $\mathrm{U}(\mathrm{VI})$, but that depends on the detailed coordination of the uranyl and the morphology of the mineral surface.

Kelly et al. (2003) determined that uranyl can substitute for calcium and two adjacent carbonate ions in a calcite speleothem originally precipitated as aragonite, producing a stable lattice position for the substitution and long-term sequestration. Evidence for two coordination sites for uranium in the same calcite as studied by Kelly et al. was found by time-resolved cryogenic laser-induced fluorescence (Wang et al. 2005b). One site was similar to uranium incorporation into synthetic calcite and the other distorted the crystal lattice to a structure similar to aragonite. Wang et al. also studied uranium substitution into calcite from contaminated Hanford sediments. They found a similar, but more complex, heterogeneous distribution of the uranium speciation but concluded that uranium was incorporated into a fairly stable mineralogical environment that likely would significantly slow the transport in the subsurface. Uranium as $\mathrm{U}(\mathrm{VI})$ was also found to substitute for calcium in an ancient organic-rich pedogenic calcite with evidence that the structure became more ordered, i.e., more stable with time (Kelly et al. 2006). Thus, the most recent studies suggest that immobilization of $\mathrm{U}(\mathrm{VI})$ in calcite without reduction may be a viable remediation strategy. Experiments of uranium sorption by Hanford formation sediments showed an increase in apparent distribution coefficient, $\mathrm{K}_{\mathrm{d}}$, that was hypothesized to be caused by coprecipitation with calcite (Um et al. 2007).

\section{Chromium}

Evidence for $\mathrm{Cr}$ (VI) coprecipitation with calcium carbonate is presented by Hua et al. (2007). They found a mixture of calcite and metastable vaterite. $\mathrm{The} \mathrm{Cr}(\mathrm{VI})$ showed a tendency to stabilize the vaterite that appeared to inhibit the reduction of $\mathrm{Cr}(\mathrm{VI})$. In a separate study, chromium coprecipitation with calcite was also shown to be present as $\mathrm{Cr}(\mathrm{VI})$ through x-ray absorption near edge structure (XANES) analysis (Tang et al. 2007). The presence of $\mathrm{Cr}(\mathrm{VI})$ in the calcite distorted the crystal structure but is consistent with substitution into the carbonate sites. Thus, the precipitation of calcium carbonate may limit the mobility of $\mathrm{Cr}(\mathrm{VI})$. 


\subsubsection{Other Precipitation Mechanisms}

The interaction of inorganic contaminants with iron oxyhydroxide phases is a complex mixture of sorption and possible coprecipitation or formation of separate microscale phases during aggregation and aging of particles. The typically amorphous or nano-sized particles formed during precipitation of iron oxyhydroxide phases have a large effect on the sorption properties and the mechanisms of particle aggregation and growth (Waychunas et al. 2005). Sorption and coprecipitation of U(VI) and Tc(VII) on iron oxyhydroxides has been reported to occur at $\mathrm{pH}<5.5$, but desorption and/or dissolution occurred at higher $\mathrm{pH}(\mathrm{Gu}$ et al. 2003). The reaction of metals and anionic contaminants with iron oxyhydroxide nanoparticles appears to occur through surface complexation and encapsulation into particle aggregates (Waychunas et al. 2005). This combined sorption and/or physical sequestration mechanism potentially complicates application in remedial system design, because of the potential for desorption and the need to control the aggregation mechanism. A further complication is the potential for redox reactions between the iron and the contaminants. These redox reactions play a dominant role in successful long-term sequestration of the contaminants of concern with iron oxyhydroxide phases, as discussed in Section 3.3.

The dipotassium salt of 1,3-benzendiamidoethanethiol (BDET) was shown to remove $\mathrm{Hg}$ (II) from aqueous solution over the $\mathrm{pH}$ range of 4 to 10 . Mercury could be removed to levels less than $0.5 \mathrm{ug} / \mathrm{L}$ from contaminated groundwater samples with a $\mathrm{pH}$ of 4.7-6.4 (Blue et al. 2008). The BDET ligand complexes $\mathrm{Hg}(\mathrm{II})$, forming a stable solid complex that resists remobilization of the mercury. The authors thus suggest the use of BDET for in situ stabilization of $\mathrm{Hg}(\mathrm{II})$.

Barium chromate is a moderately low-solubility $\mathrm{Cr}(\mathrm{VI})$ solid. The solid solution between barium chromate and barium sulfate can be precipitated at low temperatures and has a lower solubility than the pure end member barium chromate and may control the aqueous concentration of $\mathrm{Cr}(\mathrm{VI})$ when sufficient barium and sulfate are present (Rai et al. 1989). Unidentified Cr(VI) solids were found in the Hanford Site vadose zone beneath the S-SX high-level-waste tank farm; a fraction of the solid Cr(VI) was resistant to leaching (Zachara et al. 2004). Thus, there is some potential for $\mathrm{Cr}(\mathrm{VI})$ in situ fixation that does not involve reduction to $\mathrm{Cr}(\mathrm{III})$.

Mattigod et al. (2003) reviewed artificial and natural substances for the removal of Tc(VII) from solution. They summarized studies of Tc(VII) removal by sulfide minerals. The removal may be through either precipitation of $\mathrm{Tc}(\mathrm{VII})$ sulfide, $\mathrm{Tc}_{2} \mathrm{~S}_{7}$, or by reduction and removal as $\mathrm{Tc}(\mathrm{IV})$ solid phases. Precipitation of $\mathrm{Tc}_{2} \mathrm{~S}_{7}$ was also reported by Elwear et al. (1992), who measured its solubility. However, extended x-ray absorption fine structure spectra of technetium sulfide in reducing grout indicated that the phase that has been reported as $\mathrm{Tc}_{2} \mathrm{~S}_{7}$ is actually the $\mathrm{Tc}(\mathrm{IV})$ phase $\mathrm{Tc}_{3} \mathrm{~S}_{10}$ (Lukens et al. 2005).

Wang et al. (2005a) investigated sediments collected from a high-level-waste leak at the Hanford Site and reported the in situ precipitation of uranium silicate similar to boltwoodite $\left[(\mathrm{K}, \mathrm{Na})\left(\mathrm{UO}_{2}\right)\left(\mathrm{HSiO}_{4}\right) \cdot 0.5(\mathrm{H} 2 \mathrm{O})\right]$ and uranophane $\left[\mathrm{Ca}\left(\mathrm{UO}_{2}\right)_{2}\left(\mathrm{HSiO}_{4}\right)_{2} \cdot 5(\mathrm{H} 2 \mathrm{O})\right]$. They were able to readily leach the uranium with carbonate solutions. Ilton and coworkers measured the solubility of synthetic sodium-boltwoodite and the leaching rate from Hanford Site contaminated sediments (Ilton et al. 2006; Ilton et al. 2008). Significant amounts of uranium were leached from the boltwoodite, indicating that this is not an ideal phase for sequestration of uranium. However, the ready formation of lowtemperature silicate phases suggests silicate phases have the potential to sequester contaminants. We found no references to the use of silicate phases for subsurface remediation of any metal contaminants. 


\subsubsection{State of Development}

With the exception of systems that involve redox manipulation, relatively few remediation technologies that apply mineral precipitation and/or sequestration methods for contaminants have been developed. The redox methods are discussed in Section 3.3. Sequestration of uranium in phosphate minerals is the most mature for the main contaminants of interest, with field demonstrations for the saturated zone in progress. Conceptually, apatite or other phosphate mineral phases can form overgrowths for physical sequestration of sorbed or precipitated contaminants.

The uranium-phosphate association within predominantly iron-oxyhydroxide phases, as discussed above, suggests that enhanced precipitation of the iron phases may incorporate uranium either through sorption during formation or by encapsulation of a separate uranium-phosphate phase. Similarly, it appears that phosphate phases may be able to armor sorbed or precipitated contaminants. Phosphate mineral sequestration is attractive because of the low solubility of a number of phosphate phases under near-surface oxic conditions, the extensive solid-solution found in phosphate minerals such as apatite, and the potential to deliver phosphate through polyphosphate chains of different lengths for controlling reaction kinetics.

Little work has been done on manipulating the formation of low-temperature silicates or other oxides.

Carbonate precipitation shows some promise for uranium remediation, but the advantages of phosphates may outweigh further development of carbonate systems. Little information on interactions with carbonate was found for the other contaminants of interest. The mobility of $\mathrm{Cr}(\mathrm{VI})$ may be limited by coprecipitation in calcium carbonate. Manipulation of the carbonate system to form overgrowths for physical sequestration of contaminants has been proposed, but little has been published along those lines.

\subsubsection{Development Path}

Precipitation of uranium phosphate minerals through chemical additions is being tested under saturated conditions. The questions regarding application to the vadose zone remain because of the difficulty of delivering liquid solutions uniformly to the contaminated area and without mobilizing the contaminants at the liquid front. Phosphate surfactants may be useful in achieving delivery to the target zones. Further investigation of uranium interaction with carbonates would be valuable to understand the role of carbonate minerals in limiting uranium transport.

Although there are potential means of sequestration of chromate in mineral phases, the relative ease of reduction of $\mathrm{Cr}(\mathrm{VI})$ to $\mathrm{Cr}(\mathrm{III})$ and the lower toxicity of $\mathrm{Cr}(\mathrm{III})$ mean that redox methods discussed in Section 3.3 likely are preferable for development.

Little is known about Tc(VII) incorporation into mineral phases. It is likely that any significant solubility control would be from solid solutions. As discussed below, reoxidation is an issue in sequestration as Tc(IV). Thus, there may be some value in understanding the mechanisms of reoxidation and the subsequent fate of Tc(VII) in the solids. A better understanding of technetium interaction with phosphate and carbonate phases is desirable to evaluate sequestration options. 
Further investigation of immobilization mechanisms for $\mathrm{Hg}(\mathrm{II})$ would be valuable. The environmental chemistry of mercury is complex and long-term remediation will require a careful evaluation of the effectiveness versus the gamut of reaction pathways in the mercury cycle.

Novel precipitation mechanisms, such as low-temperature silicates and sulfides, should be considered for further investigation.

Physical sequestration by coating sorbed or precipitated contaminants with mineral overgrowths is attractive, because it will minimize contact with the mobile pore fluids and may inhibit chemical reactions such as technetium and uranium reoxidation or mercury methylation. Phosphate mineral formation should be pursued within this context as well as through direct incorporation of contaminants into the crystal structures. Carbonate mineral precipitation shows potential for physical sequestration because of the relative ease of manipulating the solubility through control of $\mathrm{pH}$ or $\mathrm{P}_{\mathrm{CO} 2}$.

\subsection{Oxidation-Reduction Processes}

Geochemical sequestration of metals and radionuclides through oxidation-reduction processes exploits the use of chemical reactants to change the oxidation state of contaminants of interest to a form that is more prone to being removed from the aqueous phase to the solid phase. This could occur by altering the oxidation state of the contaminant of concern to one that readily forms minerals with low solubility or is more strongly adsorbed by ambient mineral surfaces. Reduction to an oxidation state that forms minerals with low solubility is the most common mechanism used for most contaminants of interest. For example, reduction of Cr(VI), U(VI), and Tc(VII) all form oxidation states [Cr(IV), U(IV), and Tc(IV)], which form oxides with relatively low solubility. Because most metals and radionuclides of interest here are most mobile in the oxidized state, only reduction processes will be discussed further.

A considerable variety of chemical reductants has been considered for remediation of metals and radionuclides including zero-valent iron, ferrous salts, sodium dithionite, sulfides salts, hydrogen sulfide, and hydroxylamine (Khan and Puls 1999; Knox et al. 2001). Biologically mediated reduction reactions are discussed separately in Section 4.2.

\subsubsection{State of Development}

The state of development of oxidation-reduction processes involving zero-valent iron, sodium sithionite, sulfide salts and minerals, ferrous iron, gaseous reduction, and other reductants are described in the following sections.

\subsubsection{Zero-Valent Iron}

The use of chemical reduction as a remediation approach is fairly advanced with a large body of research conducted to support this technology over the last 15 years and a large number of field deployments in groundwater being documented (ITRC 2005). The most widely used reductant to date for remediation is zero-valent iron. Most applications have been in the form of permeable reactive barriers in groundwater. A permeable reactive barrier is defined as an in situ permeable treatment zone designed to intercept and remediate a contaminant plume. Zero-valent iron is the most common media used in permeable reactive barriers to treat a variety of chlorinated organic compounds, metals, and radionuclides. 
As of 2005, nearly 120 zero-valent-based permeable reactive barriers have been installed, 83 of which are considered full scale (ITRC 2005). The majority of these permeable reactive barriers emplaced to date target remediation of chlorinated hydrocarbons; however, a number of applications have been directed toward remediation of metals and/or radionuclides as well. Metals and/or radionuclides that have been treated include chromium, uranium, arsenic, technetium, lead, cadmium, molybdenum, mercury, phosphorous, selenium, and nickel (ITRC 2005). Removal of metals and metalloids by zero-valent iron permeable reactive barriers occurs primarily through reductive precipitation on the surfaces of the zerovalent iron, or as coprecipitates with iron oxyhydroxides that form on the surfaces of the zero-valent iron. Sorption onto iron oxyhydroxides formed during the oxidation of the zero-valent iron can provide an additional mechanism by which metals and metalloids (including arsenic) are removed in zero-valent iron permeable reactive barriers.

Zero-valent iron permeable reactive barriers for remediation of metals have most commonly been applied to chromate. Reduction of $\mathrm{Cr}(\mathrm{VI})$, precipitation of $\mathrm{Cr}(\mathrm{III})$ hydroxide, and the coprecipitation of $\mathrm{Cr}(\mathrm{III})$ with ferric oxyhydroxides by zero-valent iron has been extensively investigated in the laboratory and in a full-scale permeable reactive barrier field application at Elizabeth City, North Carolina (Powell et al. 1995; Blowes et al. 1997; Pratt et al. 1997; Blowes et al. 1999b; Blowes and Mayer 1999; Blowes et al. 1999a).

Increasingly, investigations have applied zero-valent iron technology to uranium contamination. Laboratory- and full-scale field studies of zero-valent iron permeable reactive barriers have been conducted for treatment at a site in Monticello, Utah, that is contaminated by uranium mill tailings (Morrison et al. 2001; Morrison et al. 2002b; Morrison 2003). Elevated concentrations of uranium, arsenic, selenium, molybdenum, vanadium, manganese, and nitrate occur at the site. The treatment system was found to be highly effective for all these contaminants except manganese (Morrison et al. 2002b). The uranium was removed as $\mathrm{U}(\mathrm{VI}) \mathrm{O}_{2}$ (Morrison et al. 2002a). After 2.7 years, the reactivity of the permeable reactive barrier was found to decrease (Morrison et al. 2003). This was attributed to consumption of available contaminant removal sites on the zero-valent iron and a loss of reactivity caused by precipitation of secondary carbonate minerals on the zero-valent iron grain surfaces. No decrease in hydraulic conductivity was detected as a result of this precipitate formation, which was consistent with evaluations of the zero-valent iron permeable reactive barrier at Elizabeth City. At a uranium mine tailings site in Colorado, earlier than anticipated failure of a zero-valent iron permeable reactive barrier was attributed to hydraulic changes caused by the precipitation of minerals within the barrier (Morrison et al. 2006). Research to support remediation of uranium contamination at the Oak Ridge Site also found that zero-valent iron could reduce U(VI), but the potential for reoxidation is uncertain (Gu et al. 1998).

Laboratory study has indicated that zero-valent iron reduces Tc(VII) to Tc(IV) (Liang et al. 1996). Zero-valent iron had a high removal capacity for $\mathrm{Tc}(\mathrm{VII})$; the removal was rapid and the technetium was not leached from the iron when subjected to a toxicity characteristic leaching procedure (TCLP) test.

A study of the removal of mercury from groundwater by zero-valent iron showed substantial removal and precipitation of the mercury in an ex-situ column experiment (Weisener et al. 2005). The mercury was removed as $\mathrm{HgS}$ similar to metacinnabar. The removal extent was kinetically controlled.

Since the 1994 introduction of the first zero-valent iron permeable reactive barrier in the United States, this technology has developed from innovative to accepted standard practice. Several issues regarding the use of zero-valent iron permeable reactive barriers require additional research and 
development. As the technology continues to mature and some of the early permeable reactive barrier installations age, these challenging issues will become the main focus for additional research and development. Additional research and development are needed in the following areas:

- The longevity of zero-valent iron used in permeable reactive barriers is not fully understood and cannot be accurately predicted. Additional research should be focused on how to predict longevity based upon site-specific factors.

- Current methods for determining hydraulic performance of permeable reactive barriers are inadequate; better approaches are needed.

- Research is needed on zero-valent iron replenishment or regeneration, which could reduce long-term operation and maintenance costs of this technology.

- Research is also needed on source zone treatment using zero-valent iron.

- Monitoring permeable reactive barrier performance in cases when a preexisting contaminant plume occurs downgradient of the permeable reactive barrier is difficult. Better monitoring techniques for this situation are needed. In addition a better understanding of desorption kinetics and transport of downgradient residual contamination is required.

Emplacement of conventional granular zero-valent iron into the vadose zone is challenging from a practical engineering standpoint and may not be cost effective. However, innovative techniques for the emplacement of micro- and nanoscale iron particles are being developed. Li et al. (2006) recently reviewed the use of nanoscale zero-valent iron particles for remediation of contaminated sites. They cite 29 examples of projects in which zero-valent iron nanoparticles have been used for site remediation. Shear-thinning polymer fluids may be used to emplace zero-valent iron in the subsurface (Cantrell and Kaplan 1997; Cantrell et al. 1997; Oostrom et al. 2007).

A critical issue for future development of this technology involves the transport, dispersion, and fate of these zero-valent iron nanoparticles in the subsurface environment. Data from some recent field tests indicate that zero-valent iron nanoparicles may migrate only a few inches to a few feet from the point of injection. The mobility of pure zero-valent iron nanoparticles has been observed to be limited because of efficient filtration mechanisms of aquifer materials. The mobility of nanoparticles in the subsurface environment depends on many factors, including particle size, solution $\mathrm{pH}$, ionic strength, soil composition, and groundwater velocity.

Recent research indicates that promising new synthetic methods are being developed to produce more mobile zero-valent iron nanoparticles without sacrificing surface reactivity. Schrick et al. (2004) have successfully synthesized zero-valent iron nanoparticles with high densities of negative charges to aid in electrostatic repulsion between the zero-valent iron nanoparticles and the predominantly negatively charges aquifer materials. The negative charges are produced using anionic hydrophilic carbon and poly(acrylic acid), which bind strongly to the zero-valent iron nanoparticles, thereby creating highly negative surfaces that effectively reduce aggregation among the zero-valent iron particles and reduce their filtration removal by aquifer materials. Results of laboratory tests using soil- and sand-packed columns indicate that transport of anionic hydrophilic carbon and poly(acrylic acid)-supported zero-valent iron nanoparticles is enhanced, whereas unsupported zero-valent iron nanoparticles aggregate and impede the flow of water through the column. More recently poly(vinyl alcohol-co-vinyl acetate-co-itaconic acid) has been used as a dispersant for zero-valent iron nanoparticles. This new class of zero-valent iron 
nanoparticles appears to have substantially better subsurface mobility potential (Sun 2006). Another approach being developed to inject nanoscale zero-valent iron into the subsurface is called nanoscale emulsified zero-valent iron (Quinn et al. 2005). In this approach, zero-valent iron particles are surrounded by an oil-liquid membrane to form a surfactant-stabilized biodegradable emulsion. A field demonstration was conducted at the National Aeronautics and Space Administration's Launch Complex 34 using a pressure pulse injection method. Sampling results indicated that the method was effective in reducing contaminants in both soil and groundwater, with contaminant reductions ranging from 57 to $100 \%$. He and Zhao (2005) have developed a preparation of starch-stabilized bi-metallic nanoparticles for remediation of contaminants in water. They have demonstrated that this formulation greatly reduces particle agglomeration and reaction with surrounding media that occurs with non-starched particles. The particles were also found to be much more reactive with respect to the degradation of chlorinated hydrocarbons.

The use of zero-valent iron nanoparticles as an approach for remediation of metals and radionuclides appears to have promise. A number of major challenges must be overcome before this approach can become cost effective. One of the biggest challenges for widespread application of zero-valent iron nanoparticles in remediation is cost. In order for these materials to make a significant impact on future remediation activities, synthesis processes must be developed that can produce these materials much more economically that is currently possible.

To date, remediation demonstrations using zero-valent iron nanoparticles have relied on the injection of aqueous solutions into saturated porous media. This approach could be problematic in the vadose zone, because some contaminants could be driven deeper, potentially contaminating the underlying aquifer. Long-term performance and the potential for remobilization after oxidizing conditions return to the treated zone are issues of concern for most treated metals and radionuclides that must be addressed. This could be especially relevant for a relatively shallow vadose zone with high permeability where oxygen diffusion could be significant. More information is also required regarding the geochemistry and transport properties of these materials. This includes reactions of zero-valent iron nanoparticles with groundwater, interactions with soils and sediments, and aggregation and transport properties in porous media.

An additional consideration in the application of zero-valent iron technology to vadose zone remediation of metals is the interaction of the iron particles with dissolved oxygen to form powerful oxidants. It has been reported that reaction of dissolved oxygen with zero-valent iron can lead to the production of hydrogen peroxide and hydroxyl radical, which in turn can result in oxidative degradation of organic compounds (Joo and Chang 2006). Although the production of these highly oxidizing species in contact with zero-valent iron is most significant under acidic conditions, the impact of these species on reductive sequestration of vadose zone metals and radionuclides and on the potential for reoxidation should be considered.

\subsubsection{Sodium Dithionite}

A technology called In Situ Redox Manipulation (ISRM) is a method for creating a reducing zone or permeable reactive barrier through injection of soluble reagents into groundwater (Amonette et al. 1994; Fruchter et al. 1996). With this technology, sodium dithionite $\left(\mathrm{Na}_{2} \mathrm{~S}_{2} \mathrm{O}_{4}\right)$ is used to reduce natural ferric iron in sediments to ferrous iron, which in turn acts as the reductant in the permeable reactive barrier. This technology has been applied at the Hanford Site for $\mathrm{Cr}(\mathrm{VI})$ remediation. A pilot test was conducted 
at the 100-H Area (Fruchter et al. 1996), a treatability test was conducted at the 100-D Area (Vermeul et al. 2002), and a full-scale deployment is ongoing at the 100-D Area (Fruchter et al. 2004). Installation of the full-scale deployment occurred between 1999 and 2003 (U.S. Department of Energy 2004). Initial results indicated that the technology was working effectively-reducing chromate concentrations from $1000 \mathrm{ppb}$ to less than the detection limit (8 ppb) (Vermeul et al. 2002). Based upon iron analysis of the treated sediments, a barrier lifetime of 23 years was predicted (Vermeul et al. 2002). However, several years after initial and secondary treatment, groundwater in some wells has been found to contain elevated concentrations of chromium indicating some loss of reductive capacity within the aquifer (U.S. Department of Energy 2004). Analysis of the problem suggested that the likely cause of this premature loss in effectiveness was preferential flow resulting in large quantities of oxic groundwater to flow rapidly through certain areas of the treatment zone, thereby rapidly reducing its reductive capacity, and that estimates of barrier longevity that did not include additional oxidants in the groundwater such as nitrate (U.S. Department of Energy 2004). In addition to flushing with high volumes of groundwater, these preferential pathways are likely to be deficient in reactive iron, again limiting the reductive capacity of the barrier and the performance of the dithionite lixiviant.

Szecsody et al. (1998) conducted laboratory experiments and computer simulations to assess the extent of uranium remobilization after reoxidation of a permeable reactive barrier created using the ISRM method occurred. It was determined that although precipitated uranium will remobilize upon reoxidation of the ISRM permeable reactive barrier, its release would likely be limited to a maximum of $35 \mathrm{ppb}$ U(VI) under typical Hanford groundwater conditions.

\subsubsection{Sulfide Salts and Minerals}

$\mathrm{Cr}(\mathrm{VI}), \mathrm{Tc}(\mathrm{VII})$, and $\mathrm{U}(\mathrm{VI})$ can be reduced by sulfide at ambient subsurface temperatures. The sulfide may be in the form of aqueous solutions or sulfide minerals. In the case of ferrous sulfide minerals, there is potential for reduction by $\mathrm{Fe}(\mathrm{II})$ or $\mathrm{S}(\mathrm{IV})$.

Technetium and uranium surface-mediated reactions on the surface of mackinawite $\left[(\mathrm{Fe}, \mathrm{Ni}) \mathrm{S}_{0.9}\right]$ effectively removed them from solution (Livens et al. 2004). XANES spectroscopy indicated that the technetium is reduced to $\mathrm{Tc}(\mathrm{IV})$ and forms a $\mathrm{TcS}_{2}$-like phase. The uranium appeared to form a mixed $\mathrm{U}(\mathrm{IV})-\mathrm{U}(\mathrm{VI})$ oxide. However, $\mathrm{Tc}_{2} \mathrm{~S}_{7}$ may also be formed, keeping the technetium in the $\mathrm{Tc}(\mathrm{VII})$ state (Mattigod et al. 2003). Reduction of U(VI) at the surface of pyrite $\left(\mathrm{FeS}_{2}\right)$ was shown to involve oxidation of the Fe(II) in the pyrite (Eglizaud et al. 2006).

Calcium polysulfide has proven to be highly useful for in situ groundwater remediation systems because of its ability to migrate sufficient distances from the point of injection to the point of reaction and remain sufficiently reactive to reduce hexavalent chromium upon contact (Rouse et al. 2001). Calcium polysulfide is widely used as an agricultural soil-conditioning agent and hence is relatively inexpensive. It has been authorized for use by the National Sanitation Foundation in potable water systems, making it particularly attractive from a regulatory approval standpoint. When dissolved in water, polysulfide dissociates to form bisulfide (HS) and aqueous hydrogen sulfide $\left[\mathrm{H}_{2} \mathrm{~S}(\mathrm{aq})\right]$ with the relative distribution being a function of $\mathrm{pH}$. Polysulfide has been used to conduct in situ remediation of uranium, selenium, arsenic, copper, and chromium contamination. For most metals, immobilization is effected through precipitation as the metal sulfide. In the case of $\mathrm{Cr}(\mathrm{VI}), \mathrm{Cr}(\mathrm{VI})$ is reduced to $\mathrm{Cr}(\mathrm{III})$, which precipitates as the hydroxide. Sulfide can react directly with dissolved metal to cause its reduction or sulfide can reduce $\mathrm{Fe}(\mathrm{III})$ present in aquifer minerals to $\mathrm{Fe}(\mathrm{II})$, which can subsequently act as a reductant for contaminants. 
A large-scale injection of calcium polysulfide solution was conducted at a former chemical manufacturing site in northern California (Zawislanski et al. 2002). More recently a treatability test was conducted at the 100-K Area of the Hanford Site (Petersen and Hedquist 2006). Results of the treatability test indicate that $\mathrm{Cr}(\mathrm{VI})$ was effectively eliminated from the treated aquifer. Analysis of groundwater chemistry before, during, and after the test shows that manganese, iron, and arsenic were mobilized under the strongly reducing conditions in the aquifer, but all of these remained far below drinking water standards.

Storch et al. (2004) conducted laboratory-scale, pilot-scale, and full-scale demonstrations to fix $\mathrm{Cr}(\mathrm{VI})$ in the vadose zone and mitigate migration to groundwater at a former metal-plating facility. The study demonstrated reduction of $\mathrm{Cr}(\mathrm{VI})$ in situ. The authors noted a degree of preferential flow in the chemical infiltration that did not completely correspond to the location of the contamination. In addition, their groundwater monitoring showed initial displacement of $\mathrm{Cr}(\mathrm{VI})$ to groundwater due to the infiltration system.

Once $\mathrm{Cr}(\mathrm{VI})$ is reduced it is known to be quite stable. Available information indicates that the rate of oxidation of $\mathrm{Cr}$ (III) by oxygen is very slow if significant at all (Eary and Rai 1987). Manganese oxides are the only other known naturally occurring oxidants capable of oxidizing $\mathrm{Cr}(\mathrm{III})$. Although $\mathrm{Cr}$ (III) oxidation readily occurs on manganese oxides, a number of factors have been found that greatly limit the progress of this reaction (Eary and Rai 1987; Fendorf et al. 1992; Fendorf et al. 1993). A major concern for most other metals immobilized through reduction, including uranium and technetium, is the possible remobilization after oxidizing conditions return to the treated system.

Because the reagent is applied as an aqueous solution, care must be taken during the initial vadose zone treatment to prevent mobilization and contamination of the groundwater. If the reduction reaction does not take place immediately upon contact with the treatment solution, contaminants could potentially be driven deeper, contaminating the underlying aquifer. The chances of this happening increase as the reagents are used up. As indicated earlier, remobilization of treated metals and radionuclide other than chromium may occur after oxidizing conditions return to the treated system. This could be especially relevant for a relatively shallow vadose zone with high permeability where oxygen diffusion could be significant.

Hyman and Dupont (2001) discuss the use of sodium sulfide, sodium bisulfide, and ferrous sulfide in the context of groundwater remediation; however, no sites where these reductants have been used for groundwater or deep vadose zone remediation could be found in the literature.

\subsubsection{Ferrous Iron}

Laboratory and field studies have been conducted to evaluate the performance of a ferrous sulfate and/or sodium dithionite reductant blend for treating a $\mathrm{Cr}(\mathrm{VI})$ sources area and an associated dissolved $\mathrm{Cr}(\mathrm{VI})$ plume in groundwater (Ludwig et al. 2004; Su and Ludwig 2005). The source area consisted primarily of chromite $\left(\mathrm{FeCr}_{2} \mathrm{O}_{4}\right)$ ore processing residue with $\mathrm{Cr}(\mathrm{VI})$ levels as high as $550 \mathrm{mg} / \mathrm{kg}$. The source area produces a highly alkaline $\mathrm{Cr}(\mathrm{VI})$ leachate resulting in groundwater concentrations as high as $57 \mathrm{mg} / \mathrm{L} \mathrm{Cr}(\mathrm{VI})$ with $\mathrm{pH}$ values as high as 11.5. The laboratory studies indicated that ferrous iron in the form of ferrous sulfate or ferrous chloride was effective in treating the solid phase $\mathrm{Cr}(\mathrm{VI})$. Direct injection of ferrous salts was not considered to be practical because of its tendency to rapidly precipitate in groundwater, particularly at high $\mathrm{pH}$. The laboratory studies also indicated that sodium dithionite was 
not effective for treating the $\mathrm{Cr}(\mathrm{VI})$ source material. The authors theorized that sodium dithionite could act as a stabilizing agent to maintain ferrous iron in solution and allow for its injection into the subsurface.

Based on the laboratory results above, two in situ pilot field studies were conducted (Ludwig et al. 2007). One was directed at treating saturated source zone material and a second in the path of the dissolved phase $\mathrm{Cr}(\mathrm{VI})$ plume. The treatment solution consisted of $0.20 \mathrm{M}$ ferrous sulfate and/or $0.20 \mathrm{M}$ sodium dithionite. Post-injection groundwater monitoring and sediment core sampling indicated that both the source treatment and in situ treatment zone were effectively treating the $\mathrm{Cr}(\mathrm{VI})$ contamination. At the time of the most recent sampling event reported in the study (545 days after injection), the treatment zone was reducing $\mathrm{Cr}(\mathrm{VI})$ concentrations of 5 to $6 \mathrm{mg} / \mathrm{L}$ to less than $0.01 \mathrm{mg} / \mathrm{L}$. No well or formation clogging occurred during the injection. Infiltration of the iron solution into the highly alkaline environment of the source zone appeared to be impeded by limited acidity of the injection solution resulting in the precipitation of ferrous hydroxide $\left[\mathrm{Fe}(\mathrm{OH})_{2}\right]$ and siderite.

$\mathrm{Tc}(\mathrm{VII})$ can be reduced by Fe(II) but the homogeneous reaction in solution is very slow. The surface-mediated reaction is considerably more rapid when Fe(II) is sorbed or precipitated (Cui and Eriksen 1996a; Cui and Eriksen 1996b). Zachara et al. (2007) found similar results in a later study and showed that the reoxidation of Tc(IV) from the iron and/or technetium ferrihydrite and magnetite product was slower than from $\mathrm{TcO}_{2} \cdot \mathrm{nH}_{2} \mathrm{O}$. The reduction of $\mathrm{Tc}(\mathrm{VII})$ is much slower for $\mathrm{Fe}$ (II) adsorbed on phyllosilicates than for Fe(II) sorbed on Fe(III) oxides (Peretyazhko et al. 2008). A series of reduction and reoxidation experiments performed on sediments from a number of groundwater and marine environments showed that the rate of Tc(IV) remobilization was dependent on the sediment type and oxidant (nitrate versus air). In some instances mixed Tc(IV) and Tc(VII) forms were seen in the solids and in others the Tc(IV) was resistant to reoxidation, possibly by incorporation into Fe(III) phases (Morris et al. 2008). Thus, the controls on technetium remobilization are not yet fully understood.

\subsubsection{Gaseous Reduction}

The use of hydrogen sulfide gas to treat hexavalent chromium in the vadose zone in situ was successfully demonstrated at the White Sands Missile Range in New Mexico (Thornton et al. 2007a). The demonstration involved injecting hydrogen sulfide, diluted in air, into contaminated vadose zone sediment to reduce $\mathrm{Cr}(\mathrm{VI})$ to relatively immobile $\mathrm{Cr}(\mathrm{III})$. The gaseous mixture was injected directly into the contaminated sediment through a central injection well and vacuum extracted through the flow field with six boreholes at the site periphery over a 76-day period. Comparison of soil samples taken before and after the test indicated $70 \%$ of the total mass of hexavalent chromium originally present at the site was reduced and immobilized. The zone of highest contamination was nearly completely treated, with average $\mathrm{Cr}(\mathrm{VI})$ concentrations decreasing in this interval from an average of $8.1 \mathrm{mg} / \mathrm{kg}$ before treatment to $1.1 \mathrm{mg} / \mathrm{kg}$ after treatment. Treatment was most effective in higher-permeability clean gypsum sands and less effective in zones containing greater amounts of silt and clay and a slightly higher iron content. All hexavalent chromium concentrations measured in the post-test samples were well below the remedial goal and regulatory limit of $30 \mathrm{mg} / \mathrm{kg}$. The field test also demonstrated that vadose zone treatment of contamination can be safely conducted using diluted hydrogen sulfide gas mixtures.

In laboratory column studies it was determined that the quantity and type of iron oxide content were major factors in determining the quantity of $\mathrm{H}_{2} \mathrm{~S}$ required to treat a particular sediment (Cantrell et al.

2003a). It was determined that $\mathrm{H}_{2} \mathrm{~S}$ was most reactive with ferrihydrite while reaction rates with goethite 
and hematite were considerably lower. In addition, the nature of the carrier gas (air, $\mathrm{O}_{2}$, or $\mathrm{N}_{2}$ ) was determined to have a major impact on the reactivity of $\mathrm{H}_{2} \mathrm{~S}$ with the iron oxides (Cantrell et al. 2003b). When air or oxygen was used as the carrier gas, increased formation of $\mathrm{S}^{0}$ resulted in significantly earlier breakthrough compared to an $\mathrm{N}_{2}$ carrier gas. These results indicated that the use of air or $\mathrm{O}_{2}$ carrier gas may be better for direct treatment of redox-sensitive contaminants in the vadose zone, but that $\mathrm{N}_{2}$ carrier gas would be better for installing an in situ permeable treatment zone in the vadose zone.

In another study, the feasibility of using in situ gaseous reduction to establish a vadose zone permeable reactive barrier in Hanford Formation sediments was evaluated through a combination of laboratory testing and consideration of fundamental vadose zone transport concepts (Thornton et al. 2007b). For the experimental evaluation, a series of laboratory column tests was conducted in which sediment was first treated with a diluted hydrogen sulfide gas mixture to reduce sediment iron oxide to ferrous sulfide. Water containing dissolved oxygen was then pumped through the columns at different flow rates to determine the reoxidation rate and the reductive capacity of the treated sediment. Results indicated that treated sediment has a significant reductive capacity that was dependent on the flow rate of water. In the theoretical assessment, oxygen diffusion was identified as the dominant mechanism leading to reoxidation of the barrier. Depending on vadose zone characteristics, the predicted barrier lifetime varies from several years to more than 100 years.

Zhong et al. (2007) assessed the potential of applying in situ gaseous reduction for immobilizing uranium in the vadose zone. The mobility of $\mathrm{U}(\mathrm{VI})$ in $\mathrm{H}_{2} \mathrm{~S}$-treated soils was investigated using column experiments with Hanford Formation sediments. These studies indicated that humidification of the $\mathrm{H}_{2} \mathrm{~S}$ gas enhanced reduction of soil $\mathrm{Fe}(\mathrm{III})$. It was also determined that sediments treated with humid $\mathrm{H}_{2} \mathrm{~S}$ gas effectively immobilized over $80 \%$ of the mobile U(VI). Uranium immobilization was determined to occur through a combination of sorption to sediments, reduction of U(VI) to U(IV), and enhanced adsorption of $\mathrm{U}(\mathrm{VI})$ to newly formed iron oxides. Remobilization of uranium following reoxidation of the sediment was relatively insignificant under the experimental conditions applied because of the enhanced adsorption of uranium to poorly crystallized hydrous ferric oxides oxidation products.

Sulfur dioxide has shown to be effective for in situ reduction of $\mathrm{Cr}(\mathrm{VI})$. The reduction is rapid and the rate was dependent on water content under the conditions tested (Ahn 2003). Thus, sulfur dioxide may be an effective alternative to hydrogen sulfide if needed. It should be noted that hydrogen gas has been shown to reduce U(VI) at low temperatures if a catalytic surface is present (Spahiu et al. 2004).

\subsubsection{Other Reductants}

The previous sections discuss the reductants that have been most extensively investigated for abiotic reduction of contaminants. Limited investigation has been performed on other systems. The redox capacity of humic substances can be enhanced by incorporation of quinonoid groups and their application was suggested for remediation of uranium and technetium contamination (Perminova et al. 2005).

\subsubsection{Development Path}

The development path for oxidation-reduction processes will need to address issues involving delivery mechanisms, competing redox reactions, reoxidation rate and longevity, subsurface heterogentities, and cost-effectives as discussed below. 


\subsubsection{Delivery Mechanisms}

For any remediation strategy that depends upon reduction for contaminant immobilization, getting the reducing agent to the contaminant without causing an undesirable mobilization of the contaminant is of paramount importance. This is particularly true for reducing agents in the liquid phase that could potentially mobilize contaminants at the wetting front moves as it moves through the porous media to the contaminated zone. This is typically not an issue for gas-phase reactants.

Technology development for innovative delivery systems that can move reactants to the contaminants in the vadose zone without mobilizing the contaminants is needed. An example of one such delivery system that is currently being researched at Pacific Northwest National Laboratory is foam injection (submitted to Vadose Zone Journal). In this approach, a surfactant is mixed with a dissolved reactant or nanoparticles to create an aqueous solution that is used to create foam, which can then be forced into the vadose zone for treatment of contaminants.

\subsubsection{Competing Redox Reactions}

The effect of other natural or contaminant redox-sensitive species on vadose zone redox manipulation technology needs further investigation. The presence of nitrate contamination is believed to be a factor limiting the longevity of the ISRM barrier at Hanford (Szecsody et al. 2005; U.S. Department of Energy 2007). High concentrations ( $>400 \mathrm{mg} / \mathrm{L}$ ) of naturally occurring nitrate have been described in uncontaminated Hanford vadose zone (Serne et al. 2002).

The effect of manganese oxides on the reoxidation of $\mathrm{Cr}(\mathrm{III})$ is thought to be minor, as discussed in Section 3.3.1.3, but its impact on other contaminants should be evaluated. One possible approach is to measure an operationally defined oxidation capacity of the sediments of interest (Heron et al. 1994). Under this approach, the degree of reaction between the sediments and $\mathrm{a} \mathrm{Ti}^{+3} /$ EDTA solution is used to measure the electron acceptors in the sample, expressed as micromoles per gram of sediment. Thus, the oxidation capacity is a measure of the overall potential of the soil to react with introduced reductants.

It is important to evaluate the potential for competing redox reactions during all phases of remedial system design, treatability testing, and deployment. It is recommended that bench-scale testing be performed as much as possible with site materials to be representative of conditions that possibly may reduce the effectiveness of redox manipulations. Laboratory testing can increase the probability of successful pilot-scale field deployments.

\subsubsection{Reoxidation Rates/Longevity}

For any reduction-based remediation technology applied to a system that is initially oxidizing, the impact of the return to oxidizing conditions is typically a key issue. Reoxidation in the vadose zone can result from transport of dissolved oxidants via infiltrating water or by diffusion of oxygen in air from the surface through the vadose zone to the treated zone. The generally oxic state of the vadose zone, particularly in arid sites, needs to be recognized considering that active control of the soil-gas environment is not likely feasible over long time periods. The rate of reoxidation is important in determining the suitability of reductive remediation technologies. However, even when measureable reoxidation occurs, the rate may be slow enough that risk standards will not be exceeded. 
Research is needed to better understand the rates and mechanisms of these reoxidation processes, and impact of reoxidation on remobilization of various contaminants and on methods to prevent or reduce reoxidation of treated zones. Reactive transport study and modeling of technetium and uranium reoxidation are key to evaluating reductive remediation technologies for application to these contaminants.

\subsubsection{Subsurface Heterogeneities}

Subsurface heterogeneity in hydrologic properties and geochemical properties can have major impacts on the effectiveness of various remediation technologies. Heterogeneous hydraulic properties can impede reagent delivery to the desired location or result in transport of the reagents to undesirable locations. Heterogeneous geochemical properties can potentially result in erroneous estimates of the quantity of reagents needed for effective remediation, leading to inaccurate estimates of the effectiveness and cost of a remediation method under consideration. Approaches that can provide a better understanding of the impact of heterogeneity on remedial systems include models that use geostatistical simulation of sequence-stratigraphic relations of lithofacies and the geostatistical distribution of flow-andtransport properties within those facies (Last et al. 2007). Further research is needed on how to better characterize and model subsurface heterogeneities and how to exploit or overcome the impacts of these heterogeneities on the emplacement of vadose zone treatment technologies.

\subsubsection{Cost Effectiveness}

Better, cheaper, and faster approaches to current remediation technologies can turn a technology that currently is not cost effective into one that is cost effective. For example, various nanoscale zero-valent iron particles are currently being developed that show significant potential for effective remediation of various metals and radionuclides; however, current production costs are so high that widespread application of these materials appears unlikely. If lower-cost production methods can be developed, these promising approaches could become cost effective. 



\subsection{Biological Sequestration Processes}

Biological processes can potentially be manipulated as a remediation strategy in the vadose zone. This section reviews mechanisms by which microbial processes affect contaminants, factors that influence microbial processes in the vadose zone, and implementation concepts for vadose zone bioremediation.

\subsection{Factors that Impact Bioremediation in the Vadose Zone}

Microbial activity is influenced by the water potential (Soil Science Society of America 1981). Water potential is the potential energy of the water in a system relative to the potential energy of water in a reference pool of pure water. Water in the vadose zone has lower water potential than the reference pool of water and the availability of water for physiological processes decreases with decreasing water potential. The two key factors in the vadose zone with respect to water potential are the matric potential and the osmotic potential. Matric potential is related to the adsorption and capillary effects of the sediment on the water. Osmotic potential increases with increasing amount of solutes in the water. Thus, evaluation of bioremediation in the vadose zone must consider the moisture content, and associated matric potential, and the solute concentration.

Geochemical conditions also impact microbial activity. Key factors include the $\mathrm{pH}$, buffering capacity, oxidation-reduction potential, and the presence of dissolved or solid-phase electron acceptors. While each of these parameters can be manipulated to some extent, the initial conditions must be known and considered in the bioremediation evaluation, design, and implementation processes.

Heterogeneities can impact bioremediation for the vadose zone. Key heterogeneities may be interrelated and include variability in the distribution of sediment properties, moisture content, geochemical conditions, solutes, and contaminants and variations in the microbial ecology. Evaluation and implementation of bioremediation needs to consider how these variations will impact the amount and type of microbial activity that will be stimulated in the targeted treatment zone.

Microbial activity in response to bioremediation is dependent on the type of substrate, nutrients, and electron acceptors added or already present in the treatment zone. The flux of any of these components over time must also be considered (e.g., a flux of oxygen into an anaerobic treatment zone).

Bioremediation processes are broadly categorized as either aerobic or anaerobic processes depending on the whether oxygen is present as an electron acceptor. A wide variety of electron acceptors may be used during anaerobic bioremediation where the dominant processes are controlled by the free energy and concentration of the electron acceptor, the concentration and type of electron donor, the presence and concentration of inhibitory compounds, and the microbes initially present and able to grow under the imposed and existing subsurface geochemical conditions. Microbial use of substrates and electron acceptors reflects the interdependency among different microbial metabolisms (Lovley and Chapelle 1995). For anaerobic processes, many different types of bacteria can use the same type of substrate and therefore compete for these substrates. For example, when Fe(III) is readily available, sulfate reduction and methanogenesis from hydrogen and acetate may be inhibited because Fe(III)-reducing bacteria can maintain hydrogen and acetate concentrations lower than the minimum concentration required for sulfatereducing bacteria and methanogens to actively metabolize. 


\subsection{Bioremediation Mechanisms}

Subsurface microbial processes can affect contaminant compounds directly or indirectly by the mechanisms discussed in the following sections. The relative importance of these mechanisms is dependent on the microbial ecology in the subsurface, the geochemical conditions, the type of reagents used to stimulate microbial processes, and the contaminant chemistry. The discussion below is focused primarily on technetium, uranium, chromate, and nitrate contaminants. With the exception of nitrate, the microbial processes do not destroy the contaminant. Thus, each of the mechanisms must be considered with respect to the long-term effect on contaminant transport for the site-specific conditions. Mercury bioremediation processes are discussed separately.

Recent articles with thorough discussion of biological mechanisms include those of Begg et al. (2007) for technetium and Wall and Krumholz (2006) for uranium. Several field studies have been conducted in groundwater systems, including those of Istok et al. (2004), Lloyd and Renshaw (2005) for technetium and Anderson et al. (2003), Chang et al. (2005), Istok et al. (2004), North et al. (2004), Ortiz-Bernad et al. (2004), Senko et al. (2002), and Vrionis et al. (2005) for uranium. Additional relevant groundwater field studies for uranium are continuing at site in Rifle, Colorado; Oak Ridge, Tennessee; and Hanford, Washington.

Chromate and nitrate bioremediation in groundwater are commercially established processes. Continued research includes two field studies at the Hanford Site (100-D Area Test: Truex et al. 2007 and Truex et al. 2008; 100H Area test: http://esd.lbl.gov/ERT/hanford100h).

\subsubsection{Direct Reduction}

Implementation of a remediation process based on direct biological contaminant reduction is dependent on whether 1) the microbe is reducing the inorganic contaminant as part of metabolic processes for sustaining cellular energy and growth, 2) the contaminant is fortuitously reduced by enzymes used for reducing other inorganic compounds, or 3) the contaminant is reduced as a microbial response to the toxicity of the contaminant. The relative importance of these mechanisms is specific to each contaminant and, in some cases, the type of microbes present. The following sections review the mechanisms for each of the target contaminants, the applicability to vadose zone remediation, and the information currently available to support use of the direct biological reduction processes in remediation.

\subsubsection{Technetium Reduction}

Microbial reduction of technetium is a fortuitous reductive process catalyzed by some bacteria (Lloyd and Macaskie 1997; Lloyd et al. 2000; De Luca et al. 2001). Direct reduction of technetium is likely only efficient at relatively high molar concentrations of technetium (Lloyd et al. 1999), although one study suggests that enzymatic reduction may be important under certain environmentally relevant conditions (Wildung et al. 2004). Reduction occurs under anaerobic conditions with a suitable substrate present. The relative concentration of electron acceptors is a key factor controlling the anaerobic microbial processes in response to added substrate and will impact the direct reduction of technetium. For instance, oxygen must be depleted and the presence of nitrate will promote denitrification and minimize iron, sulfate, and technetium reduction ( $\mathrm{Li}$ and Krumholz 2008). Nitrate is a ubiquitous co-contaminant with technetium at DOE sites such as Hanford. 
In addition to the impact of vadose zone factors discussed in Section 4.1, identification of electron donors that will promote conditions suitable for technetium reduction in the vadose zone is a key issue. The vadose zone system in terms of microbial ecology and the availability and impact of other electron acceptors on technetium reduction also need to be evaluated. As with any type of technetium reductive process, the effectiveness for immobilization is strongly dependent on conditions that impact reoxidation of the technetium. McBeth et al. (2007) found that reduced technetium in aquifer sediments was reoxidized by dissolved oxygen but not nitrate.

\subsubsection{Uranium Reduction}

Microbial reduction of uranium is catalyzed by a wide range of bacteria with some able to couple uranium reduction to growth (Wall and Krumholz 2006). Reduction occurs under anaerobic conditions with a suitable substrate present. The relative concentration of electron acceptors is a key factor controlling the anaerobic microbial processes in response to added substrate and will impact the direct reduction of uranium. For instance, oxygen must be depleted and the presence of nitrate will promote denitrification and minimize uranium reduction. Nitrate is a ubiquitous co-contaminant with uranium at DOE sites such as Hanford. Uranium reduction may occur in conjunction with iron or sulfate reduction depending on the bacteria present, the type of substrate, and the relative concentration of electron acceptors. Inhibitors such as copper may also be important to consider, although copper is not a prevalent co-contaminant at DOE sites.

In addition to the impact of vadose zone factors discussed in Section 4.1, identification of electron donors that will promote conditions suitable for uranium reduction in the vadose zone is a key issue. The vadose zone system in terms of microbial ecology and the availability and impact of other electron acceptors on uranium reduction also need to be evaluated. As with any type of uranium reductive process, the effectiveness for immobilization is strongly dependent on conditions that impact reoxidation of the uranium. Uranium reoxidation can occur with oxygen, nitrate, manganese, and Fe(III) and may be facilitated by microbial siderophores, humic substances, and microbially generated bicarbonate (Wall and Krumholz 2006). Some bacteria can couple uranium oxidation to denitrification (Wall and Krumholz 2006).

\subsubsection{Chromium(VI) Reduction}

Microbial reduction of chromium is either a fortuitous reductive process or the chromium is reduced by the bacteria to decrease its toxicity to the bacteria. The ability to reduce $\mathrm{Cr}(\mathrm{VI})$ to $\mathrm{Cr}(\mathrm{III})$ is distributed among a wide variety of bacteria (e.g., Horitsu et al. 1987; Bopp and Ehrlich 1988; Ishibashi et al. 1990; Caccavo et al. 1992; Lovley and Phillips 1994; Alam et al. 2006). Reduction typically occurs under anaerobic conditions with a suitable substrate present to promote growth and/or metabolism of nitrate-, iron-, and sulfate-reducing bacteria. Chromate reduction can also occur under aerobic conditions during microbial growth (Horitsu et al. 1987; Bopp and Ehrlich 1988; Ishibashi et al. 1990). The rate and extent of chromate reduction is dependent on its concentration (i.e., toxicity to bacteria) and on the type of microbes present and the dominant microbial process occurring. Thus, the relative concentration of electron acceptors can be an important factor for direct reduction of chromium. Reduced chromium is stable and immobile under most conditions. Reoxidation can occur in the presence of some manganese compounds but not appreciably by dissolved oxygen (e.g., Fendorf and Zasoski 1992; Eary and Rai 1987). 
The effectiveness of chromium reduction in the vadose zone is primarily related to the vadose zone factors discussed in Section 4.1. Identification of electron donors that will promote conditions suitable for chromium reduction in the vadose zone is also an important issue.

\subsubsection{Nitrate Reduction}

Dissimilatory denitrification is a term generally applied to microbial reduction of nitrate to nitrogen gas coupled to substrate oxidation, which provides and gain energy for growth. This reduction typically occurs as a two-step process, often mediated by two different bacteria. The first step is the reduction of nitrate to nitrite. The nitrite can then be further reduced to nitrogen gas. Some bacteria catalyze conversion of nitrate all the way to nitrogen gas. During this reaction, protons are consumed and the $\mathrm{pH}$ of the system may increase. Denitrification is energetically very favorable and bacterial growth rates and yields are high compared to growth rates and yields of other anaerobic metabolisms. After dissolved oxygen is removed from a system, denitrification will occur to the exclusion of most other metabolisms, if sufficient nitrate is present. Under some conditions, the conversion of nitrate to nitrite is faster than the subsequent conversion of nitrite to nitrogen gas. This disparity in rates may cause the buildup of nitrite, which is inhibitory to many bacteria. Thus, denitrifiers may be important to biological treatment of metals and radionuclides by 1) inhibiting the reduction of other anaerobic electron acceptors until nitrate and nitrite are depleted, 2) causing an increase in $\mathrm{pH}$, and 3) depleting substrate until nitrate and nitrite are depleted. Denitrifiers can be integral to an in situ biological treatment for metals if nitrate is a cocontaminant.

The effectiveness of nitrate reduction in the vadose zone is primarily related to the vadose zone factors discussed in Section 4.1. Identification of electron donors that will promote conditions suitable for nitrate reduction in the vadose zone is also an important issue.

\subsubsection{Indirect Reduction}

Microbes can metabolize a range of organic compounds and create geochemically reduced conditions. The reduced conditions are established through depletion or reduction of oxygen and other oxidized species that are used by the microbes as electron acceptors. Once oxygen and nitrate (and associated nitrogen-containing compounds) are depleted, microbes can transform some other chemical species from their oxidized form to their reduced form. Microbially reduced species, predominantly iron- and sulfur-based compounds, can subsequently reduce some contaminants. Thus, microbes can cause reduction of some contaminants as an indirect result of anaerobic metabolic processes and the creation of geochemically reduced conditions. This type of indirect reduction process may be particularly important for technetium (e.g., Begg et al. 2007; Lloyd et al. 2000; Beasley et al. 1998; Morris et al. 2000; Fredrickson et al. 2004; Burke et al. 2005) and uranium (e.g., Amonette et al. 1994; Deng and Stone 1996; Fredrickson and Gorby 1996). Additionally, biologically catalyzed phosphate mineral precipitation of uranium may occur and provide a stable precipitate with low solubility (e.g., Martinez et al. 2007).

The capability to reduce structural Fe(III) in minerals has been established for a number of microbial species (Fredrickson and Gorby 1996). These bacteria have a broad spectrum of other metabolic capabilities. For instance, Shewanella alga can use $\mathrm{O}_{2}, \mathrm{NO}_{3}^{-}, \mathrm{U}(\mathrm{VI}), \mathrm{Mn}(\mathrm{IV})$, and $\mathrm{Fe}(\mathrm{III})$ as electron acceptors. Desulfovibrio desulfuricans is a well-known sulfate-reducing bacteria (SRB), but can also use $\mathrm{Fe}(\mathrm{III}), \mathrm{U}(\mathrm{VI})$, and Cr(VI) as electron acceptors (Lovley and Phillips 1992, 1994). The Fe(III) in minerals 
such as amorphous and poorly crystalline iron (e.g., ferrihydrite) (Lovley 1991; Coleman et al. 1993; Lovley 1994) and crystalline iron oxides/hydroxides (e.g., hematite, goethite, and magnetite) (Arnold et al. 1988; DiChristina 1994; Kostka and Nealson 1995; Roden and Zachara 1996) can be microbially reduced and create the potential for indirect reduction of contaminants.

Sulfate-reducing bacteria produce hydrogen sulfide ( $\mathrm{H}_{2} \mathrm{~S}$ or HS-) by coupling the reduction of sulfate to the oxidation of organic compounds, such as lactate, acetate, ethanol, or $\mathrm{H}_{2}$ (Widdel 1988). It is also important to note that sulfate reduction and the direct reduction of Fe(III) can occur simultaneously depending on how labile the available Fe(III) is to microbial reduction (Lovley and Phillips 1987).

The effectiveness of indirect contaminant reduction in the vadose zone is primarily related to the vadose zone factors discussed in Section 4.1. Implementation of remediation through indirect processes requires knowledge of the microbiology and geochemistry that control the production of compounds that subsequently sequester the uranium. In particular, additional efforts to understand phosphate-based processes may lead to uranium sequestration that is stable and not impacted by oxic conditions within the vadose zone.

\subsubsection{Microbially Induced Coprecipitation}

Microbially induced transformation of chemical species from their oxidized form to their reduced form may also create conditions that lead to the formation of precipitates. In particular, combinations of reduced iron and sulfur species form precipitates. Iron and sulfur compounds may be present in the subsurface porewater at concentrations much higher than contaminant species. During precipitation, some contaminants may co-precipitate by being incorporated into the precipitate matrix or, if sorbed to sediments, may be isolated from the aqueous phase by being covered with precipitates. This mechanism is closely related to the indirect reduction mechanism discussed above. The geochemical processes associated with co-precipitation are the key additional research need and are discussed in more detail in the geochemistry section of this report (Section 3.2).

\subsubsection{Biologically Enhanced Sorption}

Stimulating biological activity in the subsurface typically results in a significant increase in the numbers of bacteria and the related biomass. Biomass is a combination of live and dead bacteria and extracellular organic material produced by the bacteria. This biomass can be considered an organic constituent of the vadose zone and likely acts similarly to soil organic matter in terms of the adsorption of contaminants. The biomass may adhere to portions of the sediment surfaces that were previously either good or poor adsorption sites for contaminants and affect the overall sorption of the contaminant. Biological activity also impacts adsorption through biochemical alteration of the sediment surfaces (e.g., reductive dissolution of iron oxide coatings) and production of precipitates. While the primary biological phenomena that can potentially impact sorption are known, the extent of change in sorption for a given sediment for an induced biological reaction needs to be determined for each site similar to the need for determining standard adsorption parameters. Biomass-related sorption is likely to be a transient phenomena because of the eventual decay of the biomass stimulated through bioremediation activities. However, long-term impacts related to enhanced sorption have not been investigated to determine what portion of the added carbon during bioremediation remains as a long-term residual. Enhanced sorption 
caused by precipitates or sediment surface alteration would need to be investigated as a geochemical process as discussed in the geochemistry section of this report (Section 3.1).

\subsubsection{Mercury Bioremediation}

Biological treatment for mercury in wastewater has focused on either biological reduction of ionic mercury (II) to elemental mercury (0) or biological production of reduced mercury compounds (e.g., $\mathrm{H}_{2} \mathrm{~S}$ and thiols) to create insoluble mercury-sulfur compounds (Essa et al. 2002; U.S. Environmental Protection Agency 2007). Both of these mechanisms could be extended to in situ treatment for ionic mercury contamination, although unwanted production of methylmercury compounds is a potential issue that may eliminate this process from consideration (Barkay and Schaefer 2001). Phytoremediation, in particular with genetically modified plants, may have potential for mercury treatment in the shallow vadose zone. The engineered plants could convert methylmercury to ionic mercury, hyperaccumulate mercury, or reduce ionic mercury to elemental mercury (U.S. Environmental Protection Agency 2007). The volatility of elemental mercury must be considered in any of the bioremediation processes that produce elemental mercury. It is most likely that phytoremediation, potentially combined with microbial processes, may have merit for application in the vadose zone.

\subsubsection{Potential Impacts of Biological Reaction Byproducts}

Products of microbial activity can include increased concentrations of carbon dioxide. Microbial activity can also change the $\mathrm{pH}$ of the porewater. The geochemical impact of increased $\mathrm{P}_{\mathrm{CO} 2}$ and changes in $\mathrm{pH}$ should be considered when evaluating the overall impact of bioremediation in the vadose zone. In some cases, microbial activity will transform added organic substrates to other organic compounds that may be relatively stable in the porewater because conditions are not right for their further consumption and full conversion to carbon dioxide. These organic compounds should be considered with respect to contaminant mobility and other impacts to the porewater geochemistry. Another product of microbial activity is increased biomass. The increased biomass can potentially extend the duration of microbial activity over a longer timeframe than the added substrate is present. These considerations should be included, as appropriate, for each of the biological mechanisms discussed above and with respect to the bioremediation implementation concepts discussed in the next section.

\subsection{Development Status}

Bioremediation has been successfully applied in the vadose zone for organic contamination. Primary examples are bioventing for aerobically degraded hydrocarbons (e.g., Leeson and Hinchee 1996) and aerobic co-metabolic dechlorination for chlorinated ethene compounds (e.g., U.S. Environmental Protection Agency 2000c). These successes demonstrate that the factors affecting bioremediation in the vadose zone can be overcome for aerobic processes. These successes also demonstrate that the delivery of gas-phase nutrients, substrates, and electron acceptors at a field scale is feasible. For metal and radionuclide remediation, typically anaerobic conditions will be required. This section provides a discussion of potential implementation concepts.

For each concept requiring anaerobic conditions, the generally oxic state of the soil gas in the vadose zone needs to be recognized, including its impact considering that active control of the soil-gas environment is not likely feasible over long time periods. 
Gas-phase delivery of nutrients, substrates, and electron acceptors is a likely approach for bioremediation in the vadose zone. Delivery of these constituents within an anoxic carrier gas such as nitrogen may also help maintain anaerobic conditions if needed for the bioremediation process. Use of a nitrogen carrier gas has been successfully implemented in the field for application of abiotic hydrogensulfide-reducing gas treatment of chromium (Thornton et al. 1999). Investigation of appropriate gasphase chemicals for anaerobic bioremediation and their biochemical and transport properties in the vadose zone is needed as input to developing viable vadose zone bioremediation strategies.

A potentially useful technique may be delivery of a gas-phase substrate that can be biodegraded under aerobic conditions. The aerobic biodegradation would remove oxygen and eventually create anaerobic conditions. Subsequent anaerobic processes could then be initiated where the substrate for these reactions would be the decaying biomass. There is a wider variety of gas-phase substrates (e.g., small hydrocarbons) that may be suitable for the initial aerobic step of this process than the types of gas-phase substrates that would directly support anaerobic activity. If nitrate is present in the vadose zone (e.g., as found at Hanford Site), aerobic reactions and then denitrification may be the necessary initial steps of this process before anaerobic conditions appropriate to the other contaminants (e.g., technetium and uranium) are induced.

\subsection{Development Path}

This section summarizes the development needs that were highlighted in the above sections.

The predominant development need for deep vadose zone bioremediation of metals and radionuclides is to identify substrates and nutrients that can be effectively delivered in the deep vadose zone to cause the desired reactions. Gas-phase delivery is likely the most effective transport process for the deep vadose zone. Infiltration of aqueous phase additives is also a potential delivery process in some situations. Use of foams as a delivery mechanism for remediation reagents has been investigated recently in the laboratory (Lirong Zhong, personal communication). Further research is needed to evaluate the characteristics of foam delivery for bioremediation. Foam and other liquid delivery mechanisms need to be evaluated in terms of their impact on contaminant transport during injection. Phased bioremediation processes, such as using an aerobically degraded substrate to induce subsequent anaerobic conditions, could also be considered in developing implementation approaches for the vadose zone.

Implementation for many of the bioremediation mechanisms relies on biogeochemical reactions to induce changes to the chemical form of the contaminant. The success of the sequestration based on sorption, precipitation, or co-precipitation depends on the stability of the induced change over time. Thus, quantifying the stability of the sequestration for candidate biological processes under vadose zone conditions is needed to estimate their performance as remediation techniques. For instance, biologically induced phosphate-based processes may lead to uranium sequestration that is stable and not impacted by oxygen within the vadose zone. Quantifying the change in sorption that is induced by biological reactions and determining what portion of the added carbon during bioremediation remains as a long-term residue may be important components of using a biological process in the vadose zone. As with chemical processes, identifying effective co-precipitates for long-term sequestration may be important if these precipitates can be induced through biological activity. 



\subsection{Hydraulic Control}

Deep vadose zone contaminants are effectively inaccessible by human and ecological receptors. However, mobile contaminants represent a present or possible future ongoing source of groundwater contamination. Thus control of the mobilization of contaminants by aqueous recharge is a potential remediation strategy. Chemical interactions were discussed in previous sections; this section discusses technologies to limit movement of moisture through the vadose zone and mobilization of contaminants. The state of development is discussed in the following sections for each hydraulic control technology; the path for hydraulic control development is discussed in the final section.

Technical aspects of barrier systems including caps and/or covers and other forms of hydraulic control are discussed by Chien et al. (2006); the book presents extensive information about predicting and monitoring the long-term performance of barriers.

\subsection{Caps and Covers}

Placement of covers or caps over waste sites is frequently used to prevent the mobilization of contaminants in the subsurface and to prevent contact with the contaminants by human or ecological receptors. Cover design will not be discussed in detail here, but some aspects are of particular concern for sites with deep vadose zone contamination. Determination of the required cover extent is challenging for deep vadose contamination. Recharge outside the cover may be subject to considerable lateral flow caused by lithologic changes, dipping beds, and small-scale anisotropy in sediments. Thus, the recharge may flow under the cap area, limiting the effective depth of infiltration control and mobilizing contaminants. Drainage at the edge of the cover may produce focused recharge leading to increased infiltration. Long-term performance of the cover is difficult to predict.

\subsubsection{State of Development}

Caps and covers are used extensively at industrial and DOE sites for containment at landfills and for sequestration of contaminants released to soil and sediments. Transferring the technology to containment of deep vadose contamination is conceptually straightforward. The design of caps for very large areas may be more difficult in terms of design for attributes such as runoff control, leachate collection, and physical integrity.

Modeling and monitoring of cover performance need further development in addition to any research needed to develop more effective or less expensive covers. Chien et al. (2006) present a framework for evaluating the long-term performance of barriers including caps and covers. They discuss modeling of barrier performance and methods for barrier monitoring. The state of the art for covers and other technologies used to control water infiltration and contact with waste was assessed for DOE needs by Gerber and Fayer (1994). A prototype Hanford surface barrier has been monitored since 1994 (Ward et al. 2008). 


\subsection{Thermal Treatment}

In situ vitrification of soils can encapsulate the contaminants in a glass matrix and minimize their mobility. In situ vitrification technology was developed in the 1980s and has been described in a number of reviews (e.g., U.S. Environmental Protection Agency 1997a; Looney and Falta 2000). In situ vitrification is deployed by AMEC Earth and Environmental Inc. under the name "GeoMelt". An in situ vitrification test at Los Alamos National Laboratory's Material Disposal Area V was successful in immobilizing radionuclides in a homogeneous glass monolith (Coel-Roback et al. 2003). Field-scale testing for vitrification of simulated Hanford Site waste has also been performed successfully (Morse et al. 2006).

In situ heating has typically been through Joule heating although microwave heating has been investigated (Jones et al. 2002; Abramovitch et al. 2003; Jou 2006). Self-propagating high-temperature synthesis has been suggested for in situ stabilization of inorganic wastes (Xanthopoulou and Vekinis 2001); it is unclear how this would be implemented.

Thermal treatment may also immobilize contaminants without vitrifying the soil. Diffusion of radionuclides or metals into crystal matrices at sub-melting temperature, $1000{ }^{\circ} \mathrm{C}$, effectively sequestered radionuclides in laboratory experiments (Spalding 2001).

\subsubsection{State of Development}

A full-scale in situ vitrification deployment was performed at a superfund site in Michigan (U.S. Environmental Protection Agency 1995). Issues regarding steam generation causing release of melted material occurred in early tests but were addressed by changing to a bottom-up heating method (Looney and Falta 2000). The technology has been deployed.

Thermal treatment at sub-melting temperatures has not been developed but may be more cost effective than vitrification. Self-propagating high-temperature synthesis appears to be only a theoretical concept at this time.

\subsection{Soil Desiccation}

Soil desiccation was recommended as a potentially effective deep vadose zone remediation technology for metals and radionuclides by a vadose zone technical panel convened at Hanford to evaluate vadose zone remediation of technetium (Fluor Hanford Inc. 2006) and in the Deep Vadose Zone Treatability Test Plan for the Hanford Central Plateau (U.S. Department of Energy 2008). Desiccation involves drying a targeted portion of the vadose zone by injecting dry air and extracting soil moisture at soil-gas extraction wells. Because desiccation removes water already in the vadose zone, it reduces the amount of pore fluid available to support downward transport of contaminants in the deep vadose zone and augments the impact of surface water infiltration control. Furthermore, the low moisture content of the desiccated zone may act as a capillary barrier that will impede water and contaminant migration. Desiccation also provides a resilience to natural and extreme recharge events because the soil moisture deficit provides for storage of water within the zone of desiccation until it is rewetted to match conditions in the surrounding vadose zone. In addition, desiccation may induce precipitation of mineral phases containing the contaminants leading to a decrease in contaminant mobility. Thus, under the right 
conditions, decreasing the soil moisture results in an overall decrease in the contaminant flux toward the groundwater. The non-linear relationship between several variables associated with desiccation and potential chemical reactions leads to uncertainties in applying desiccation and its impact on contaminant migration in the Hanford Site vadose zone. Desiccation would typically need to be applied in conjunction with a surface barrier as a long-term remedy for the vadose zone.

\subsubsection{State of Development}

Efforts have been initiated at the Hanford Site to conduct a treatability test for soil desiccation (DOE 2008). Treatability testing includes laboratory, modeling, and field efforts. The laboratory efforts include evaluation of energy considerations during desiccation, the impact of solute concentration on desiccation and rewetting, and the impact of hydrogeologic heterogeneities on desiccation and rewetting. Modeling is being conducted to support the design of a field test and evaluation of how desiccation can be implemented to meet remediation goals. Field testing is primarily focused on evaluating the process of desiccation, although longer-term monitoring will be used to evaluate rewetting of the desiccated zone and potential contaminant migration. The laboratory and field efforts will also investigate techniques for monitoring desiccation and rewetting processes, including electrical resistance tomography, temperature probes, humidity probes, soil moisture indicators, and tracer gases.

The Hanford Site desiccation treatability test is primarily focused on testing the implementation of desiccation and its short-term performance in terms of rewetting phenomena. Longer-term performance will then be extrapolated using numerical modeling. Additional studies complementary to the Hanford Site desiccation treatability test may be of value to examine methods for long-term monitoring of desiccation or the combination of desiccation with other in situ technologies.

\subsection{Permeability Control}

Soil desiccation limits aqueous transport by removing water, increasing the tension, and thus decreasing the unsaturated hydraulic conductivity, as discussed in Section 5.3. Permeability control limits transport by reducing the interconnected porosity through precipitation of mineral phases, addition of grout, or addition of polymer material.

Grouting technology developed for geotechnical applications may be applied for subsurface permeability control. Grouts may consist of cement with or without polymer materials designed for injection into the subsurface. Injection distance is limited by the lithology and the properties of the grout material. Further development may be valuable for application in remedial designs. Application of subsurface barrier "walls and floors" including modeling and monitoring their performance are discussed by Chien et al. (2006).

An alternative to grout injection is deep soil mixing. Mixing using augers may be an effective technology if the depth and sediment type permit penetration by the augers. The augers allow for precise application of the grout. Reductants or other chemicals may be mixed with the grout for chemical fixation. Deep soil mixing has been considered for use at the Hanford Site 100 Areas. 
Polymers may be added to grout to improve the setting properties of the grout's cured strength. Potentially polymer materials may be injected in an uncured state and set up in situ. This could offer advantages over attempting to inject grouts containing a large proportion of solids.

Geochemical manipulation to precipitate phosphate, carbonate, or other phases may have a significant effect on permeability. Microscale mineralogical sequestration was discussed in Section 3.2; similar mechanisms may be able to reduce sediment permeability. It should be noted that the complete filling of the pore space is not necessarily needed to decrease the permeability if the interconnection between pores can be reduced.

\subsubsection{State of Development}

Grouting technology is fairly well established, but there are few applications to permeability control for remediation. In situ grouting may be most applicable to relatively small, well-characterized areas.

Geochemical manipulations appear to be promising but have not been developed to the stage of deployment for physical control of vadose zone contaminant migration.

Electrokinetic methods have been used to indurate subsurface materials for geotechnical applications (e.g., Mohamedelhassan and Shang 2008). The applicability of these methods to permeability control for contaminant sequestration has been the subject of limited evaluation, although a number of electrokinetic remediation papers are concerned with methods to avoid plugging of the subsurface in the vicinity of the electrodes. Electrokinetic methods using a sacrificial iron electrode were used to develop lowpermeability iron-rich bands in preliminary tests (Faulkner et al. 2005).

\subsection{Development Path}

An evaluation of heating methods for thermal treatment may be of interest for economic reasons. Sub-melting thermal treatment should be evaluated as a more cost-effective alternative to vitrification for some contaminant zones. Hybrid thermal-chemical methods may be of use. For instance, thermal methods may speed chemical reactions or change the phases produced during treatment and addition of chemical fluxes may lower melting temperatures.

In-depth evaluation of the potential for permeability control through geochemical manipulations is needed to determine if successful deployment is likely. A greater understanding of mechanisms for manipulating the conditions to precipitate mineral phases is also needed. These mechanisms may include electrokinetic, biological, or other chemical interactions.

Methods for increasing the injection area for grouts and polymers would improve the cost effectiveness of their use in vadose hydraulic control. 


\subsection{Chemical Delivery}

Effective delivery of chemicals is a recurring issue for implementation of the remediation methods discussed previously. This includes chemical reductants and other reactants for sequestration, nutrients for bioremediation, and materials for permeability control. It is difficult to introduce chemicals into finegrained, low-permeability sediments. Heterogeneities in the subsurface may lead to reactants bypassing the contaminated zones.

Three primary methods were identified that show promise for effective chemical treatment of the deep vadose zone. These are gas-phase delivery (e.g., gaseous reductants), foam-based delivery of liquids and gases, and nanoparticles.

\subsection{Gas-Phase Delivery}

Gaseous delivery has advantages in deep vadose zone remediation because of the ease of transport through the sediments. Gravitational and capillary forces have a minimal effect on gases compared to liquids, thus promoting more uniform distribution of gases. The evaluation of gas-phase reactants has been recommended by Denham and Looney (2007). Injection of $\mathrm{H}_{2} \mathrm{~S}$ for in situ manipulation of chromium redox has been field-demonstrated (Section 3.3). Controversy over the safety of $\mathrm{H}_{2} \mathrm{~S}$ as a reductant for vadose zone application has been an issue for application at DOE sites. Gas-phase delivery of nutrients to promote biodegradation is another potential application, as discussed in Section 1.0.

Treatability studies examining the use of gas-phase reagents for geochemical sequestration of uranium are planned at the Hanford Site (U.S. Department of Energy 2008). Initial efforts will be focused on a comparative evaluation of potential approaches to select the most promising candidate for subsequent detailed laboratory, modeling, and field testing. The Hanford treatability tests will have a preference for techniques that are suitable for field testing in the near term.

Soil desiccation may be thought of as a specialized case of gas-phase remediation where gas flow is used to remove porewater, thereby reducing contaminant mobility (Denham and Looney 2007). As discussed in Section 5.3, a field demonstration is planned at the Hanford Site. The non-linear relationship between several variables associated with desiccation and potential chemical reactions requires further study and testing to demonstrate long-term effectiveness of desiccation as a remedial measure.

\subsection{Foam Delivery}

Surfactant foam has potential application as a flushing fluid (Section 2.1); for delivery of reductant liquids, nanoparticles, or other chemicals for in situ treatment (Section 3.3); nutrient for bioremediation (Section 4.4); and other chemical delivery applications. Foam is a mixture of liquid and gas phases whose transport in the subsurface is dominated by the pressure gradient rather than gravitational forces - favoring lateral movement over downward drainage to the water table. This increased lateral movement may provide more uniform distribution of chemicals to the target area.

A number of questions remain regarding the viability of foam delivery for deep vadose zone remediation. The practical extent of injection has not been established in large-scale 2- or 3-dimensional 
experiments. The water saturation levels generated when the foam ultimately breaks down and the impact on subsequent downward transport has not been established. In addition, further study is needed to understand the effects of heterogeneous sediments and varying saturation on foam transport.

\subsection{Nanoparticles}

Nanoparticles show potential for delivery of solid reactants. However, their emplacement in the vadose zone may be problematic. In addition to foam-based delivery, it may be possible to use air pressure to blow them into the subsurface, but the injection distance may be limited by the sediment permeability, tortuousity, or effects of surface charges. The major developments thus far in use of nanoparticles for in situ vadose zone remediation has been the use of zero-valent iron or surface-modified zero-valent iron for in situ reduction (Section 3.3). However, the effectiveness of this application remains to be demonstrated, particularly for treating large, deep areas of contamination. 


\subsection{Conclusions and Recommendations}

There are significant challenges to remediation of metals and radionuclides in the deep vadose zone. Technologies that have been applied to groundwater or shallow vadose zone remediation may not be applicable to the deep vadose zone or may require modification. This section summarizes the major recommendations for additional research or demonstration based on the mechanisms and literature reviewed. Innovative methods may overcome some of the shortcomings of different remediation processes and certain remediation systems may be applicable in specific situations. Thus, the recommendations below are promising areas in which to focus resources, but they may not include all concepts worth pursuing. It would be valuable to keep the resource allocation process open to novel concepts that may advance alternate technologies.

1. A balanced approach to developing concepts at different stages of maturity is needed to address deep vadose remediation challenges. Transfer of remediation technologies from groundwater, shallow vadose zone, or waste treatment applications generally will require additional laboratory and proofof-principle field testing. Methods with a clear development path through this process are likely to have more immediate payoff, whereas novel methods without a track record in other areas have a greater risk but may overcome major challenges in the existing methods.

2. In evaluating the proposed development or proof-of-principle testing of remedial technologies, the target scale should be considered. Some technologies may not be applicable to widely dispersed contamination, but they may be valuable for addressing small high-risk areas of contamination.

3. It is likely that significant new breakthroughs in treatment of the deep vadose zone will entail a combination of different chemical and physical processes to overcome shortcomings in individual methodologies. Possible hybrid remediation methods that show promise include
a. reduction of uranium or technetium followed by geochemical manipulation to sequester the
reduced species under precipitated mineral coating such as carbonate minerals or iron oxides
b. gaseous reduction to fix contaminants in place followed by liquid treatment for permanent sequestration while avoiding mobilization of the contaminant at the liquid front
c. coupling of aerobic biological activity to develop biomass with subsequent development of anaerobic conditions for bioreduction
d. coupled abiotic and/or biotic processes such as bioremediation of co-contaminants (e.g., nitrate) allowing for more effective reduction of metals and radionuclides.

4. Delivery of chemical reactants or nutrients to targeted areas of the deep vadose zone is a major issue for the success of all remedial processes. At this time, gas-phase or foam-based delivery appear to be the most advantageous for deep vadose remediation. Three-phase gas, liquid, and solid, foam-based delivery may also be effective for dispersing nanoparticles in the subsurface. Electrokinetic methods should be evaluated to enhance the delivery of chemicals, especially in areas where low permeability or high heterogeneity limits the effective treatment of contaminated zones.

5. Phosphate phases show great promise for stabilization of contaminants of interest and may provide significant hydraulic control. Emplacement and development of low-temperature phosphates in the vadose zone should be studied further. The relationship of phosphate formation to its role in biological processes needs to be better understood to develop new remedial options. Delivery 
mechanisms including triethyl phosphate gas and phosphate surfactants should be evaluated. A greater understanding of the role of phosphate in mercury and technetium geochemistry is needed.

6. Research on the emplacement of carbonate and possibly silicate phases would be valuable for chemical and physical sequestration. Methods to control $\mathrm{pH}$ for manipulation of the carbonate system, such as carbon dioxide or ammonia gas, need further development. Technetium-carbonate geochemical relationships are not as well developed as for uranium and need more investigation.

7. Thus far only a few reductants have been considered for in situ vadose zone remediation. Other reductants should be considered, either to provide preferential reaction with the target constituents or to produce reduced phases with better stability as more oxic conditions return. Alternate gaseous reductants and zero-valent iron are potential targets. However, the successful deployment of zerovalent iron first requires further understanding of reported enhancement of oxidative reactions by iron surfaces and effective methods for particulate delivery.

8. Chemical, electrochemical, or biochemical manipulations to alter subsurface permeability likely will provide more targeted sequestration and greater longevity than surface capping. These processes should be evaluated versus grouting or polymer methods for in situ hydraulic control.

9. Desiccation is undergoing testing at Hanford and progress should be monitored with respect to information that is useful for future desiccation applications or as input for evaluation and development of other gas-phase technologies. 


\subsection{References}

Abdel-Samad, H. and P. R. Watson. 1997. "An XPS Study of the Adsorption of Chromate on Goethite (Alpha-Feooh)." Applied Surface Science 108(3):371-377.

Abdelouas, A., W. Lutze, and E. Nuttall. 1998. "Chemical Reactions of Uranium in Ground Water at a Mill Tailings Site." Journal of Contaminant Hydrology 34(4):343-361.

Abramovitch, R. A., C. Lu, E. Hicks, and J. Sinard. 2003. "In Situ Remediation of Soils Contaminated with Toxic Metal Ions Using Microwave Energy." Chemosphere 53(9):1077-1085.

Acar, Y. B. and A. N. Alshawabkeh. 1993. "Principles of Electrokinetic Remediation." Environ. Sci. Technol. 27(13):2638-2647.

Acar, Y. B., R. J. Gale, A. N. Alshawabkeh, R. E. Marks, S. Puppala, M. Bricka, and R. Parker. 1995. "Electrokinetic Remediation - Basics and Technology Status." Journal of Hazardous Materials 40(2):117-137.

Adams, V., G. M. Chamberlain, Jr, T. L. Stewart, and R. S. Aylward. 2008. "Department of Energy Soil and Groundwater Science and Technology Needs, Plans and Initiatives." Waste Management 2008 Conference, Phoenix, Arizona.

Ahn, M. (2003) Remediation of Chromium(VI) in the Vadose Zone: Stoichiometry and Kinetics of Chromium(VI) Reduction by Sulfur Dioxide. Texas A\&M University, College Station, Texas.

Al-Hamdan, A. Z. and K. R. Reddy. 2008. "Transient Behavior of Heavy Metals in Soils During Electrokinetic Remediation." Chemosphere 71(5):860-871.

Alam, M., M. A. Hossain, D. R. Yonge, B. M. Peyton, and J. N. Petersen. 2006. "Bioreduction of Hexavalent Chromium in Flow-through Quartz Sand Columns." Journal of Environmental EngineeringASCE 132(3):358-366.

Alshawabkeh, A. N., A. T. Yeung, and M. R. Bricka. 1999. "Practical Aspects of in-Situ Electrokinetic Extraction." Journal of Environmental Engineering-ASCE 125(1):27-35.

Ames, L. L., J. E. McGarrah, B. A. Walker, and P. F. Salter. 1982. "Sorption of Uranium and Cesium by Hanford Basalts and Associated Secondary Smectite." Chemical Geology 35(3-4):205-225.

Amonette, J. E., J. E. Szecsody, H. T. Schaef, J. C. Templeton, Y. A. Gorby, and J. S. Fruchter. 1994. "Abiotic Reduction of Aquifer Materials by Dithionite: A Promising in-Situ Remediation Technology." In In-Situ Remediation: Scientific Basis for Current and Future Technologies. Eds. G. W. Gee and N. R. Wing), pp. 851-881, Battelle Press, Columbus, Ohio.

Anderson, R. T., H. A. Vrionis, I. Ortiz-Bernad, C. T. Resch, P. E. Long, R. Dayvault, K. Karp, S. Marutzky, D. R. Metzler, A. Peacock, D. C. White, M. Lowe, and D. R. Lovley. 2003. "Stimulating the in Situ Activity of Geobacter Species to Remove Uranium from the Groundwater of a UraniumContaminated Aquifer." Appl. Environ. Microbiol. 69(10):5884-5891.

Arnold, R. G., T. J. Dichristina, and M. R. Hoffmann. 1988. "Reductive Dissolution of Fe(III) Oxides by Pseudomonas Sp 200." Biotechnology and Bioengineering 32(9):1081-1096. 
Aurivillius, K. and B. A. Nilsson. 1975. "Crystal-Structure of Mercury(II)Phosphate, Hg3(Po4)2." Zeitschrift Fur Kristallographie 141(1-2):1-10.

Barkay, T. and J. Schaefer. 2001. "Metal and Radionuclide Bioremediation: Issues, Considerations and Potentials." Current Opinion in Microbiology 4(3):318-323.

Beasley, T. M., P. R. Dixon, and L. J. Mann. 1998. ${ }^{199}$ Tc, ${ }^{236} \mathrm{U}$, and ${ }^{237} \mathrm{~Np}$ in the Snake River Plain Aquifer at the Idaho National Engineering and Environmental Laboratory, Idaho Falls, Idaho " Environ. Sci. Technol. 32(24):3875-3881.

Begg, J. D. C., I. T. Burke, and K. Morris. 2007. "The Behaviour of Technetium During Microbial Reduction in Amended Soils from Dounreay, UK." Science of the Total Environment 373(1):297-304.

Blowes, D. W., C. J. Ptacek, and J. L. Jambor. 1997. "In-Situ Remediation of Cr(VI)-Contaminated Groundwater Using Permeable Reactive Walls: Laboratory Studies." Environ. Sci. Technol. 31(12):33483357.

Blowes, D. W. and K. U. Mayer. 1999. An in Situ Permeable Reactive Barrier for the Treatment of Hexavalent Chromium and Trichloroethylene in Ground Water: Vol. 3, Multicomponent Reactive Transport Modeling. EPA/600/R-99/095c, U.S. Environmental Protection Agency, Washington, D.C.

Blowes, D. W., R. W. Puls, R. W. Gillham, C. J. Ptacek, T. A. Bennett, J. G. Bain, C. J. Hanton-Fong, and C. J. Paul. 1999a. An in Situ Permeable Reactive Barrier for the Treatment of Hexavalent Chromium and Trichloroethylene in Ground Water: Vol. 2, Performance Monitoring. EPA/600/R99/095b, U.S. Environmental Protection Agency, Washington, D.C.

Blowes, D. W., R. W. Gillham, C. J. Ptacek, R. W. Puls, T. A. Bennett, S. F. O'Hannesen, C. J. HantonFong, and J. G. Bain. 1999b. An in Situ Permeable Reactive Barrier for the Treatment of Hexavalent Chromium and Trichloroethylene in Ground Water: Vol. 1, Design and Installation. EPA/600/R99/095a, U.S. Environmental Protection Agency, Washington, D.C.

Blue, L. Y., M. A. Van Aelstyn, M. Matlock, and D. A. Atwood. 2008. "Low-Level Mercury Removal from Groundwater Using a Synthetic Chelating Ligand." Water Research 42(8-9):2025-2028.

Booher, W. F., E. R. Lindgren, and P. V. Brady. 1997. Electrokinetic Removal of Uranium from Contaminated, Unsaturated Soils. SAND-97-0122, Sandia National Laboratory, Albuquerque, New Mexico.

Bopp, L. H. and H. L. Ehrlich. 1988. "Chromate Resistance and Reduction in Pseudomonas-Fluorescens Strain Lb300." Archives of Microbiology 150(5):426-431.

Borovec, Z., B. Kribek, and V. Tolar. 1979. "Sorption of Uranyl by Humic Acids." Chemical Geology 27(1-2):39-46.

Borzunov, A. I., S. V. D'Yakov, and P. P. Poluektov. 2004. "Immobilization of Radioactive Wastes by Embedding in Phosphate Ceramic." Atomic Energy 96(2):123-126.

Bradl, H. B. 2004. "Adsorption of Heavy Metal Ions on Soils and Soils Constituents." Journal of Colloid and Interface Science 277(1):1-18. 
Brown, G. E., V. E. Henrich, W. H. Casey, D. L. Clark, C. Eggleston, A. Felmy, D. W. Goodman, M. Gratzel, G. Maciel, M. I. McCarthy, K. H. Nealson, D. A. Sverjensky, M. F. Toney, and J. M. Zachara. 1999. "Metal Oxide Surfaces and Their Interactions with Aqueous Solutions and Microbial Organisms." Chem. Rev. 99(1):77-174.

Brown, G. E. and G. A. Parks. 2001. "Sorption of Trace Elements on Mineral Surfaces: Modern Perspectives from Spectroscopic Studies, and Comments on Sorption in the Marine Environment." International Geology Review 43(11):963-1073.

Buck, E. C., N. R. Brown, and N. L. Dietz. 1996. "Contaminant Uranium Phases and Leaching at the Fernald Site in Ohio." Environ. Sci. Technol. 30(1):81-88.

Burgess, J., S. Flynn, P. Jessmore, J. Keck, S. McCormick, M. Rohe, I. Stepan, R. VanHorn, S. Fu, and L. Trozollo. 2000. Comprehensive Remedial Investigation/Feasibility Study for the Central Facilities Area Operable Unit 4-13 at the Ldaho National Engineering and Environmental Laboratory. DOEIID-10680 Rev 1, U.S. Department of Energy, Idaho Falls, Idaho.

Burke, D. C. 2007. Lawrence Livermore National Laboratory Environmental Report 2006. UCRL-TR50027-06, Lawrence Livermore National Laboratory, Livermore, California.

Burke, I. T., C. Boothman, J. R. Lloyd, R. J. G. Mortimer, F. R. Livens, and K. Morris. 2005. "Effects of Progressive Anoxia on the Solubility of Technetium in Sediments." Environ. Sci. Technol. 39(11):41094116.

Caccavo, F., R. P. Blakemore, and D. R. Lovley. 1992. "A Hydrogen-Oxidizing, Fe(III)-Reducing Microorganism from the Great Bay Estuary, New-Hampshire." Appl. Environ. Microbiol. 58(10):32113216.

Cang, L., D. M. Zhou, A. N. Alshawabkeh, and H. F. Chen. 2007. "Effects of Sodium Hypochlorite and High pH Buffer Solution in Electrokinetic Soil Treatment on Soil Chromium Removal and the Functional Diversity of Soil Microbial Community." Journal of Hazardous Materials 142(1-2):111-117.

Cantrell, K. J. and D. I. Kaplan. 1997. "Zero-Valent Iron Colloid Emplacement in Sand Columns." Journal of Environmental Engineering-Asce 123(5):499-505.

Cantrell, K. J., D. I. Kaplan, and T. J. Gilmore. 1997. "Injection of Colloidal Fe ${ }^{0}$ Particles in Sand with Shear-Thinning Fluids." Journal of Environmental Engineering 123(8):786-791.

Cantrell, K. J., R. J. Serne, and G. V. Last. 2003a. Hanford Contaminant Distribution Coefficient Database and Users Guide. PNNL-13895 Rev. 1, Pacific Northwest National Laboratory, Richland, Washington.

Cantrell, K. J., S. B. Yabusaki, M. H. Engelhard, A. V. Mitroshkov, and E. C. Thornton. 2003b. "Oxidation of $\mathrm{H}_{2} \mathrm{~S}$ by Iron Oxides in Unsaturated Conditions." Environ. Sci. Technol. 37(10):2192-2199.

Catalano, J. G., J. P. McKinley, J. M. Zachara, S. M. Heald, S. C. Smith, and G. E. Brown. 2006. "Changes in Uranium Speciation through a Depth Sequence of Contaminated Hanford Sediments." Environ. Sci. Technol. 40(8):2517-2524.

Chang, T. C. and J. H. Yen. 2006. "On-Site Mercury-Contaminated Soils Remediation by Using Thermal Desorption Technology." Journal of Hazardous Materials 128(2-3):208-217. 
Chang, Y. J., P. E. Long, R. Geyer, A. D. Peacock, C. T. Resch, K. Sublette, S. Pfiffner, A. Smithgall, R. T. Anderson, H. A. Vrionis, J. R. Stephen, R. Dayvault, I. Ortiz-Bernad, D. R. Lovley, and D. C. White. 2005. "Microbial Incorporation of C-13-Labeled Acetate at the Field Scale: Detection of Microbes Responsible for Reduction of U(VI)." Environ. Sci. Technol. 39(23):9039-9048.

Chien, C. C., H. I. Inyang, and L. G. Everett. 2006. Barrier Systems for Environmental Containment and Treatment. CRC Taylor \& Francis, Boca Raton, Florida.

Chisholm-Brause, C. J., J. M. Berg, R. A. Matzner, and D. E. Morris. 2001. "Uranium(VI) Sorption Complexes on Montmorillonite as a Function of Solution Chemistry." Journal of Colloid and Interface Science 233(1):38-49.

Chowdiah, P., B. R. Misra, J. J. Kilbane, V. J. Srivastava, and T. D. Hayes. 1998. "Foam Propagation through Soils for Enhanced in-Situ Remediation." Journal of Hazardous Materials 62(3):265-280.

Coel-Roback, B., P. Lowery, M. Springer, L. Thompson, and G. Huddleston. 2003. "Non-Traditional in Situ Vitrification-A Technology Demonstration at Los Alamos National Laboratory." In Proceedings of $W M^{\prime} 03$, WMsymposia, Tucson, Arizona,

Coleman, M. L., D. B. Hedrick, D. R. Lovley, D. C. White, and K. Pye. 1993. "Reduction of Fe(III) in Sediments by Sulfate-Reducing Bacteria." Nature 361(6411):436-438.

Cox, C. D., M. A. Shoesmith, and M. M. Ghosh. 1996. "Electrokinetic Remediation of MercuryContaminated Soils Using Iodine/Iodide Lixiviant." Environ. Sci. Technol. 30(6):1933-1938.

Craw, D. 2005. "Potential Anthropogenic Mobilisation of Mercury and Arsenic from Soils on Mineralised Rocks, Northland, New Zealand." Journal of Environmental Management 74(3):283-292.

Cui, D. and T. E. Eriksen. 1996a. "Reduction of Pertechnetate by Ferrous Iron in Solution: Influence of Sorbed and Precipitated Fe(II)." Environ. Sci. Technol. 30(7):2259-2262.

Cui, D. Q. and T. E. Eriksen. 1996b. "Reduction of Pertechnetate in Solution by Heterogeneous Electron Transfer from Fe(II)-Containing Geological Material." Environ. Sci. Technol. 30(7):2263-2269.

Dai, M., J. M. Kelley, and K. O. Buesseler. 2002. "Sources and Migration of Plutonium in Groundwater at the Savannah River Site." Environ. Sci. Technol. 36(17):3690-3699.

Davis, J. A. and J. O. Leckie. 1980. "Surface Ionization and Complexation at the Oxide/Water Interface. III. Adsorption of Anions." J. Colloid Interf. Sci. 74(1):32-43.

De Luca, G., P. De Philip, Z. Dermoun, M. Rousset, and A. Vermeglio. 2001. "Reduction of Technetium(VII) by Desulfovibrio Fructosovorans Is Mediated by the Nickel-Iron Hydrogenase." Appl. Environ. Microbiol. 67(10):4583-4587.

DeFlaun, M. F. and C. W. Condee. 1997. "Electrokinetic Transport of Bacteria." Journal of Hazardous Materials 55(1-3):263-277.

Del Debbio, J. A. 1991. "Sorption of Strontium, Selenium, Cadmium, and Mercury in Soil." Radiochimica Acta 52(53):181-186. 
Demirkanli, D. I., F. J. Molz, D. I. Kaplan, R. A. Fjeld, and S. M. Serkiz. 2007. "Modeling Long-Term Plutonium Transport in the Savannah River Site Vadose Zone." Vadose Zone J. 6(2):344-353.

Deng, B. L. and A. T. Stone. 1996. "Surface-Catalyzed Chromium(VI) Reduction: Reactivity Comparisons of Different Organic Reductants and Different Oxide Surfaces." Environ. Sci. Technol. 30(8):2484-2494.

Denham, M. E. and B. B. Looney. 2007. "Gas: A Neglected Phase in Remediation of Metals and Radionuclides." Environ. Sci. Technol. 41(12):4193-4198.

DiChristina, T. J. 1994. "Bioextraction (Reductive Dissolution) of Iron from Low-Grade Iron-Ores Fundamental and Applied Studies." Annals of the New York Academy of Sciences 721:440-449.

Dong, W. M., W. P. Ball, C. X. Liu, Z. M. Wang, A. T. Stone, J. Bai, and J. M. Zachara. 2005. "Influence of Calcite and Dissolved Calcium on Uranium(VI) Sorption to a Hanford Subsurface Sediment." Environ. Sci. Technol. 39(20):7949-7955.

Dresel, P. E. 1989. The Dissolution Kinetics of Siderite and Its Effect on Acid Mine Drainage. Ph.D. Thesis, The Pennsylvania State University, University Park, Pennsylvania.

Eary, L. E. and D. Rai. 1987. "Kinetics of Chromium(III) Oxidation to Chromium(VI) by Reaction with Manganese-Dioxide." Environ. Sci. Technol. 21(12):1187-1193.

Eglizaud, N., F. Miserque, E. Simoni, M. Schlegel, and M. Descostes. 2006. "Uranium(VI) Interaction with Pyrite (Fes2): Chemical and Spectroscopic Studies." Radiochimica Acta 94(9-11):651-656.

Elkolaly, M. T. 1993. "A Mo-99 Tc-99m Generator Based on the Use of Zirconium MolybdophosphateMo-99 Gel." Journal of Radioanalytical and Nuclear Chemistry-Articles 170(2):293-298.

Elwear, S., K. E. German, and V. F. Peretrukhin. 1992. "Sorption of Technetium on Inorganic Sorbents and Natural Minerals." Journal of Radioanalytical and Nuclear Chemistry-Articles 157(1):3-14.

Essa, A. M. M., L. E. Macaskie, and N. L. Brown. 2002. "Mechanisms of Mercury Bioremediation." Biochemical Society Transactions 30:672-674.

Faulkner, D. W. S., L. Hopkinson, and A. B. Cundy. 2005. "Electrokinetic Generation of Reactive IronRich Barriers in Wet Sediments: Implications for Contaminated Land Management." Mineralogical Magazine 69(5):749-757.

Fendorf, S. E., M. Fendorf, D. L. Sparks, and R. Gronsky. 1992. "Inhibitory Mechanisms of Cr(III) Oxidation by Delta-Mno." Journal of Colloid and Interface Science 153(1):37-54.

Fendorf, S. E. and R. J. Zasoski. 1992. "Chromium(III) Oxidation by Delta-Mno2. 1. Characterization." Environ. Sci. Technol. 26(1):79-85.

Fendorf, S. E., R. J. Zasoski, and R. G. Burau. 1993. "Competing Metal-Ion Influences on Chromium(III) Oxidation by Birnessite." Soil Science Society of America Journal 57(6):1508-1515.

Fluor Hanford Inc. 2006. Evaluation of Vadose Zone Treatment Technologies to Immobilize Technetium-99. WMP-27397 Rev. 1, Fluor Hanford Inc., Richland, Washington. 
Ford, R. G., R. T. Wilkin, and R. W. Puls. 2007a. "Monitored Natural Attenuation of Inorganic Contaminants in Ground Water." Vol. 1: Technical Basis for Assessment. EPA/600/R-07/139, U.S. Environmental Protection Agency, Ada, Oklahoma.

Ford, R. G., R. T. Wilkin, and R. W. Puls. 2007b. "Monitored Natural Attenuation of Inorganic Contaminants in Ground Water." Vol. 2: Assessment for Non-Radionuclides Including Arsenic, Cadmium, Chromium, Copper, Lead, Nickel, Nitrate, Perchlorate, and Selenium. EPA/600/R-07/140, U.S. Environmental Protection Agency, Ada, Oklahoma.

Fox, P. M., J. A. Davis, and J. M. Zachara. 2006. "The Effect of Calcium on Aqueous Uranium(VI) Speciation and Adsorption to Ferrihydrite and Quartz." Geochim. Cosmochim. Acta 70(6):1379-1387.

Fredrickson, J. K. and Y. A. Gorby. 1996. "Environmental Processes Mediated by Iron-Reducing Bacteria." Current Opinion in Biotechnology 7(3):287-294.

Fredrickson, J. K., J. M. Zachara, D. W. Kennedy, R. K. Kukkadapu, J. P. McKinley, S. M. Heald, C. Liu, and A. E. Plymale. 2004. "Reduction of Tco4- by Sediment-Associated Biogenic Fe(II)." Geochim. Cosmochim. Acta 68(15):3171-3187.

Fruchter, J. S., J. E. Amonette, C. R. Cole, Y. A. Gorby, M. D. Humphrey, J. D. Istok, F. A. Spane, J. E. Szecsody, S. S. Teel, V. R. Vermeul, M. D. Williams, and S. B. Yabusaki. 1996. In Situ Redox Manipulation Field Injection Test Report - Hanford 100-H Area. PNNL-11372, Pacific Northwest National Laboratory, Richland, Washington.

Fruchter, J. S., V. R. Vermeul, M. D. Williams, and J. E. Szecsody. 2004. "In Situ Redox Manipulation for Treatment of Chromium-Contaminated Groundwater." In Proceedings of 4th International Conference on Remediation of Chlorinated and Recalcitrant Compounds, 4C-12, Monterey, California.

Fuller, C. C., J. R. Bargar, J. A. Davis, and M. J. Piana. 2002. "Mechanisms of Uranium Interactions with Hydroxyapatite: Implications for Groundwater Remediation." Environ. Sci. Technol. 36(2):158165.

Gent, D. B., R. M. Bricka, A. N. Alshawabkeh, S. L. Larson, G. Fabian, and S. Granade. 2004. "Benchand Field-Scale Evaluation of Chromium and Cadmium Extraction by Electrokinetics." Journal of Hazardous Materials 110(1-3):53-62.

Gerber, M. A. and M. J. Fayer. 1994. In Situ Remediation Program: Evaluation and Assessment of Containment Technology. PNL-8902, Pacific Northwest Laboratory, Richland, Washington.

Griffin, R. A., A. K. Au, and R. R. Frost. 1977. "Effect of pH on Adsorption of Chromium from Landfill-Leachate by Clay-Minerals." Journal of Environmental Science and Health Part aEnvironmental Science and Engineering \& Toxic and Hazardous Substance Control 12(8):431-449.

Gu, B., L. Liang, M. J. Dickey, X. Yin, and S. Dai. 1998. "Reductive Precipitation of Uranium(VI) by Zero-Valent Iron." Environ. Sci. Technol. 32(21):3366-3373.

Gu, B. H., S. C. Brooks, Y. Roh, and P. M. Jardine. 2003. "Geochemical Reactions and Dynamics During Titration of a Contaminated Groundwater with High Uranium, Aluminum, and Calcium." Geochim. Cosmochim. Acta 67(15):2749-2761. 
Haran, B. S., B. N. Popov, G. H. Zheng, and R. E. White. 1996. "Development of a New Electrokinetic Technique for Decontamination of Hexavalent Chromium from Low Surface Charged Soils." Environmental Progress 15(3):166-172.

Harms, H. and L. Y. Wick. 2006. "Dispersing Pollutant-Degrading Bacteria in Contaminated Soil without Touching It." Engineering in Life Sciences 6(3):252-260.

He, F. and D. Zhao. 2005. "Preparation and Characterization of a New Class of Starch-Stabilized Bimetallic Nanoparticles for Degradation of Chlorinated Hydrocarbons in Water." Environ. Sci. Technol. 39(9):3314-3320.

Heron, G., T. H. Christensen, and J. C. Tjell. 1994. "Oxidation Capacity of Aquifer Sediments." Environ. Sci. Technol. 28(1):153-158.

Ho, S. V., C. J. Athmer, P. W. Sheridan, and A. P. Shapiro. 1997. "Scale-up Aspects of the Lasagna(Tm) Process for in Situ Soil Decontamination." Journal of Hazardous Materials 55(1-3):39-60.

Ho, S. V., C. Athmer, P. W. Sheridan, B. M. Hughes, R. Orth, D. McKenzie, P. H. Brodsky, A. Shapiro, R. Thornton, J. Salvo, D. Schultz, R. Landis, R. Griffith, and S. Shoemaker. 1999a. "The Lasagna Technology for in Situ Soil Remediation. 1. Small Field Test." Environ. Sci. Technol. 33(7):1086-1091.

Ho, S. V., C. Athmer, P. W. Sheridan, B. M. Hughes, R. Orth, D. McKenzie, P. H. Brodsky, A. M. Shapiro, T. M. Sivavec, J. Salvo, D. Schultz, R. Landis, R. Griffith, and S. Shoemaker. 1999b. "The Lasagna Technology for in Situ Soil Remediation. 2. Large Field Test." Environ. Sci. Technol. 33(7):1092-1099.

Holdren, K. J., D. L. Anderson, B. H. Becker, N. L. Hampton, L. D. Koeppen, S. O. Magnuson, and A. J. Sondrup. 2006. Remedial Investigation and Baseline Risk Assessment for Operable Unit 7-13/14. DOE/ID-11241, U.S. Department of Energy, Idaho Falls, Idaho.

Horitsu, H., S. Futo, Y. Miyazawa, S. Ogai, and K. Kawai. 1987. "Enzymatic Reduction of Hexavalent Chromium by Hexavalent Chromium Tolerant Pseudomonas-Ambigua G-1." Agricultural and Biological Chemistry 51(9):2417-2420.

Hsi, C. K. D. and D. Langmuir. 1985. "Adsorption of Uranyl onto Ferric Oxyhydroxides - Application of the Surface Complexation Site-Binding Model." Geochim. Cosmochim. Acta 49(9):1931-1941.

Hua, B., B. L. Deng, E. C. Thornton, J. Yang, and J. E. Amonette. 2007. "Incorporation of Chromate into Calcium Carbonate Structure During Coprecipitation." Water Air and Soil Pollution 179(1-4):381390.

Hughes, J. 2007. Oak Ridge Reservation Annual Site Environmental Report for 2006. DOE/ORO/2233, U.S. Department of Energy, Oak Ridge, Tennessee.

Hyman, M. and R. R. Dupont. 2001. Groundwater and Soil Remediation: Process Design and Cost Estimating of Proven Technologies. ASCE Press, Reston, Virginia.

Ilton, E. S., C. Liu, W. Yantasee, Z. Wang, D. A. Moore, A. R. Felmy, and J. M. Zachara. 2006. "The Dissolution of Synthetic Na-Boltwoodite in Sodium Carbonate Solutions." Geochim. Cosmochim. Acta 70(19):4836-4849. 
Ilton, E. S., N. P. Qafoku, C. X. Liu, D. A. Moore, and J. M. Zachara. 2008. "Advective Removal of Intraparticle Uranium from Contaminated Vadose Zone Sediments, Hanford, US." Environ. Sci. Technol. 42(5):1565-1571.

Ishibashi, Y., C. Cervantes, and S. Silver. 1990. "Chromium Reduction in Pseudomonas Putida." Appl. Environ. Microbiol. 56:2268-2270.

Iskandar, I. K. 2001. Environmental Restoration of Metals-Contaminated Soils. Lewis Publishers, Boca Raton, Florida.

Istok, J. D., J. M. Senko, L. R. Krumholz, D. Watson, M. A. Bogle, A. Peacock, Y. J. Chang, and D. C. White. 2004. "In Situ Bioreduction of Technetium and Uranium in a Nitrate-Contaminated Aquifer." Environ. Sci. Technol. 38(2):468-475.

The Interstate Technology and Regulatory Council (ITRC). 2005. Permeable Reactive Barriers: Lessons Learned/New Directions. Washington, D.C.

Jerden, J. L. and A. K. Sinha. 2006. "Geochemical Coupling of Uranium and Phosphorous in Soils Overlying an Unmined Uranium Deposit: Coles Hill, Virginia." Journal of Geochemical Exploration 91(1-3):56-70.

Jones, D. A., T. P. Lelyveld, S. D. Mavrofidis, S. W. Kingman, and N. J. Miles. 2002. "Microwave Heating Applications in Enviromnental Engineering - A Review." Resources Conservation and Recycling 34(2):75-90.

Joo, S. H. and I. F. Chang. 2006. Nanotechnology for Environmental Remediation. Springer, New York.

Jou, C. J. G. 2006. "An Efficient Technology to Treat Heavy Metal-Lead-Contaminated Soil by Microwave Radiation." Journal of Environmental Management 78(1):1-4.

Kaback, D. S., M. H. Young, T. W. Fogwell, S. W. Petersen, M. D. Ankeny, J. H. Hendrickx, B. B. Looney, W. E. P., and S. E. Silliman. 2006. Evaluation of Vadose Zone Treatment Technologies to Immobilize Technetium-99. WMP-27397 Rev 1, Fluor Hanford, Inc., Richland Washington.

Kantar, C. and B. D. Honeyman. 2006. "Citric Acid Enhanced Remediation of Soils Contaminated with Uranium by Soil Flushing and Soil Washing." Journal of Environmental Engineering-Asce 132(2):247255.

Kaya, A. and Y. Yukselen. 2005. "Zeta Potential of Soils with Surfactants and Its Relevance to Electrokinetic Remediation." Journal of Hazardous Materials 120(1-3):119-126.

Keck, J. F., L. S. Cahn, S. C. Ashworth, J. D. Folker, D. R. Myers, D. E. Shanklin, and D. R. Tyson. 2006. Operable Unit (Ou) 3-14 Tank Farm Soil and Groundwater Feasibility Study (Fs). DOE/ID11247 Rev. 00, U.S. Department of Energy, Idaho Falls, Idaho.

Kelly, S. D., M. G. Newville, L. Cheng, K. M. Kemner, S. R. Sutton, P. Fenter, N. C. Sturchio, and C. Spotl. 2003. "Uranyl Incorporation in Natural Calcite." Environ. Sci. Technol. 37(7):1284-1287.

Kelly, S. D., E. T. Rasbury, S. Chattopadhyay, A. J. Kropf, and K. M. Kemner. 2006. "Evidence of a Stable Uranyl Site in Ancient Organic-Rich Calcite." Environ. Sci. Technol. 40(7):2262-2268. 
Kelsh, D. J. and M. W. Parsons. 1997. "Department of Energy Sites Suitable for Electrokinetic Remediation." Journal of Hazardous Materials 55(1):109-116.

Kent, D. B., V. S. Tripathi, N. B. Ball, J. O. Leckie, and M. D. Siegel. 1988. Surface-Complexation Modeling of Radionuclide Adsorption in Subsurface Environments. NUREG/CR-4807, U.S. Nuclear Regulatory Commission, Washington, D.C.

Khan, F. A. and R. W. Puls. 1999. "In Situ Treatment of Chromium Source Area Using Redox Manipulation." In Proceedings of Abiotic In Situ Technologies for Groundwater Remediation, Dallas, Texas, August 31-September 2, 1999, EPA/625/R-99/012, U.S. Environmental Protection Agency, Washington, D.C.

Kim, K. H., S. O. Kim, C. W. Lee, M. H. Lee, and K. W. Kim. 2003. "Electrokinetic Processing for the Removal of Radionuclides in Soils." Separation Science and Technology 38(10):2137-2163.

Knox, A. S., J. C. Seaman, M. J. Mench, and J. Vangronsveld. 2001. "Remediation of Metal- and Radionuclides- Contaminated Soils by in Situ Stabilization Techniques." In Environmental Restoration of Metals-Contaminated Soil. Ed. I. K. Iskandar, Lewis Publishers, Boca Raton, Florida.

Kostka, J. E. and K. H. Nealson. 1995. "Dissolution and Reduction of Magnetite by Bacteria." Environ. Sci. Technol. 29(10):2535-2540.

Krestou, A., A. Xenidis, and D. Panias. 2004. "Mechanism of Aqueous Uranium(VI) Uptake by Hydroxyapatite." Minerals Engineering 17(3):373-381.

Krupka, K. M. and W. J. Martin. 2001. Subsurface Contaminant Focus Area: Monitored Natural Attenuation (Mna) - Programmatic, Technical, and Regulatory Issues. PNNL-13569, Pacific Northwest National Laboratory, Richland, Washington.

Kunkel, A. M., J. J. Seibert, L. J. Elliott, R. Kelley, L. E. Katz, and G. A. Pope. 2006. "Remediation of Elemental Mercury Using in Situ Thermal Desorption (Istd)." Environ. Sci. Technol. 40(7):2384-2389.

Lageman, R., R. L. Clarke, and W. Pool. 2005. "Electro-Reclamation, a Versatile Soil Remediation Solution." Engineering Geology 77(3-4):191-201.

Last, G. V., C. J. Murray, D. A. Bush, E. C. Sullivan, M. L. Rockhold, R. D. Mackley, and B. N. Bjornstad. 2007. "Standardization of Borehole Data to Support Vadose Zone Flow and Transport Modeling." Vadose Zone J. 6(4):906-912.

Leckie, J. O., M. M. Benjamin, K. Hayes, G. Kaufman, and S. Altman. 1980. Adsorption/Coprecipitation of Trace Elements from Water with Iron Oxyhydroxides. EPRI RP-910, Electric Power Research Institute, Palo Alto, California.

Lee, G., H. Ro, and S. Lee. 2006. "Electrokinetically Enhanced Transport of Organic and Inorganic Phosphorus in a Low Permeability Soil." Geosciences Journal 10(1):85-89.

Leeson, A. and R. Hinchee. 1996. Principles and Practices of Bioventing Volume I: Bioventing Principles. Air Force Center for Environmental Excellence, Brooks City-Base, Texas. Web Address: http://www.afcee.af.mil/shared/media/document/AFD-070926-074.pdf. 
Li, X. Q., D. W. Elliott, and W. X. Zhang. 2006. "Zero-Valent Iron Nanoparticles for Abatement of Environmental Pollutants: Materials and Engineering Aspects." Critical Reviews in Solid State and Materials Sciences 31(4):111-122.

Li, X. Z. and L. R. Krumholz. 2008. "Influence of Nitrate on Microbial Reduction of Pertechnetate." Environ. Sci. Technol. 42(6):1910-1915.

Li, Z. M., J. W. Yu, and I. Neretnieks. 1998. "Electroremediation: Removal of Heavy Metals from Soils by Using Cation Selective Membrane." Environ. Sci. Technol. 32(3):394-397.

Liang, L., B. Gu, and Y. Xiangping. 1996. "Removal of Technetium-99 from Contaminated Groundwater with Sorbents and Reductive Materials." Separations Technology 6:111-122.

Livens, F. R., M. J. Jones, A. J. Hynes, J. M. Charnock, J. F. W. Mosselmans, C. Hennig, H. Steele, D. Collison, D. J. Vaughan, R. A. D. Pattrick, W. A. Reed, and L. N. Moyes. 2004. "X-Ray Absorption Spectroscopy Studies of Reactions of Technetium, Uranium and Neptunium with Mackinawite." Journal of Environmental Radioactivity 74(1-3):211-219.

Lloyd, J. R. and L. E. Macaskie. 1997. "Microbially-Mediated Reduction and Removal of Technetium from Solution." Research in Microbiology 148(6):530-532.

Lloyd, J. R., J. Ridley, N. N. Khizniak, N. N. Lyalikova, and L. E. Macaskie. 1999. "Reduction of Technetium by Desulfovibrio Desulfuricans: Biocatalyst Characterization and Use in a Flowthrough Bioreactor." Appl. Environ. Microbiol. 65(6):2691-2696.

Lloyd, J. R., V. A. Sole, C. V. G. Van Praagh, and D. R. Lovley. 2000. "Direct and Fe(II)-Mediated Reduction of Technetium by Fe(III)-Reducing Bacteria." Appl. Environ. Microbiol. 66(9):3743-3749.

Lloyd, J. R. and J. C. Renshaw. 2005. "Bioremediation of Radioactive Waste: Radionuclide-Microbe Interactions in Laboratory and Field-Scale Studies." Current Opinion in Biotechnology 16(3):254-260.

Logue, B. A., R. W. Smith, and J. C. Westall. 2004. "Role of Surface Alteration in Determining the Mobility of U(VI) in the Presence of Citrate: Implications for Extraction of U(VI) from Soils." Environ. Sci. Technol. 38(13):3752-3759.

Looney, B. B. and R. W. Falta. 2000. Vadose Zone: Science and Technology Solutions. Battelle Press, Columbus Ohio.

Los Alamos National Laboratory. 2007. Environmental Surveillance at Los Alamos During 2006. LA14341-ENV, Los Alamos National Laboratory, Los Alamos, New Mexico.

Lovley, D. R. and E. J. P. Phillips. 1987. "Competitive Mechanisms for Inhibition of Sulfate Reduction and Methane Production in the Zone of Ferric Iron Reduction in Sediments." Appl. Environ. Microbiol. 53(11):2636-2641.

Lovley, D. R. 1991. "Dissimilatory Fe(III) and Mn(Iv) Reduction." Microbiological Reviews 55(2):259287.

Lovley, D. R. and E. J. P. Phillips. 1992. "Reduction of Uranium by Desulfovibrio-Desulfuricans." Appl. Environ. Microbiol. 58(3):850-856. 
Lovley, D. R. and E. J. P. Phillips. 1994. "Reduction of Chromate by Desulfovibrio-Vulgaris and Its C(3) Cytochrome." Appl. Environ. Microbiol. 60(2):726-728.

Lovley, D. R. 1994. Microbial Reduction of Iron, Manganese, and Other Metals. In Advances in Agronomy, Vol. 54. Ed. D. L. Sparks, pp. 175-231, Academic Press, New York.

Lovley, D. R. and F. H. Chapelle. 1995. "Deep Subsurface Microbial Processes." Reviews of Geophysics 33(3):365-381.

Ludwig, R., C. Su, F. Beck, P. Clark, S. Acree, R. Ross, and K. Jones. 2004. "In Situ Cr(VI) Treatment Using a Ferrous Iron-Based Reductant." In Proceedings of 4th International Conference on Remediation of Chlorinated and Recalcitrant Compounds.

Ludwig, R. D., C. M. Su, T. R. Lee, R. T. Wilkin, S. D. Acree, R. R. Ross, and A. Keeley. 2007. "In Situ Chemical Reduction of Cr(VI) in Groundwater Using a Combination of Ferrous Sulfate and Sodium Dithionite: A Field Investigation." Environ. Sci. Technol. 41(15):5299-5305.

Lukens, W. W., J. J. Bucher, D. K. Shuh, and N. M. Edelstein. 2005. "Evolution of Technetium Speciation in Reducing Grout." Environ. Sci. Technol. 39(20):8064-8070.

Macaskie, L. E., J. R. Lloyd, R. A. P. Thomas, and M. R. Tolley. 1996. "The Use of Micro-Organisms for the Remediation of Solutions Contaminated with Actinide Elements, Other Radionuclides, and Organic Contaminants Generated by Nuclear Fuel Cycle Activities." Nuclear Energy-Journal of the British Nuclear Energy Society 35(4):257-271.

MacNaughton, M. G. 1977. "Adsorption of Chromium(VI) at the Oxide-Water Interface." In Biological Implications of Metals in the Environment. Eds. H. Drucker and R. F. Wildung, pp. 244-253, National Technical Information Service, Springfield, Virginia.

Martinez, R. J., M. J. Beazley, M. Taillefert, A. K. Arakaki, J. Skolnick, and P. A. Sobecky. 2007. "Aerobic Uranium (VI) Bioprecipitation by Metal-Resistant Bacteria Isolated from Radionuclide- and Metal-Contaminated Subsurface Soils." Environmental Microbiology 9(12):3122-3133.

Mason, C. F. V., W. Turney, B. M. Thomson, N. Lu, P. A. Longmire, and C. J. ChisholmBrause. 1997. "Carbonate Leaching of Uranium from Contaminated Soils." Environ. Sci. Technol. 31(10):2707-2711.

Mattigod, S. V., R. J. Serne, and G. E. Fryxell. 2003. Selection and Testing of "Getters" for Adsorption of Iodine-129 and Technetium-99: A Review. PNNL-14208, Pacific Northwest National Laboratory, Richland Washington.

McBeth, J. M., G. Lear, J. R. Lloyd, F. R. Livens, K. Morris, and I. T. Burke. 2007. "Technetium Reduction and Reoxidation in Aquifer Sediments." Geomicrobiology Journal 24(3-4):189-197.

Melamed, R. and R. C. V. Boas. 1998. "Phosphate-Background Electrolyte Interaction Affecting the Transport of Mercury through a Brazilian Oxisol." Science of the Total Environment 213(1-3):151-156.

Melamed, R. and R. C. V. Boas. 2000. "Application of Physico-Chemical Amendments for the Counteraction of Mercury Pollution." Science of the Total Environment 261(1-3):203-209.

Miller, R. M. 1995. "Biosurfactant-Facilitated Remediation of Metal-Contaminated Soils." Environmental Health Perspectives 103:59-62. 
Mishchuk, N., B. Kornilovich, and R. Klishchenko. 2007. "pH Regulation as a Method of Intensification of Soil Electroremediation." Colloids and Surfaces a-Physicochemical and Engineering Aspects 306(13):171-179.

Mohamedelhassan, E. and J. Q. Shang. 2008. "Electrokinetic Cementation of Calcareous Sand for Offshore Foundations." International Journal of Offshore and Polar Engineering 18(1):73-80.

Moore, R. C., C. Sanchez, K. Holt, P. C. Zhang, H. F. Xu, and G. R. Choppin. 2004. "Formation of Hydroxyapatite in Soils Using Calcium Citrate and Sodium Phosphate for Control of Strontium Migration." Radiochimica Acta 92(9-11):719-723.

Morris, K., J. C. Butterworth, and F. R. Livens. 2000. "Evidence for the Remobilization of Sellafield Waste Radionuclides in an Intertidal Salt Marsh, West Cumbria, U.K." Estuarine, Coastal and Shelf Science 51:613-625.

Morris, K., F. R. Livens, J. M. Charnock, I. T. Burke, J. M. McBeth, J. D. C. Begg, C. Boothman, and J. R. Lloyd. 2008. "An X-Ray Absorption Study of the Fate of Technetium in Reduced and Reoxidised Sediments and Mineral Phases." Applied Geochemistry 23(4):603-617.

Morrison, S. 2003. "Performance Evaluation of a Permeable Reactive Barrier Using Reaction Products as Tracers." Environ. Sci. Technol. 37(10):2302-2309.

Morrison, S. J. and R. R. Spangler. 1992. "Extraction of Uranium and Molybdenum from AqueousSolutions - a Survey of Industrial Materials for Use in Chemical Barriers for Uranium Mill Tailings Remediation." Environ. Sci. Technol. 26(10):1922-1931.

Morrison, S. J., D. R. Metzler, and C. E. Carpenter. 2001. "Uranium Precipitation in a Permeable Reactive Barrier by Progressive Irreversible Dissolution of Zerovalent Iron." Environ. Sci. Technol. 35(2):385-390.

Morrison, S. J., D. R. Metzler, and B. P. Dwyer. 2002a. "Removal of as, Mn, Mo, Se, U, V and Zn from Groundwater by Zero-Valent Iron in a Passive Treatment Cell: Reaction Progress Modeling." Journal of Contaminant Hydrology 56(1-2):99-116.

Morrison, S. J., C. E. Carpenter, D. R. Metzler, T. R. Barlett, and S. A. Morris. 2002b. "Design and Performance of a Permeable Reactive Barrier for Containment of Uranium, Arsenic, Selenium, Vanadium, Molybdenum, and Nitrate at Monticello, Utah." In Handbook of Groundwater Remediation Using Permeable Reactive Barriers: Applications to Radionuclides, Trace Metals, and Nutrients. Eds. D. L. Naftz, S. J. Morrison, J. A. Davis, and C. C. Fuller, pp. 372-401, Elsevier Science, San Diego, California.

Morrison, S. J., P. S. Mushovic, and P. L. Niesen. 2006. "Early Breakthrough of Molybdenum and Uranium in a Permeable Reactive Barrier." Environ. Sci. Technol. 40(6):2018-2024.

Morse, M. K., B. R. Nowack, and L. E. Thompson. 2006. "Subsurface Planar Vitrification of Problematic Tru Wastes: Status of a Technology Demonstration Program." In Proceedings of $W M^{\prime} 06$, WMsymposia, Tucson, Arizona.

Mulligan, C. N., R. N. Yong, and B. F. Gibbs. 2001. "Remediation Technologies for MetalContaminated Soils and Groundwater: An Evaluation." Engineering Geology 60(1-4):193-207. 
Mulligan, C. N. and S. L. Wang. 2006. "Remediation of a Heavy Metal-Contaminated Soil by a Rhamnolipid Foam." Engineering Geology 85(1-2):75-81.

North, N. N., S. L. Dollhopf, L. Petrie, J. D. Istok, D. L. Balkwill, and J. E. Kostka. 2004. "Change in Bacterial Community Structure During in Situ Biostimulation of Subsurface Sediment Cocontaminated with Uranium and Nitrate." Appl. Environ. Microbiol. 70(8):4911-4920.

Oostrom, M., T. W. Wietsma, M. A. Covert, and V. R. Vermeul. 2007. "Zero-Valent Iron Emplacement in Permeable Porous Media Using Polymer Additions." Ground Water Monitoring and Remediation 27(1):122-130.

Ortiz-Bernad, I., R. T. Anderson, H. A. Vrionis, and D. R. Lovley. 2004. "Resistance of Solid-Phase U(VI) to Microbial Reduction During in Situ Bioremediation of Uranium-Contaminated Groundwater." Appl. Environ. Microbiol. 70(12):7558-7560.

Page, M. M. and C. L. Page. 2002. "Electroremediation of Contaminated Soils." Journal of Environmental Engineering-Asce 128(3):208-219.

Paillat, T., E. Moreau, P. O. Grimaud, and G. Touchard. 2000. "Electrokinetic Phenomena in Porous Media Applied to Soil Decontamination." IEEE Transactions on Dielectrics and Electrical Insulation 7(5):693-704.

Pamukcu, S., A. Weeks, and J. K. Wittle. 2004. "Enhanced Reduction of Cr(VI) by Direct Electric Current in a Contaminated Clay." Environ. Sci. Technol. 38(4):1236-1241.

Peretyazhko, T., J. M. Zachara, S. M. Heald, B. H. Jeon, R. K. Kukkadapu, C. Liu, D. Moore, and C. T. Resch. 2008. "Heterogeneous Reduction of Tc(VII) by Fe(II) at the Solid-Water Interface." Geochim. Cosmochim. Acta 72(6):1521-1539.

Perminova, I. V., A. N. Kovalenko, P. Schmitt-Kopplin, K. Hatfield, N. Hertkorn, E. Y. Belyaeva, and V. S. Petrosyan. 2005. "Design of Quinonoid-Enriched Humic Materials with Enhanced Redox Properties." Environ. Sci. Technol. 39(21):8518-8524.

Petersen, S. W. and K. A. Hedquist. 2006. Treatability Test Report for Calcium Polysulfide in the 100-K Area. DOE/RL-2006-17 Rev 0, U.S. Department of Energy, Richland Washington.

Phillips, D. H., D. B. Watson, and Y. Roh. 2007. "Uranium Deposition in a Weathered Fractured Saprolite/Shale." Environ. Sci. Technol. 41(22):7653-7660.

Porter, S. K., K. G. Scheckel, C. A. Impellitteri, and J. A. Ryan. 2004. "Toxic Metals in the Environment: Thermodynamic Considerations for Possible Immobilization Strategies for $\mathrm{Pb}, \mathrm{Cd}, \mathrm{As}$, and Hg." Critical Reviews in Environmental Science and Technology 34(6):495-604.

Powell, R. M., R. W. Puls, S. K. Hightower, and D. A. Sabatini. 1995. "Coupled Iron Corrosion and Chromate Reduction - Mechanisms for Subsurface Remediation." Environ. Sci. Technol. 29(8):19131922.

Pratt, A. R., D. W. Blowes, and C. J. Ptacek. 1997. "Products of Chromate Reduction on Proposed Subsurface Remediation Material." Environ. Sci. Technol. 31(9):2492-2498. 
Puppala, S. K., A. N. Alshawabkeh, Y. B. Acar, R. J. Gale, and M. Bricka. 1997. "Enhanced Electrokinetic Remediation of High Sorption Capacity Soil." Journal of Hazardous Materials 55(13):203-220.

Quinn, J., C. Geiger, C. Clausen, K. Brooks, S. C. Coon, S. O'Hara, T. Krug, D. Major, W. S. Yoon, A. Gavaskar, and T. Holdsworth. 2005. "Field Demonstration of DNAPL Dehalogenation Using Emulsified Zero-Valent Iron." Environ. Sci. Technol. 39(5):1309-1318.

Rai, D., J. M. Zachara, A. P. Schwab, R. L. Schmidt, D. C. Girvin, and J. E. Rogers. 1984. Chemical Attenuation Rates, Coefficients, and Constants in Leachate Migration. Volume 1: A Critical Review. EPRI-EA-3356, Electric Power Research Institute, Palo Alto, California.

Rai, D., L. E. Eary, and J. M. Zachara. 1989. "Environmental Chemistry of Chromium." Science of the Total Environment 86(1-2):15-23.

Raicevic, S., J. V. Wright, V. Veljkovic, and J. L. Conca. 2006. "Theoretical Stability Assessment of Uranyl Phosphates and Apatites: Selection of Amendments for in Situ Remediation of Uranium." Science of the Total Environment 355(1-3):13-24.

Randall, P. and S. Chattopadhyay. 2004. "Advances in Encapsulation Technologies for the Management of Mercury-Contaminated Hazardous Wastes." Journal of Hazardous Materials 114(1-3):211-223.

Read, D., T. A. Lawless, R. J. Sims, and K. R. Butter. 1993. "Uranium Migration through Intact Sandstone Cores." Journal of Contaminant Hydrology 13(1-4):277-289.

Reddy, K. R., U. S. Parupudi, S. N. Devulapalli, and C. Y. Xu. 1997. "Effects of Soil Composition on the Removal of Chromium by Electrokinetics." Journal of Hazardous Materials 55(1-3):135-158.

Reddy, K. R., C. Chaparro, and R. E. Saichek. 2003a. "Iodide-Enhanced Electrokinetic Remediation of Mercury-Contaminated Soils." Journal of Environmental Engineering-Asce 129(12):1137-1148.

Reddy, K. R., S. Chinthamreddy, R. E. Saichek, and T. J. Cutright. 2003b. "Nutrient Amendment for the Bioremediation of a Chromium-Contaminated Soil by Electrokinetics." Energy Sources 25(9):931-943.

Reddy, K. R., C. Chaparro, and R. E. Saichek. 2003c. "Removal of Mercury from Clayey Soils Using Electrokinetics." Journal of Environmental Science and Health Part a-Toxic/Hazardous Substances \& Environmental Engineering 38(2):307-338.

Reddy, K. R. and P. R. Ala. 2005. "Electrokinetic Remediation of Metal-Contaminated Field Soil." Separation Science and Technology 40(8):1701-1720.

Reeder, R. J., M. Nugent, G. M. Lamble, C. D. Tait, and D. E. Morris. 2000. "Uranyl Incorporation into Calcite and Aragonite: XAFS and Luminescence Studies." Environ. Sci. Technol. 34(4):638-644.

Reeder, R. J., M. Nugent, C. D. Tait, D. E. Morris, S. M. Heald, K. M. Beck, W. P. Hess, and A. Lanzirotti. 2001. "Coprecipitation of Uranium(VI) with Calcite: XAFS, Micro-XAS and Luminescence Characterization." Geochim. Cosmochim. Acta 65(20):3491-3503.

Reeder, R. J., E. J. Elzinga, C. D. Tait, K. D. Rector, R. J. Donohoe, and D. E. Morris. 2004. "SiteSpecific Incorporation of Uranyl Carbonate Species at the Calcite Surface." Geochim. Cosmochim. Acta 68(23):4799-4808. 
Riley, R. G. and J. M. Zachara. 1992. Chemical Contaminants on DOE Lands and Selection of Contaminant Mixtures for Subsurface Science Research. DOE/ER-0547T, U.S. Department of Energy, Office of Energy Research, Washington, D.C.

Roden, E. E. and J. M. Zachara. 1996. "Microbial Reduction of Crystalline Iron(III) Oxides: Influence of Oxide Surface Area and Potential for Cell Growth." Environ. Sci. Technol. 30(5):1618-1628.

Rouse, J. V., I. N. Davies, J. Hutton, and A. DeSanis. 2001. "In-Situ Hexavalent Chromium Reduction and Geochemical Fixation in Varied Geohydrological Regimes." In Proceedings of First International Conference on Oxidation and Reduction Technologies for In-Situ Treatment of Soil and Groundwater. Niagara Falls, Ontario.

Rufyikiri, G., J. Wannijn, L. Wang, and Y. Thiry. 2006. "Effects of Phosphorus Fertilization on the Availability and Uptake of Uranium and Nutrients by Plants Grown on Soil Derived from Uranium Mining Debris." Environmental Pollution 141(3):420-427.

Sanjay, K., A. Arora, R. Shekhar, and R. P. Das. 2003. "Electroremediation of Cr(VI) Contaminated Soils: Kinetics and Energy Efficiency." Colloids and Surfaces a-Physicochemical and Engineering Aspects 222(1-3):253-259.

Sato, T., T. Murakami, N. Yanase, H. Isobe, T. E. Payne, and P. L. Airey. 1997. "Iron Nodules Scavenging Uranium from Groundwater." Environ. Sci. Technol. 31(10):2854-2858.

Sawada, A., K. Mori, S. Tanaka, M. Fukushima, and K. Tatsumi. 2004. "Removal of Cr(VI) from Contaminated Soil by Electrokinetic Remediation." Waste Management 24(5):483-490.

Schrick, B., B. W. Hydutsky, J. L. Blough, and T. E. Mallouk. 2004. "Delivery Vehicles for Zerovalent Metal Nanoparticles in Soil and Groundwater." Chemistry of Materials 16(11):2187-2193.

Schwartz, D. T., M. F. Buehler, D. X. Christiansen, and E. J. Davis. 1997. "In-Situ Monitoring of Electrochemical Transport Processes in Hanford Grout Vault Soil." Journal of Hazardous Materials 55(1-3):23-37.

Seaman, J. C., B. B. Looney, and M. K. Harris. 2007. "Research in Support of Remediation Activities at the Savannah River Site." Vadose Zone J. 6(2):316-326.

Senko, J. M., J. D. Istok, J. M. Suflita, and L. R. Krumholz. 2002. "In-Situ Evidence for Uranium Immobilization and Remobilization." Environ. Sci. Technol. 36(7):1491-1496.

Serkiz, S. M., W. H. Johnson, L. M. J. Wile, and S. B. Clark. 2007. "Environmental Availability of Uranium in an Acidic Plume at the Savannah River Site." Vadose Zone J. 6(2):354-362.

Serne, R. J., B. N. Bjornstad, H. T. Schaef, B. A. Williams, D. C. Lanigan, D. G. Horton, R. E. Clayton, A. V. Mitroshkov, V. L. LeGore, M. J. O'Hara, C. F. Brown, K. E. Parker, I. V. Kutnyakov, J. N. Serne, G. V. Last, S. C. Smith, C. W. Lindenmeier, J. M. Zachara, and D. B. Burke. 2002. Characterization of Vadose Zone Sediment: Uncontaminated RCRA Borehole Core Samples and Composite Samples. PNNL-13757-1, Pacific Northwest National Laboratory, Richland Washington.

Shanbhag, P. M. and G. R. Choppin. 1981. "Binding of Uranyl by Humic-Acid." Journal of Inorganic \& Nuclear Chemistry 43(12):3369-3372. 
Shrestha, R., R. Fischer, and W. Sillanpaa. 2007. "Investigations on Different Positions of Electrodes and Their Effects on the Distribution of $\mathrm{Cr}$ at the Water Sediment Interface." International Journal of Environmental Science and Technology 4(4):413-420.

Simon, F. G., V. Biermann, C. Segebade, and M. Hedrich. 2004. "Behaviour of Uranium in Hydroxyapatite-Bearing Permeable Reactive Barriers: Investigation Using U-237 as a Radioindicator." Science of the Total Environment 326(1-3):249-256.

Singh, D., V. R. Mandalika, S. J. Parulekar, and A. S. Wagh. 2006. "Magnesium Potassium Phosphate Ceramic for Tc-99 Immobilization." Journal of Nuclear Materials 348(3):272-282.

Sivapullaiah, P. V. and B. S. N. Prakashb. 2007. "Electroosmotic Flow Behaviour of Metal Contaminated Expansive Soil." Journal of Hazardous Materials 143(3):682-689.

Soil Science Society of America. 1981. Water Potential Relations in Soil Microbiology. Special Publication 9, Soil Science Society of America, Madison, Wisconsin.

Spahiu, K., J. Devoy, D. Q. Cui, and M. Lundstrom. 2004. "The Reduction of U(VI) by near Field Hydrogen in the Presence of $\mathrm{UO}_{2}(\mathrm{~S})$." Radiochimica Acta 92(9-11):597-601.

Spalding, B. P. 2001. "Fixation of Radionuclides in Soil and Minerals by Heating." Environ. Sci. Technol. 35(21):4327-4333.

Storch, P., A. Messer, M. Barone, and R. Pyrih. 2004. "In Situ Geochemical Fixation of Cr(VI) in Soil Using Calcium Polysulfide." In Proceedings of 4th International Conference on Remediation of Chlorinated and Recalcitrant Compounds, Monterey, California.

Stubbs, J. E., D. C. Elbert, D. R. Veblen, and C. Zhu. 2006. "Electron Microbeam Investigation of Uranium-Contaminated Soils from Oak Ridge, TN, USA." Environ. Sci. Technol. 40(7):2108-2113.

Stumm, W. and J. J. Morgan. 1996. Aquatic Chemistry. Wiley Interscience, New York.

Sturges, S. G., P. McBeth, and R. C. Pratt. 1991. "Performance of Soil Flushing and Groundwater Extraction at the United Chrome Superfund Site." Journal of Hazardous Materials 29(1):59-78.

Su, C. M. and R. D. Ludwig. 2005. "Treatment of Hexavalent Chromium in Chromite Ore Processing Solid Waste Using a Mixed Reductant Solution of Ferrous Sulfate and Sodium Dithionite." Environ. Sci. Technol. 39(16):6208-6216.

Suer, P. and B. Allard. 2003. "Mercury Transport and Speciation During Electrokinetic Soil Remediation." Water Air and Soil Pollution 143(1-4):99-109.

Suer, P. and T. Lifvergren. 2003. "Mercury-Contaminated Soil Remediation by Iodide and Electroreclamation." Journal of Environmental Engineering-Asce 129(5):441-446.

Sun, Y.-P. 2006. Dispersion of Nanoscale Iron Particles, Lehigh University, Bethlehem, Pennsylvania.

Svab, M., M. Zilka, M. Mullerova, V. Koci, and V. Muller. 2008. "Semi-Empirical Approach to Modeling of Soil Flushing: Model Development, Application to Soil Polluted by Zinc and Copper." Science of the Total Environment 392(2-3):187-197. 
Szecsody, J. E., K. M. Krupka, M. D. Williams, K. J. Cantrell, C. T. Resch, and J. S. Fruchter. 1998. Uranium Mobility During in Situ Redox Manipulation of the 100 Areas of the Hanford Site. PNNL12048, Pacific Northwest National Laboratory, Richland, Washington.

Szecsody, J. E., J. S. Fruchter, J. L. Phillips, M. L. Rockhold, V. R. Vermeul, B. J. Devary, and Y. Liu. 2005. Influence of Nitrate on the Hanford 100d Area in Situ Redox Manipulation Barrier Longevity. PNNL-15262, Pacific Northwest National Laboratory, Richland, Washington.

Tang, Y., E. J. Elzinga, Y. Jae Lee, and R. J. Reeder. 2007. "Coprecipitation of Chromate with Calcite: Batch Experiments and X-Ray Absorption Spectroscopy." Geochim. Cosmochim. Acta 71(6):1480-1493.

Thornton, E. C., J. T. Giblin, T. J. Gilmore, K. B. Olsen, J. M. Phelan, and R. D. Miller. 1999. In Situ Gaseous Reduction Pilot Demonstration - Final Report. PNNL-12121, Pacific Northwest National Laboratory, Richland, Washington.

Thornton, E. C., T. J. Gilmore, K. B. Olsen, J. T. Giblin, and J. M. Phelan. 2007a. "Treatment of a Chromate-Contaminated Soil Site by in Situ Gaseous Reduction." Ground Water Monitoring \& Remediation 27(1):56-64.

Thornton, E. C., L. Zhong, M. Oostrom, and B. Deng. 2007b. "Experimental and Theoretical Assessment of the Lifetime of a Gaseous-Reduced Vadose Zone Permeable Reactive Barrier." Vadose Zone J. 6(4):1050-1056.

Truex, M. J., V. R. Vermeul, P. E. Long, F. J. Brockman, M. Oostrom, S. Hubbard, R. C. Borden, and J. S. Fruchter. 2007. Treatability Test Plan for an in Situ Biostimulation Reducing Barrier. PNNL-16424, Pacific Northwest National Laboratory, Richland, Washington.

Truex, M. J., V. R. Vermeul, R. D. Mackley, B. G. Fritz, D. P. Mendoza, C. D. Johnson, R. P. Elmore, F. J. Brockman, and C. L. Bilskis. 2008. Interim Data Summary for the Substrate Injection and Process Monitoring Phases of the Field Test. PNNL-17619, Pacific Northwest National Laboratory, Richland, Washington.

U.S. Department of Energy. 1998. Comprehensive Remedial Investigation and Feasibility Study Supplement for the Test Area Norlh Operable Unit 1-1 0 at the Ldaho National Engineering and Environmental Laboratory. DOE/ID-10557,SUPPLEMENT Rev. 00, U.S. Department of Energy, Idaho Falls, Idaho.

U.S. Department of Energy. 2004. Evaluation of Amendments for Mending the ISRM Barrier. Final Technical Solutions Report. U.S. Department of Energy, Richland, Washington.

U.S. Department of Energy. 2007. Fiscal Year 2006 Annual Summary Report for the in Situ Redox Manipulation Operations. DOE/RL-2007-19 Rev 0, U.S. Department of Energy, Richland, Washington.

U.S. Department of Energy. 2008. Deep Vadose Zone Treatability Test Plan for the Hanford Central Plateau. DOE/RL-2007-56 Rev 0, U.S. Department of Energy, Richland, Washington.

U.S. Environmental Protection Agency. 1993. Handbook: Approaches for the Remediation of Federal Facilities Sites Contaminated with Explosive or Radioactive Wastes. EPA/625/R-93/013, U.S. Environmental Protection Agency, Office of Research and Development, Cincinnati, Ohio. 
U.S. Environmental Protection Agency. 1995. Abstracts of Remediation Case Studies. EPA-542-R-95001, U.S. Environmental Protection Agency.

U.S. Environmental Protection Agency. 1997a. Technology Alternatives for the Remediation of Soils Contaminated with as, $\mathrm{Cd}, \mathrm{Cr}, \mathrm{Hg}$, and $\mathrm{Pb}$. EPA/540/S-97/500, U.S. Environmental Protection Agency, Cincinnati, Ohio.

U.S. Environmental Protection Agency. 1997b. Electrokinetic Laboratory and Field Processes Applicable to Radioactive and Hazardous Mixed Waste in Soil and Groundwater. EPA/402/R-97/006, U.S. Environmental Protection Agency, Office of Research and Development, Washington D.C.

U.S. Environmental Protection Agency. 1999. Sandia National Laboratories in Situ Electrokinetic Extraction Technology. EPA/6540/R-97/509, U.S. Environmental Protection Agency, Office of Research and Development, Cincinnati, Ohio.

U.S. Environmental Protection Agency. 2000a. In Situ Bioremediation by Electrokinetic Injection. EPA/540/SR-00/503, U.S. Environmental Protection Agency, Office of Research and Development, Cincinnati, Ohio.

U.S. Environmental Protection Agency. 2000b. In Situ Treatment of Soil and Groundwater Contaminated with Chromium. EPA/625/R-00/005, U.S. Environmental Protection Agency, Office of Research and Development, Cincinnati, Ohio.

U.S. Environmental Protection Agency. 2000c. Engineered Approaches to in Situ Bioremediation of Chlorinated Solvents: Fundamentals and Field Applications. EPA-542-R-00-008, U.S. Environmental Protection Agency, Washington D.C.

U.S. Environmental Protection Agency. 2007. Treatment Technologies for Mercury in Soil, Waste, and Water. EPA-542-R-07-003, U.S. Environmental Protection Agency, Washington D.C.

U.S. Environmental Protection Agency. 1999. Understanding Variation in Partition Coefficient, $K_{d}$, Values: Volume II. Review of Geochemistry and Available $K_{d}$ Values for Cadmium, Cesium, Chromium, Lead, Plutonium, Radon, Strontium, Thorium, Tritium ( 3 H), and Uranium. EPA 402-R-99-004B, U.S. Environmental Protection Agency, Washington, D.C.

U.S. Environmental Protection Agency. 2004. Understanding Variation in Partition Coefficient, $K_{d}$, Values: Volume III. Review of Geochemistry and Available $K_{d}$ Values for Americium, Arsenic, Curium, Iodine, Neptunium, Radium, and Technetium. EPA 402-R-04-002C, U.S. Environmental Protection Agency, Washington, D.C.

Ugaz, A., S. Puppala, R. J. Gale, and Y. B. Acar. 1994. "Electrokinetic Soil Processing - Complicating Features of Electrokinetic Remediation of Soils and Slurries - Saturation Effects and the Role of the Cathode Electrolysis." Chemical Engineering Communications 129:183-200.

Um, W., R. J. Serne, and K. M. Krupka. 2007. "Surface Complexation Modeling of U(VI) Sorption to Hanford Sediment with Varying Geochemical Conditions." Environ. Sci. Technol. 41(10):3587-3592.

Vangronsveld, J. and S. D. Cunningham. 1998. Metal-Contaminated Soils. Springer-Verlag, Berlin, Germany. 
Vermeul, V. R., M. D. Williams, J. E. Szecsody, J. S. Fruchter, C. R. Cole, and J. E. Amonette. 2002. "Creation of a Subsurface Permeable Reactive Barrier Using in Situ Redox Manipulation." In Groundwater Remediation of Metals, Radionuclides, and Nutrients with Permeable Reactive Barriers. Academic Press, San Diego, California.

Vermeul, V. R., M. D. Williams, B. G. Fritz, R. D. Mackley, D. P. Mendoza, D. R. Newcomer, M. L. Rockhold, B. A. Williams, and D. M. Wellman. 2007. Treatability Test Plan for 300 Area Uranium Stabilization through Polyphosphate Injection. PNNL-16571, Pacific Northwest National Laboratory, Richland, Washington.

Virkutyte, J., M. Sillanpaa, and P. Latostenmaa. 2002. "Electrokinetic Soil Remediation - Critical Overview." Science of the Total Environment 289(1-3):97-121.

Vrionis, H. A., R. T. Anderson, I. Ortiz-Bernad, K. R. O'Neill, C. T. Resch, A. D. Peacock, R. Dayvault, D. C. White, P. E. Long, and D. R. Lovley. 2005. "Microbiological and Geochemical Heterogeneity in an in Situ Uranium Bioremediation Field Site." Appl. Environ. Microbiol. 71(10):6308-6318.

Wagh, A. S., D. Singh, and S. Y. Jeong. 2000. "Mercury Stabilization in Chemically Bonded Phosphate Ceramics." Workshop on Mercury Products, Processes, Waste, and the Environment: Eliminating, Reducing and Managing Risks, Baltimore, Maryland, March 2000. Argonne National Laboratory, City, State.

Waite, T. D., J. A. Davis, T. E. Payne, G. A. Waychunas, and N. Xu. 1994. "Uranium(VI) Adsorption to Ferrihydrite: Application of a Surface Complexation Model." Geochim. Cosmochim. Acta 58:54655478.

Wall, J. D. and L. R. Krumholz. 2006. "Uranium Reduction." Annual Review of Microbiology 60(1):149-166.

Wang, S. L. and C. N. Mulligan. 2004. "Rhamnolipid Foam Enhanced Remediation of Cadmium and Nickel Contaminated Soil." Water Air and Soil Pollution 157(1-4):315-330.

Wang, Z. M., J. M. Zachara, P. L. Gassman, C. X. Liu, O. Qafoku, W. Yantasee, and J. G. Catalan. 2005a. "Fluorescence Spectroscopy of U(VI)-Silicates and U(VI)-Contaminated Hanford Sediment." Geochim. Cosmochim. Acta 69(6):1391-1403.

Wang, Z. M., J. M. Zachara, J. P. McKinley, and S. C. Smith. 2005b. "Cryogenic Laser Induced U(VI) Fluorescence Studies of a U(VI) Substituted Natural Calcite: Implications to U(VI) Speciation in Contaminated Hanford Sediments." Environ. Sci. Technol. 39(8):2651-2659.

Ward, A. L., S. O. Link, C. E. Strickland, K. E. Draper, and R. E. Clayton. 2008. 200-Bp-1 Prototype Hanford Barrier Annual Monitoring Report for Fiscal Years 2005 through 2007. PNNL-17176, Pacific Northwest National Laboratory, Richland, Washington.

Wasay, S. A., S. Barrington, and S. Tokunaga. 2001. "Organic Acids for the in Situ Remediation of Soils Polluted by Heavy Metals: Soil Flushing in Columns." Water Air and Soil Pollution 127(1-4):301314.

Waychunas, G. A., C. S. Kim, and J. F. Banfield. 2005. "Nanoparticulate Iron Oxide Minerals in Soils and Sediments: Unique Properties and Contaminant Scavenging Mechanisms." Journal of Nanoparticle Research 7(4-5):409-433. 
Weisener, C. G., K. S. Sale, D. J. A. Smyth, and D. W. Blowes. 2005. "Field Column Study Using Zerovalent Iron for Mercury Removal from Contaminated Groundwater." Environ. Sci. Technol. 39(16):6306-6312.

Wellman, D. M., S. V. Mattigod, K. E. Parker, S. M. Heald, C. M. Wang, and G. E. Fryxell. 2006. "Synthesis of Organically Templated Nanoporous Tin(II/Iv) Phosphate for Radionuclide and Metal Sequestration." Inorganic Chemistry 45(6):2382-2384.

Wellman, D. M., E. M. Pierce, and M. M. Valenta. 2007. "Efficacy of Soluble Sodium Tripolyphosphate Amendments for the in-Situ Immobilisation of Uranium." Environmental Chemistry 4(5):293-300.

Wellman, D. M., J. N. Glovack, K. Parker, E. L. Richards, and E. M. Pierce. 2008. "Sequestration and Retention of Uranium(VI) in the Presence of Hydroxylapatite under Dynamic Geochemical Conditions." Environmental Chemistry 5(1):40-50.

Weng, C. H., Y. T. Lin, T. Y. Lin, and C. M. Kao. 2007. "Enhancement of Electrokinetic Remediation of Hyper-Cr(VI) Contaminated Clay by Zero-Valent Iron." Journal of Hazardous Materials 149(2):292302.

Widdel, F. 1988. "Microbiology and Ecology of Sulfate- and Sulfur-Reducing Bacteria." In Biology of Anaerobic Microorganisms. Ed. A. J. B. Zehnder, pp. 469-586, John Wiley and Sons, Inc, New York.

Wieczorek, S., H. Weigand, M. Schmid, and C. Marb. 2005. "Electrokinetic Remediation of an Electroplating Site: Design and Scale-up for an in-Situ Application in the Unsaturated Zone." Engineering Geology 77(3-4):203-215.

Wildung, R. E., S. W. Li, C. J. Murray, K. M. Krupka, Y. Xie, N. J. Hess, and E. E. Roden. 2004. "Technetium Reduction in Sediments of a Shallow Aquifer Exhibiting Dissimilatory Iron Reduction Potential." Fems Microbiology Ecology 49(1):151-162.

Williams, M. D., B. G. Fritz, D. P. Mendoza, M. L. Rockhold, P. D. Thorne, Y. L. Xie, B. N. Bjornstad, R. D. Mackley, J. E. Szecsody, and V. R. Vermeul. 2008. 100-NR-2 Apatite Treatability Test: Low Concentration Calcium Citrate-Phosphate Solution Injection for in Situ Strontium-90 Immobilization. PNNL-17429, Pacific Northwest National Laboratory, Richland, Washington.

Wilson, D. J. 1996. "Electrokinetic Remediation III. Enhancement with Base." Separation Science and Technology 31(4):435-451.

Wittreich, C. D. 2007. Central Plateau Vadose Zone Remediation Screening Technology Evaluation. RPP-ENV-34028 Rev 0, CH2M-Hill Hanford Group, Inc., Richland, Washington.

Wong, J. S. H., R. E. Hicks, and R. F. Probstein. 1997. "EDTA-Enhanced Electroremediation of MetalContaminated Soils." Journal of Hazardous Materials 55(1-3):61-79.

Xanthopoulou, G. and G. Vekinis. 2001. "An Overview of Some Environmental Applications of SelfPropagating High-Temperature Synthesis." Advances in Environmental Research 5(2):117-128.

Yeung, A. T., C. Hsu, and R. M. Menon. 1997. "Physicochemical Soil-Contaminant Interactions During Electrokinetic Extraction." Journal of Hazardous Materials 55(1-3):221-237. 
Yong, R. N. and C. N. Mulligan. 2004. Natural Attenuation of Contaminants in Soils. Lewis Publishers, Boca Raton, Florida.

Zachara, J. M., C. C. Ainsworth, G. E. Brown, J. G. Catalano, J. P. McKinley, O. Qafoku, S. C. Smith, J. E. Szecsody, S. J. Traina, and J. A. Warner. 2004. "Chromium Speciation and Mobility in a High Level Nuclear Waste Vadose Zone Plume." Geochim. Cosmochim. Acta 68(1):13-30.

Zachara, J. M., S. M. Heald, B.-H. Jeon, R. K. Kukkadapu, C. Liu, J. P. McKinley, A. C. Dohnalkova, and D. A. Moore. 2007. "Reduction of Pertechnetate [Tc(VII)] by Aqueous Fe(II) and the Nature of Solid Phase Redox Products." Geochim. Cosmochim. Acta 71(9):2137-2157.

Zawislanski, P. T., J. J. Beatty, and W. L. Carson. 2002. "In Situ Treatment of Low pH and Metals in Groundwater Using Calcium Polysulfide." In Proceedings of Second International Conference on Oxidation and Reduction Technologies for In-Situ Treatment of Soil and Groundwater, Toronto, Ontario

Zhang, C. L., K. T. Valsaraj, W. D. Constant, and D. Roy. 1998. "Surfactant Screening for Soil Washing: Comparison of Foamability and Biodegradability of a Plant-Based Surfactant with Commercial Surfactants." Journal of Environmental Science and Health Part a-Toxic/Hazardous Substances \& Environmental Engineering 33(7):1249-1273.

Zhong, L., E. C. Thornton, and B. Deng. 2007. "Uranium Immobilization by Hydrogen Sulfide Gaseous Treatment under Vadose Zone Conditions." Vadose Zone J. 6:149-157. 



\section{Appendix A}

\section{Technology Information Sources}





\section{Appendix A}

\section{Technology Information Sources A}

Technology information appropriate for referencing within the Comprehensive Environmental Response, Compensation, and Liability Act of 1980 (CERCLA) process (e.g., a feasibility study) is available through several types of sources. These information sources include the following items in addition to general journal and internet searches.

- Federal Remediation Technologies Roundtable. 2005. "Remediation Technologies-Screening Matrix and Reference Guide, Version 4.0.” (Accessed at http://www.frtr.gov/matrix2/top_page.html)

- U.S. Environmental Protection Agency (EPA) technology information (www.epa.com, http://www.clu-in.org/, http://www.epa.gov/tio/)

- Interstate Technology Regulatory Council information (www.itrcweb.org)

- Air Force Center for Engineering and the Environment, in particular the Technology Transfer information (http://www.afcee.af.mil/)

- U.S. Army Corps of Engineers (USACE) technology publications (http://www.usace.army.mil/)

- "Technological Approaches to the Cleanup of Radiologically Contaminated Superfund Sites" (EPA 1990, EPA/540/2-88/002).

- "Assessment of Technologies for the Remediation of Radioactively Contaminated Superfund Sites" (EPA 1993, EPA/540/2-90/001).

- "Superfund Innovative Technology Evaluation (SITE), 6th Edition” (EPA 1993, EPA/540/R-93/525).

- U.S. Environmental Protection Agency (EPA). 1997. Best Management Practices (BMPs) for Soil Treatment Technologies - Suggested Operational Guidelines to Prevent Cross-Media Transfer of Contaminants During Cleanup Activities. EPA 530-R-97-007, U.S. Environmental Protection Agency, Office of Solid Waste, Washington, D.C.

- U.S. Environmental Protection Agency (EPA). 1998. Evaluation of Subsurface Engineered Barriers at Waste Sites. EPA 542-R-98-005, U.S. Environmental Protection Agency, Office of Solid Waste and Emergency Response, Washington, D.C.

- Early, T., B. Borden, M. Heitkamp, B. Looney, D. Major, J. Waugh, G. Wein, T. Wiedemeier, K. Vangelas, K. Adams, C. Sink. 2006. "Enhanced Attenuation: Approaches to Increase the Natural Treatment Capacity of a System." WSRC-TR-2005-00198, Rev. 0, Westinghouse Savannah River Company, Aiken, South Carolina, January, 2006. (Available at http://www.mnaeacvocs.com.)

- Hanford technology reports that compile information about vadose zone technologies are listed below.

- DOE. 1999. 200 Areas Remedial Investigation/Feasibility Study Implementation PlanEnvironmental Restoration Program. DOE/RL-98-28, Rev. 0, U.S. Department of Energy, Richland Operations Office, Richland, Washington. 
- U.S. Department of Energy (DOE). 1996. Focused Feasibility Study of Engineered Barriers for Waste Management Units in the 200 Areas. DOE/RL-93-33, Draft B, U.S. Department of Energy, Richland, Washington.

- DOE. 2007. Feasibility Study for the Plutonium/Organic-Rich Process Condensate/Process Waste Group Operable Unit: Includes the 200-PW-1, 200-PW-3, And 200-PW-6 Operable Units. DOE/RL-2007-27 Draft A, U.S. Department of Energy, Richland Operations Office, Richland, Washington.

- FHI. 2006. Evaluation of Vadose Zone Treatment Technologies to Immobilize Technetium-99. WMP-27397, Rev. 1, Fluor Hanford, Inc., Richland, Washington.

- CHG. 2007. Central Plateau Vadose Zone Remediation Technology Screening Evaluation. CH2M HILL Hanford Group, Richland, Washington.

- U.S. Department of Energy. 2008. "Deep Vadose Zone Treatability Test Plan for the Hanford Central Plateau." DOE/RL-2007-56, Revision 0, U.S. DOE Richland Office, Richland, Washington.

- Truex, M.J., C.D. Johnson, and M.J. Nimmons. 2007. "Technology Survey to Support Revision to the Remedial Investigation/Feasibility Study Work Plan for the 200-SW-2 Operable Unit at the US DOE Hanford Site.” PNNL-16105, Pacific Northwest National Laboratory, Richland, Washington.

As guidance, Table A-1 shows a compilation of potentially appropriate general response actions, technology types, and remediation technologies to consider as a starting point for determining overall vadose zone remediation technology options. The technology listing for a specific site should be tailored to the specific site characteristics, stage within the CERCLA process, and remedial action objectives. Note that the remediation technologies listed in Table A-1 are, in many cases, classes of remediation technologies with multiple technology process options within each class.

Table A.1. General Response Actions, Technology Types, and Remediation Technologies Potentially Applicable to Vadose Zone Remediation

\begin{tabular}{lllc}
\hline $\begin{array}{c}\text { General Response } \\
\text { Action }\end{array}$ & \multicolumn{1}{c}{ Technology Type } & \multicolumn{1}{c}{ Remediation Technology } & Contaminants Treated \\
\hline No Action & No Action & No Action & NA \\
\hline Institutional Controls & Land Use Restrictions & Deed Restrictions & NA \\
& Access Controls & Signs and/or Fences & NA \\
& & Entry Control & NA \\
& Monitoring & Monitoring & NA \\
\hline Containment & Surface Barriers & Arid Climate Engineered Cap & I, M, R, O \\
& & Asphalt, Concrete, or Cement Type Cap & I, M, R, O \\
& & RCRA $^{(\mathrm{a}) \text { Roodle Cap }}$ & I, M, R, O \\
\hline
\end{tabular}


Table A.1. (contd)

\begin{tabular}{|c|c|c|c|}
\hline $\begin{array}{l}\text { General Response } \\
\text { Action }\end{array}$ & Technology Type & Remediation Technology & Contaminants Treated \\
\hline \multirow[t]{5}{*}{ Containment (contd) } & \multirow[t]{4}{*}{ Subsurface Barriers } & Slurry Walls & $\mathrm{I}, \mathrm{M}, \mathrm{R}, \mathrm{O}$ \\
\hline & & Grout Curtains & $\mathrm{I}, \mathrm{M}, \mathrm{R}, \mathrm{O}$ \\
\hline & & Cryogenic Walls & $\mathrm{I}, \mathrm{M}, \mathrm{R}, \mathrm{O}$ \\
\hline & & Sheet Pile & $\mathrm{I}, \mathrm{M}, \mathrm{R}, \mathrm{O}$ \\
\hline & Soil Stabilization & Membranes/Sealants/Wind Breaks/Wetting Agents & $\mathrm{I}, \mathrm{M}, \mathrm{R}, \mathrm{O}$ \\
\hline \multirow[t]{4}{*}{ Removal } & \multirow[t]{4}{*}{ Excavation } & Conventional & I, M, R, O, T \\
\hline & & Remote Processes & $\mathrm{I}, \mathrm{M}, \mathrm{R}, \mathrm{O}, \mathrm{T}$ \\
\hline & & Stabilization and Retrieval & $\mathrm{I}, \mathrm{M}, \mathrm{R}, \mathrm{O}, \mathrm{T}$ \\
\hline & & Soil Vacuum & $\mathrm{I}, \mathrm{M}, \mathrm{R}, \mathrm{O}$ \\
\hline \multirow[t]{2}{*}{ Disposal } & \multirow[t]{2}{*}{ Landfill Disposal } & Onsite Landfill & $\mathrm{I}, \mathrm{M}, \mathrm{R}, \mathrm{O}$ \\
\hline & & Offsite Landfill and/or Repository & $\begin{array}{c}\text { I, M, O, } \\
\text { R (mixed with T), T }\end{array}$ \\
\hline \multirow{21}{*}{$\begin{array}{l}\text { Ex Situ Treatment } \\
\text { (assumes excavation) }\end{array}$} & \multirow[t]{7}{*}{ Thermal Treatment } & Calcination & $\mathrm{I}, \mathrm{O}$ \\
\hline & & Thermal Desorption & $\mathrm{O}$ \\
\hline & & Incineration & $\mathrm{O}$ \\
\hline & & Pyrolysis & $\mathrm{O}$ \\
\hline & & Steam Reforming & $\mathrm{O}$ \\
\hline & & Vitrification & $\mathrm{I}, \mathrm{M}, \mathrm{R}, \mathrm{O}$ \\
\hline & & In-Container Vitrification & $\mathrm{I}, \mathrm{M}, \mathrm{R}, \mathrm{O}$ \\
\hline & \multirow{9}{*}{$\begin{array}{l}\text { Physical and/or } \\
\text { Chemical Treatment }\end{array}$} & Chemical Leaching & $\mathrm{I}, \mathrm{M}, \mathrm{R}, \mathrm{O}$ \\
\hline & & Dehalonization & $\mathrm{O}$ \\
\hline & & Vapor Extraction & $\mathrm{O}$ \\
\hline & & Soil Washing & $\mathrm{I}, \mathrm{M}, \mathrm{R}, \mathrm{O}$ \\
\hline & & Mechanical Separation & $\mathrm{I}, \mathrm{M}, \mathrm{R}, \mathrm{O}$ \\
\hline & & Solvent Extraction & $\mathrm{O}$ \\
\hline & & Chemical Reduction/Oxidation & I, M, O \\
\hline & & Solidification/ Stabilization & $\mathrm{I}, \mathrm{M}, \mathrm{R}, \mathrm{O}$ \\
\hline & & Automated radionuclide segregation & $\mathrm{I}, \mathrm{M}, \mathrm{R}, \mathrm{O}, \mathrm{T}$ \\
\hline & \multirow[t]{5}{*}{ Biological Treatment } & Composting & $\mathrm{O}$ \\
\hline & & Biological Treatment & $\mathrm{O}$ \\
\hline & & Landfarming & $\mathrm{O}$ \\
\hline & & Slurry Phase Bio Treatment & $\mathrm{O}$ \\
\hline & & Phytoremediation & $\mathrm{M}, \mathrm{R}, \mathrm{O}$ \\
\hline
\end{tabular}


Table A.1. (contd)

\begin{tabular}{|c|c|c|c|c|}
\hline \multicolumn{2}{|c|}{$\begin{array}{l}\text { General Response } \\
\text { Action }\end{array}$} & Technology Type & Remediation Technology & Contaminants Treated \\
\hline \multirow{18}{*}{\multicolumn{2}{|c|}{ In Situ Treatment }} & \multirow[t]{2}{*}{ Thermal Treatment } & Vitrification & $\mathrm{I}, \mathrm{M}, \mathrm{R}, \mathrm{O}$ \\
\hline & & & Thermally Enhanced Soil Vapor Extraction & $\mathrm{O}$ \\
\hline & & \multirow{12}{*}{$\begin{array}{l}\text { Chemical/Physical } \\
\text { Treatment }\end{array}$} & Soil Flushing & $\mathrm{I}, \mathrm{M}, \mathrm{R}, \mathrm{O}$ \\
\hline & & & Active and Passive Vapor Extraction & $\mathrm{O}$ \\
\hline & & & Grout Injection & $\mathrm{I}, \mathrm{M}, \mathrm{R}, \mathrm{O}$ \\
\hline & & & Soil Mixing & $\mathrm{I}, \mathrm{M}, \mathrm{R}, \mathrm{O}$ \\
\hline & & & Vapor Extraction & $\mathrm{O}$ \\
\hline & & & Supersaturated Grouts & $\mathrm{I}, \mathrm{M}, \mathrm{R}, \mathrm{O}$ \\
\hline & & & Soil Desiccation & $\mathrm{I}, \mathrm{M}, \mathrm{R}, \mathrm{O}$ \\
\hline & & & Electrokinetics & $\mathrm{I}, \mathrm{M}, \mathrm{R}$ \\
\hline & & & Reactive Gases (e.g., hydrogen sulfide) & $\mathrm{I}, \mathrm{M}, \mathrm{R}, \mathrm{O}$ \\
\hline & & & $\begin{array}{l}\text { Nanoparticles (e.g., zero valent iron, engineered } \\
\text { particles) }\end{array}$ & $\mathrm{I}, \mathrm{M}, \mathrm{R}, \mathrm{O}$ \\
\hline & & & Geochemical Manipulation & $\mathrm{I}, \mathrm{M}, \mathrm{R}$ \\
\hline & & & Phosphate- or Calcite-Based Immobilization & I, M, R \\
\hline & & \multirow[t]{3}{*}{ Biological Treatment } & Bioremediation & $\mathrm{I}, \mathrm{M}, \mathrm{R}, \mathrm{O}$ \\
\hline & & & Bioventing & $\mathrm{O}$ \\
\hline & & & Phytoremediation & $\mathrm{I}, \mathrm{M}, \mathrm{R}, \mathrm{O}$ \\
\hline & & Natural Attenuation & Monitored Natural Attenuation & $\mathrm{I}, \mathrm{M}, \mathrm{R}, \mathrm{O}$ \\
\hline Notes: & $\begin{array}{l}\mathrm{I}=\text { Other inc } \\
\mathrm{M}=\text { Heavy } \mathrm{I} \\
\mathrm{NA}=\text { Not ap }\end{array}$ & $\begin{array}{l}\text { anic contaminants } \\
\text { al contaminants } \\
\text { cable }\end{array}$ & $\begin{array}{l}\mathrm{R}=\text { Radionuclide contaminants } \\
\mathrm{T}=\text { Transuranic radionuclides } \\
\mathrm{O}=\text { Organic contaminants }\end{array}$ & \\
\hline
\end{tabular}




\section{Distribution}

No. of

Copies

40 Pacific Northwest National Laboratory

Dawn Wellman (30) K3-62

Evan Dresel (2) K6-96

Mike Truex K6-96

Kirk Cantrell K6-81

John Fruchter K6-96

John Icenhower K6-81

Mike Thompson (DOE) E6-35

Tom Brouns K9-69

Mark Frechley K9-33

Scott Peretsen (CHPRC) E6-35

Distr.1 




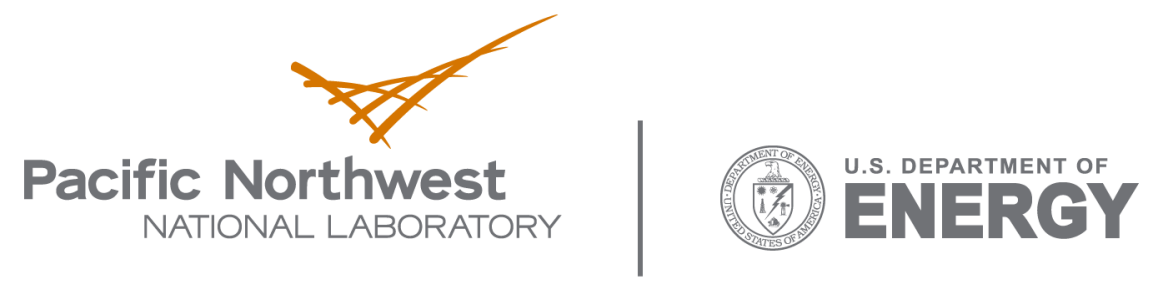

902 Battelle Boulevard

P.O. Box 999

Richland, WA 99352

1-888-375-PNNL (7665)

www.pnl.gov 